Portland State University

PDXScholar

Dissertations and Theses

Dissertations and Theses

Spring 1-1-2012

\title{
A Strategic Model for INGO Accountability Systems
}

Sarah Elizabeth Wardwell

Portland State University

Follow this and additional works at: https://pdxscholar.library.pdx.edu/open_access_etds

Part of the Finance Commons, Industrial Organization Commons, and the International Relations Commons

Let us know how access to this document benefits you.

\section{Recommended Citation}

Wardwell, Sarah Elizabeth, "A Strategic Model for INGO Accountability Systems" (2012). Dissertations and Theses. Paper 758.

https://doi.org/10.15760/etd.758

This Thesis is brought to you for free and open access. It has been accepted for inclusion in Dissertations and Theses by an authorized administrator of PDXScholar. Please contact us if we can make this document more accessible: pdxscholar@pdx.edu. 
A Strategic Model for INGO Accountability Systems

by

Sarah Elizabeth Wardwell

A thesis submitted in partial fulfillment of the

requirements for the degree of

\author{
Master of Science \\ in \\ Political Science
}

Thesis Committee:

Bruce Gilley, Chair

David Kinsella

Jill Rissi

Portland State University

(C)2012 
This thesis reconstructs the concept of International Non-Governmental Organization (INGO) accountability to beneficiaries through the development of a strategic model for INGO accountability to beneficiaries. It works through the history and arguments surrounding the rise of the debate around whether INGOs should be held accountable to their beneficiary populations. Unique definitions are developed for the terms and concepts related to this topic and a framework for understanding the strategic model for INGO accountability to beneficiaries is outlined: Accountable to whom? Accountable for what? Accountable how? A practical example of an internal assessment for measuring an INGO's accountability to beneficiaries is examined, analyzing data from Mercy Corps' internal accountability to beneficiaries survey conducted in 2010. This thesis defines accountability to beneficiaries as the process of justifying and being responsible for the manner and results of one's actions to any individual or group who is a member of the society whose interests the project or program is intended to promote. The main conclusions from this thesis are that the traditional model should be expanded to be more strategic and include a) a broader beneficiary and stakeholder population who may be affected, either positively or negatively, by the actions of an INGO, b) the actions of all members of the organization, and c) the enduring impacts of their work over time. Accountability to beneficiaries is a concept that can be applied to all INGO projects in a way that requires minimal resources and will ultimately improve the quality of the services delivered. 
This thesis would not be possible without the help and support of a great number of people. While I cannot possibly mention every single person in this small space, I want to especially thank those who have added an exceptional amount of value to this work. Firstly, I'd like to thank my advisor and mentor, Dr. Bruce Gilley, who has been a source of inspiration when I was lost, a mentor at crossroads both professionally and academically, and someone who never failed to respond to my numerous pleas for support in person and across borders. Dr. Gilley has pushed me beyond my expectations to work harder and dream bigger - even as he speeds past me in the swimming pool. Secondly, I never would have finished this project if it weren't for the continuous and loving support from my spouse, Devan Wardwell. He has been my partner in crime for most of the experiences detailed within this work and is always willing to bat around ideas with me. Third, I'd like to thank all of the members of my committee, Dr. David Kinsella and Dr. Jill Rissi; their many great ideas and careful attention to detail have ensured this thesis was completed to the best of my ability. I'd also like to thank all of my professors at Portland State University who have given me so much great material, have pushed me to think harder about the issues that surround me, and never stopped believing in me. While this list is not exhaustive, I'm especially grateful to Dr. Ron Tammen, Dr. Melanie Valdini, Dr. Marcus Ingle, and Dr. Kim Brown. I'm also thankful to my colleagues, supervisors, and especially staff for all of their questions and support - in particular Richard Jacquot, Anna Young, Barbara Willett, John Hanson, Stenley Dieujuste, Barbara Katie Juste, Dieulique Marechal and all of our team members past and 
Wardwell, Sarah

present in Saint-Marc and Mirebalais, Haiti for pushing us to make our work more meaningful every day. Last, but certainly not least, I'm grateful to my family for giving me the gift of curiosity and for encouraging me to seek solutions to the most vexing of problems. 


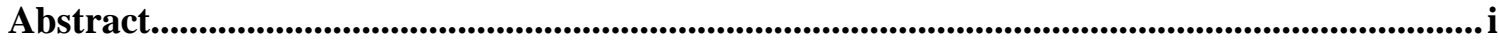

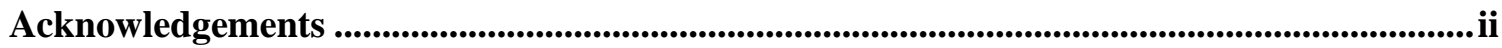

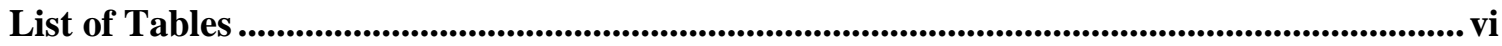

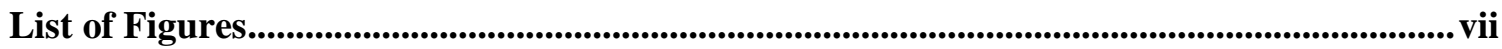

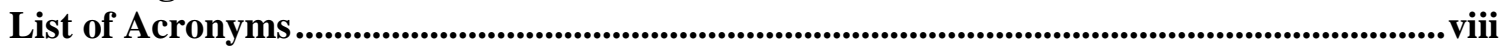

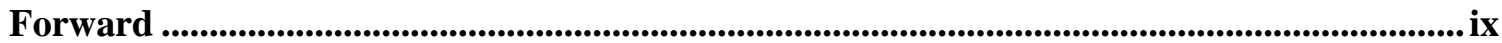

Chapter 1. Background and Topic Defense ............................................................................ 1

Chapter 2. The Rise of the Accountability Debate............................................................13

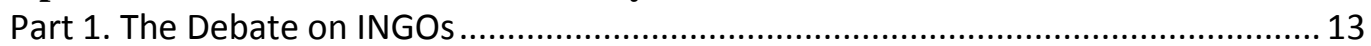

Part 2. Getting Concepts and Definitions Straight .................................................... 20

International Non-Governmental Organizations (INGOs)......................................... 21

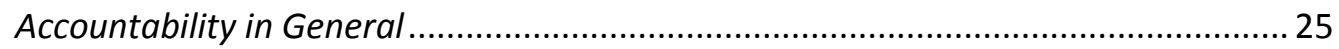

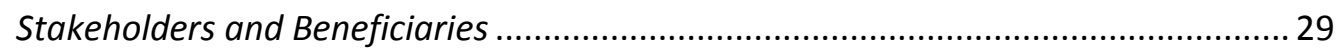

Chapter 3. Defining Accountability to Beneficiaries .........................................................33

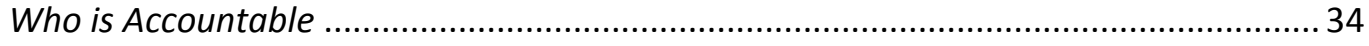

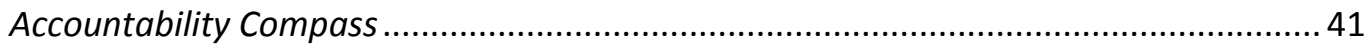

Locating Accountability to Beneficiaries within INGO Activities ..................................... 49

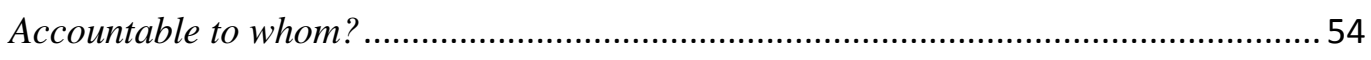

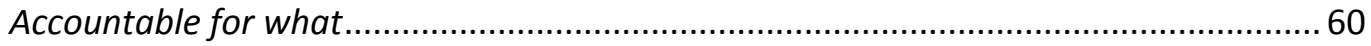

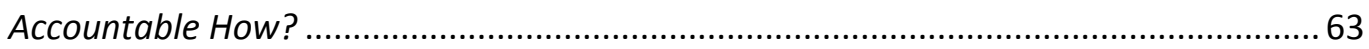

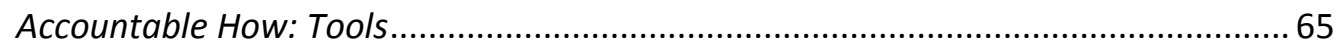

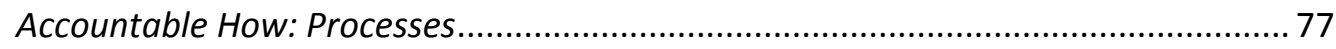

Chapter 4. Internal/Staff-Based Assessment Tools............................................................................ 88

Balanced Scorecards and Internal Strategic Management Tools.................................. 90

Building the Mercy Corps Accountability System......................................................... 94

Background to the Mercy Corps Survey ................................................................ 95

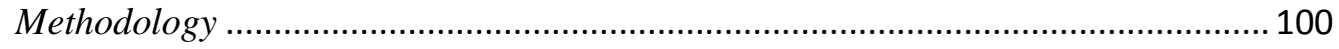

Survey Analysis: Accountability Barriers ........................................................... 104

Accountable to whom? Which beneficiaries are we targeting ? ................................ 109

Accountable how? Sharing Information with Beneficiaries ................................... 112

Accountable for what? Participation ........................................................................ 114

Accountable How? ......................................................................................... 116

A Strategic Model for INGO Accountability Systems $\quad$ iv| P a g e 
Wardwell, Sarah

Mercy Corps Example and the Role of Internal Assessments in Accountability Systems 123

Recommendations for a Future Internal Assessment

Chapter 5. Conclusion.

Summary of Main Points: SAB vs. TAB ......................................................................... 130

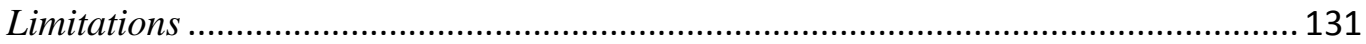

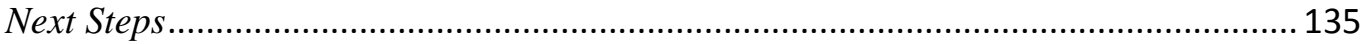

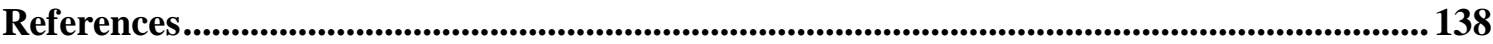

Appendix A. Mercy Corps Survey Questions............................................................................... 142

Appendix B . Institutionalization of Accountability to Beneficiaries: The World Bank.... 146

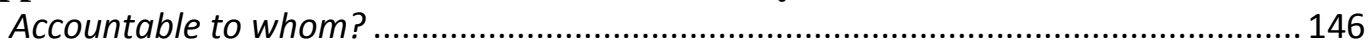

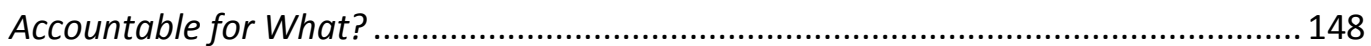

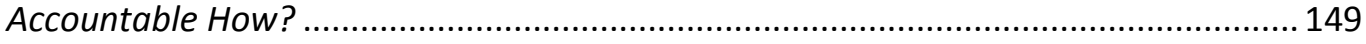

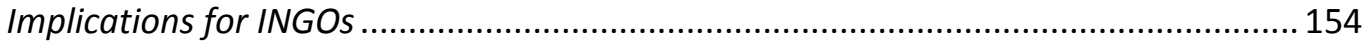

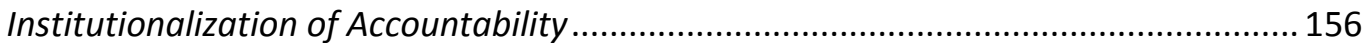


Table 1. Content analysis from qualitative responses to: What barriers to Accountability to Beneficiaries do you face? 61 total responses, some responses included multiple barriers. .105

Table 2. Response to the question, When creating beneficiaries selection criteria, to what extent does your team include input and inclusive participation from. 94 responses... 115

Table 3. Content analysis of qualitative responses to the question, through what means meetings, verbal reports, etc. - are beneficiaries given information about projects, please explain.

Table 4. Content analysis of qualitative responses to the question, what other accountability practices do you or your team regularly use to fulfill your accountability to beneficiaries? 50 total responses.

Table 5. Table Summarizing the Differences between SAB and TAB. 


\section{List of Figures}

Figure 1. "(Mis) Managing the World?" Relationships between the main players on the 21st century international political stage ...................................................................................... 2

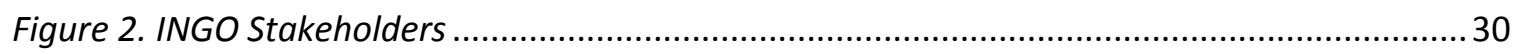

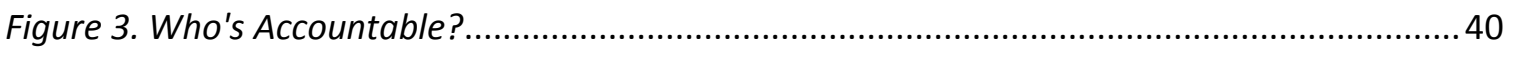

Figure 4. Accountability to Beneficiaries Components............................................................... 51

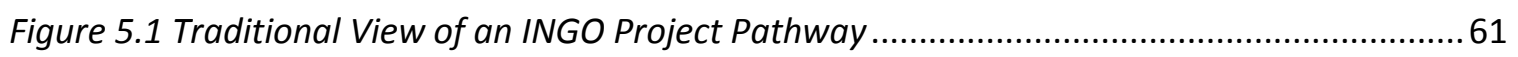

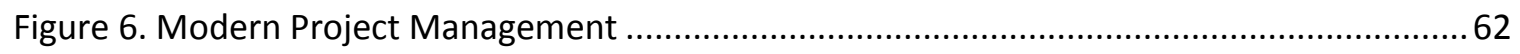

Figure 7. The overlapping dimensions of Strategic Accountability to Beneficiaries ......................66

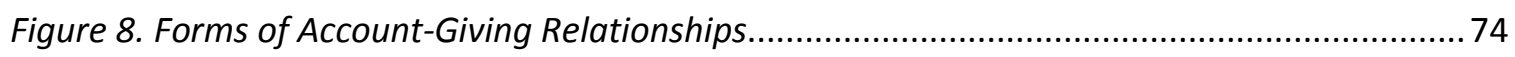

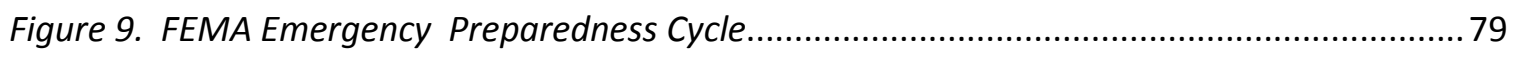

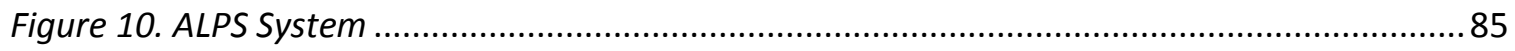

Figure 11. Mercy Corps Definitions of Accountability .......................................................... 100

Figure 12. Responses to the question: To what extent does your team include a fair and practical representation of all the groups that are members of the local populations? 92 total responses.

Figure 13. Responses to the question: To what degree does your team establish a basic profile of the population from primary and secondary sources in a transparent manner including: gender, ethnicity, religion, political affiliation, vulnerability? 90 responses. 112

Figure 14. Responses to the question: Overall, how would you rate your program's efforts to share program information with beneficiaries?

Figure 15. Response to the question, how often does your team involve beneficiaries during the following phases of the project. 94 responses.

Figure 16. Response to the question, during the assessment and design phases, how often does your team meet with the communities to clarify any of the following?. 116

Figure 17. Response to the question, to what extent does your team hold formal meetings with beneficiaries? 94 responses. 117 Figure 18. Response to the question, to what degree are beneficiaries given the opportunity from first contact to identify and prioritize their needs. 91 responses. 118 Figure 19. Response to the question, to what degree is feedback used for... 92 total responses. 
$A B$ - Accountability to Beneficiaries

ALPS - Accountability, Learning and Planning System

CoMo - Community Mobilization

CSO - Civil Society Organization

DNH - Do No Harm

DFID - UK Department for International Development

$D M \& E$ - Design, monitoring and evaluation

$E C$ - European Commission

FEMA - Federal Emergency Management Agency

$G A B$ - General Arrangements to Borrow

GEG - Good Enough Guide

HAP-I - Humanitarian Accountability Project - International

HIV/AIDS - Human Immunodeficiency Virus/Acquired Immune Deficiency Syndrome

IBRD - International Bank for Reconstruction and Development

ICSID - International Center for Settlement of Investment Disputes

IDA - International Development Assistance

IEG - Independent Evaluation Group

IFC - International Finance Committee

IMF -International Monetary Fund

INGO - International non-governmental organization

$L R P$ - Local-Regional Procurement

$M \& E-M o n i t o r i n g$ and Evaluation

$M C$ - Mercy Corps

MIGA - Multilateral Investment Guarantee Agency

NGO - Non-governmental organization

$O E D$ - Operations Evaluation Department

$S A B$ - Strategic Accountability to Beneficiaries

$T A B$ - Traditional Accountability to Beneficiaries

TSEP - Tajikistan Stability Enhancement Project

$U N$ - United Nations

USAID - United States Agency for International Development 
"Be not simply good - be good for something" Henry Thoreau

In 2005 as a Peace Corps Volunteer in Guinea, West Africa I frequently visited the small village of Tolo where a defunct chicken farm stood at the outskirts of town along the main road. All that remained of the once grandiose farm was empty concrete office spaces, dilapidated chicken coops, and a large "Provided by the American People" USAID sign at the gate. I asked the villagers about the project and they told me that some foreigners set up a chicken farm, but they only trained people from Mamou, the nearest mid-sized town how to use the farm. From what I could tell the farm was supposed to help with food security and generate income for villagers by providing chickens and eggs. Once the project funding had ended and the foreigners left, the Mamou citizens took most of the chickens and left the village of Tolo as it had been before. Children now occasionally used the farm for play, but it otherwise sat unused. The animals that were left gradually died off and the supply of eggs ended. Why? I inquired. No one seemed to know. I never had the opportunity to see official reports about this project and news about it never appeared in the media. These observations early on in my career in international development have shaped how I personally evaluate the impact of projects - the community and stakeholder's perceptions before, during, and after the project.

I chose to pursue a graduate degree in political science to learn more about the structures and institutions that often take the fall for holding back development projects from alleviating poverty. In 2010, in conjuncture with a PSU collaboration with the Ho Chi Minh National University for Politics and Public Administration, I surveyed 
Wardwell, Sarah

development professionals in Hanoi about their perceptions of the monitoring and evaluation systems they were using. Overwhelmingly, respondents who were not monitoring and evaluation experts said that they felt their systems were cumbersome and required additional work with little additional return.

All of these events led to the formulation of this thesis topic, accountability to beneficiaries. In order for international non-governmental organizations (INGOs) to be effective and efficient at achieving their intended impact, a careful analysis of accountability to beneficiaries is an essential first step. Survey data from Mercy Corps, an international NGO (INGO), about staff perceptions of accountability to beneficiaries from 35 countries will be presented to serve as a real-world example. This data was compiled from a survey conducted by Mercy Corps and analyzed by the author independently as well as part of an agency working group.

Accountability is not a topic that is specific to the aid industry. It is a more general issue across all types of organizations. We can be held accountable in our personal relationships as well. Our loved ones can ask us to give an account of our actions. When we come clean with our actions to our loved ones, difficult as it can be, this is the feeling of accountability. Scaling this idea up to an organization is difficult because it requires each individual within the organization to be accountable for their professional, and occasionally personal, actions - this is systematic accountability.

During my graduate coursework I was consistently frustrated by the use of theories that I found detached from the developing countries where I work, which has pushed my thesis writing into more of the policy science arena. I wrote this thesis under 


\section{Wardwell, Sarah}

the guidance of two political science professors and one public administration professor. My hope is that with their support, this thesis will present a practical lens on a theoretical problem, ultimately leaving my main subject, INGOs, with a pragmatic approach to improving accountability to beneficiaries.

Before I was able to complete and defend this thesis I began a new position with Mercy Corps in Haiti managing at first one and then, a bit later, two field offices in St. Marc and Mirebalais. My experiences in Haiti have greatly colored the final perspective I have stamped on this work. Chapter three, which is focused on the theoretical and scholarly debate on the topic was re-written to reflect my surroundings in Haiti. Life in post-earthquake Haiti is a perfect trial ground for this topic because there is an abundance of money being poured into "building back better" as many aid workers like to say. Despite all of this funding, my surroundings are squalid - it's impossible to disembark from the airplane without noticing that the airport itself remains cracked and blue-tarp tents cover nearly every inch of available space from the airport to the outskirts of town. From my experiences in Haiti, I am affirmed of the need to think harder on the topic of accountability to beneficiaries and I hope this thesis is a good step towards improving this vital component of aid and development work. No longer can the aid industry rely on complacent methods of accountability, what I'm calling Traditional Accountability to Beneficiaries (TAB), they must listen harder to the needs of the communities and use more innovative Strategic Accountability to Beneficiaries (SAB) tools and practices. My experience as an aid worker also helps me understand just how difficult it can be to first 
Wardwell, Sarah

get results and more importantly be held accountable for those results, whatever they may

be. 


\section{Chapter 1. Background and Topic Defense}

Before World War II, the nation-state had been the primary actor in global governance. Afterwards with the expansion of actors in the international arena such as the United Nations (UN), International Monetary Fund (IMF), International Bank for Reconstruction and Development (IBRD) (later became the World Bank), as well as international non-governmental organizations (INGOs), global governance became more of a shared responsibility between these international organizations, non-state actors and their state counterparts, graphically represented below in Figure 1. This trend has continued through the twentieth and twenty-first centuries, displaying a shifting of power in world politics away from the nation-state ${ }^{1}$. Spruyt and Evans, among other scholars, argue that while other actors may be rising in power, the state remains the most powerful actor in the international system. Global governance has shifted in the modern era into a networked system, with a plethora of actors contributing to decisions affecting populations beyond their own borders. These actors are distinguished by the "centrality of principled ideas or values motivating their formation"2. Transnationalism, a common theory in international relations, explains this organizational shift in power from a hierarchical system to one that is more dispersed ${ }^{3}$. Non-state actors have benefited from this shift in structure by gaining increased power within the international system. With

\footnotetext{
${ }^{1}$ Ahmed, Shamina and David Potter, NGOs in International Politics (West Hartford, Connecticut: Kumarian Press, 2006), 24.

${ }^{2}$ Keck, Margaret, and Kathryn Sikkink, Activists beyond Borders: Advocacy Networks in International Politics (Ithaca: Cornell University Press, 1998), 3.

${ }^{3}$ Ahmed, Shamina and David Potter, NGOs in International Politics (West Hartford, Connecticut: Kumarian Press, 2006), 13 . 
Wardwell, Sarah

this increase of power also comes the increase of responsibility and the call for accountability.

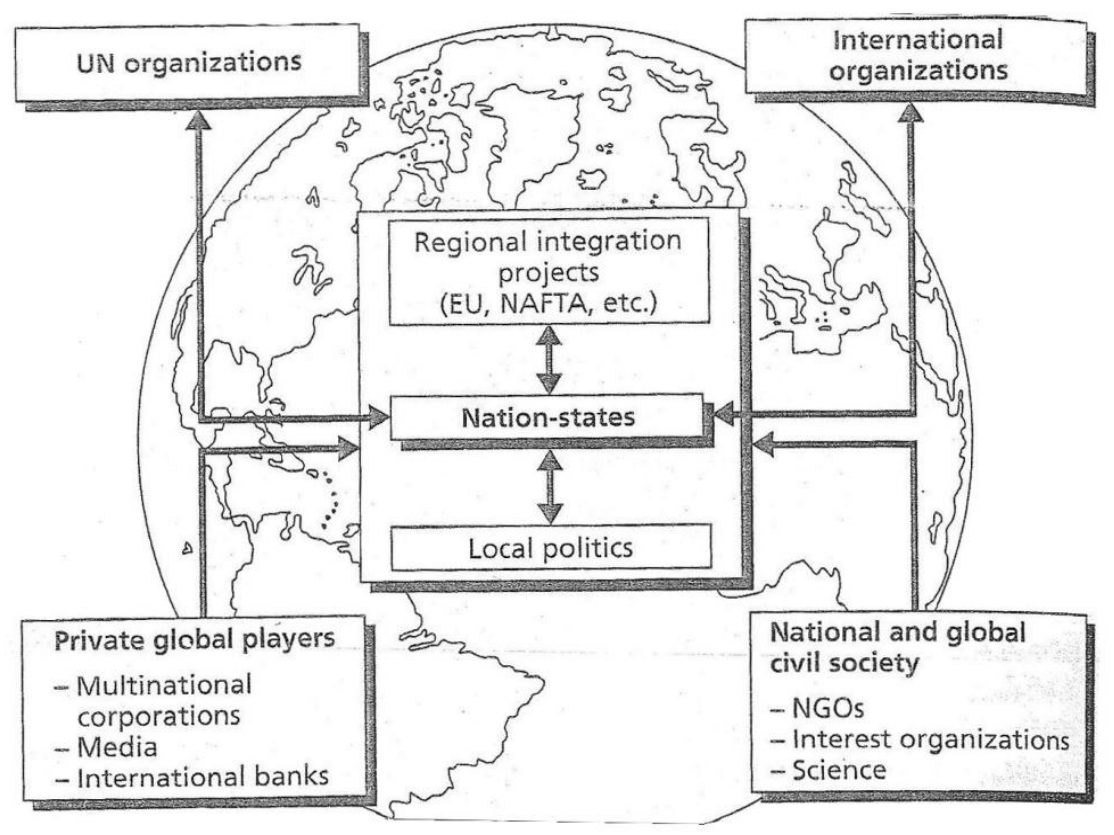

Figure 1. "(Mis) Managing the World?" Relationships between the main players on the 21st century international political stage ${ }^{4}$

At the same time, globalization has increased the interconnectedness of states. Issues such as climate change, refugee and other population flows across borders, and the need for fossil fuels, has made all states reliant upon each other. These and other transnational problems have increased the need for stronger international actors as individual states alone cannot solve these issues. This evolution in the role of the state made room for the growth of INGOs, not-for-profit organizations separate from the government that seek to advance certain conceptions of the public interest through

${ }^{4}$ Held, David and Anthony McGrew, Globalization/Anti-Globalization. (Massachusetts: Polity Press, 2002), 66. 
Wardwell, Sarah

transnational activities. The interconnectedness of individuals across borders, the speed at which information can travel, and the rise in media coverage of human suffering from natural disasters, wars, and disease has increased the willingness of states to come to the aid of suffering people around the globe. Response to the 2010 Haitian earthquake set a new record of more than 3.5 billion USD pledged to the emergency response ${ }^{5}$. As states are seen to be less able to deliver aid in a non-political manner, INGOs have been increasingly called upon to carry out transnational aid operations, from emergency relief, to agriculture development to youth employment projects. At the time of the 2010 earthquake in Haiti, $80 \%$ of all aid to Haiti and $90 \%$ of all US aid to Haiti was being channeled through INGOs, local NGOs, and contractors ${ }^{6}$.

As the foreign aid and assistance industry has matured and expanded, there have been increasing calls for INGOs to be held more accountable for their actions. As global governance arrangements have shifted, democratic accountability has not spread as easily in this network and only weak, if any, formal accountability mechanisms exist ${ }^{7}$. Donors have increased regulation, often in a reactionary manner, instituting increased monitoring and/or evaluation requirements. Since INGOs base their legitimacy largely on the premise that they are accountable to the populations they serve, especially the poor, it

\footnotetext{
5 “UN OCHA Reports," last modified Jan. 28, 2012. http://fts.unocha.org/reports/daily/OCHA_R24_E15797.XLS

${ }^{6}$ Lawry, Steven, "Paul Farmer's Call for a New Conversation on Aid to Haiti," review of Haiti: After the Earthquake, by Paul Farmer. http://hausercenter.org/iha/2011/12/09/paul-farmer\%E2\%80\%99s-call-for-anew-conversation-on-aid-to-haiti/

7 Scholte, Jan Aart, "Civil Society and Democratically Accountable Global Governance." In Global Governancce and Public Accountability, edited Held and Koening-Archibugi, 87-109 (Massachusettes: Blackwell Publishing, 2005), 87.
} 
Wardwell, Sarah

seems natural that mechanisms would be designed to measure these claims ${ }^{8}$. Yet citizens have little to no access to redress in the globalized system. Increased surveillance over the actions of INGOs increases with each large-scale humanitarian disaster; the Rwandan genocide in 1994, Kosovo in 1999, the Indonesian tsunami in 2004, the Myanmar cyclone of 2008, and the Haitian earthquake in 2010 have each renewed the debate about how INGOs are held accountable for their actions. Both cases of INGO intervention, such as after a natural disaster, and non-intervention, the Rwandan genocide for example, have brought up the discussion about the role, responsibility, and accountability of INGOs. States have also pushed back against the loss of their sovereignty as INGOs and foreign assistance donors expand their influence. States receiving aid inherently relinquish parts of their sovereignty in order to accept assistance from non-state actors. While many INGO activities may appear at first to be non-political, such as delivering health services or providing clean drinking water, these activities are all replacing the role of the government, further eroding state sovereignty; a point that INGOs frequently debate. Local populations are also increasingly making demands for improved delivery of aid. INGOs then find themselves being pressed from both sides to improve their work and be more accountable in both directions. Within the aid community there is also peer pressure to enact and strengthen accountability practices and accept democratic norms.

INGOs have no legal accountability to their beneficiaries. However, there is a moral obligation for the INGO to provide the best possible services to the beneficiaries they are serving, regardless of how strong the mechanisms may be to bind the INGO to

\footnotetext{
${ }^{8}$ Edwards, Michael and David Hulme, eds., Beyond the Magic Bullet: NGO Performance and Accountability in the Post-Cold War World (Connecticut: Kumarian Press, 1996), 14. 
Wardwell, Sarah

these obligations. INGOs play a role in the cosmopolitan society to share the functions of government and provide public goods. The government is the party generally considered accountable for the provision of these public goods. As INGOs have increasingly provided these goods and services, they could also be considered to now need to be held accountable for these actions, just as the government is.

The concept of holding an INGO accountable to their beneficiaries is a rather new and contested concept. This thesis will rethink and reconstruct the concept of INGO accountability to beneficiaries by exploring two main questions: first of all, what is the best model of accountability to beneficiaries that can be used to generate accountability tools that serve the strategic aims of an INGO? Secondly, what is the role of internal assessment tools within the overall accountability to beneficiaries model? This thesis compares the traditional or contemporary thinking about INGO accountability to beneficiaries with a strategic model.

INGOs have developed tools and practices to deal with this pressure, yet despite these efforts, criticism of the sector continues. This thesis explores this idea by acknowledging the efforts made by INGOs to achieve more accountable impact as the traditional accountability to beneficiaries (TAB) approach. The new ideas put forth here are referred to as the strategic accountability to beneficiaries (SAB) approach.

Accountability is often thought of in terms of elected public officials being held accountable to the people who elected them. However, the term originates from its Latin 
Wardwell, Sarah

root "computare" or "to count" and was used predominantly in finance until the 1980's".

In modern social science literature, accountability means the process of justifying and being responsible for the manner and results of one's actions to relevant stakeholders. States were previously assumed to be accountable to their populations by virtue that governments stayed in power as long as their populations felt they were sufficiently providing for their needs. Accountability relationships are slightly different for INGOs, who juggle the twin obligations to their donors and the populations they are trying to reach, the beneficiaries. For this thesis, a beneficiary is broadly defined as any individual or group who is a member of the society whose interests an INGO project or program is intended to promote. The terms accountability, beneficiaries, INGO, and accountability to beneficiaries remain terms that are employed in various fashions across the sector of humanitarian aid and foreign assistance. After the 2010 Haiti earthquake, an evaluator studying the coordinated efforts of INGOs responding to the disaster remarked that there continues to be a range of definitions of accountability and a lack of a commonly shared vision of what an accountable humanitarian system would look like ${ }^{10}$.

The traditional accountability relationship, based on funding commitments, is that INGOs are accountable to donors. Most studies of INGO accountability have focused on the upward accountability mechanism, or the accountability relationship between the INGO and their donor, which is the most straightforward application of the term accountability. However, as their influence has increased, they are also being seen as

\footnotetext{
${ }^{9}$ Castiglione, Dario, “Accountability," Encyclopedia of Governance (2006) SAGE Publications, 28 April, 2011, http://www.sage-ereference.com/governance/Article_n1.html.

${ }^{10}$ Humanitarian Accountability Partnership, "The 2010 Humanitarian Accountability Report," Geneva, Switzerland, 55. 
Wardwell, Sarah

accountable to beneficiaries. More importantly, the reason why INGOs exist is to help tackle these challenging global problems that aren't being effectively dealt with by governments and the private sector alone. INGOs fill theses gaps and focus on the most vulnerable populations. In order to effectively meet these goals, INGOs must hold themselves accountable to the populations they intend to serve, even if donors are not requiring these mechanisms. This thesis will expose the differences between the Traditional Accountability to Beneficiaries (TAB) approaches currently employed by INGOs and a Strategic Accountability to Beneficiaries (SAB) approach proposed here. The SAB system acknowledges the problems identified above and works to target more specifically the real needs of the communities, achieve impact, and measure the results.

Accountability to beneficiaries has grown in importance as INGOs have increased exponentially in numbers, have become increasingly important actors in the international community, and have faced public accusations about ineffective projects in recent years. The number of INGOs rose from 179 in 1909 to 28,900 in 1993 and the number of NGOs (local and international) is estimated to have doubled between 1978 and $1998^{11}$. The power of INGOs, some scholars argue, is in their power to persuade; their ability to divert some of the power once held solely by governments, persuading other governments and citizens of other state's how to act $^{12}$. Critics of government foreign aid spending and INGO activities have also caused this issue to rise in importance today.

\footnotetext{
${ }^{11}$ Commission on Global Governance 1995 as cited in Edwards, Michael and David Hulme, eds., Beyond the Magic Bullet: NGO Performance and Accountability in the Post-Cold War World, (Connecticut: Kumarian Press, 1996), 1.

Union of International Associations, ed., 2002 as cited in Ahmed, Shamina and David Potter, NGOs in International Politics, (West Hartford, Connecticut: Kumarian Press, 2006).

${ }^{12}$ Ahmed, Shamina and David Potter, NGOs in International Politics (West Hartford, Connecticut: Kumarian Press, 2006), 15. 
Wardwell, Sarah

Increasingly, institutional donors, especially European donors, are expecting or even requiring INGOs to have accountability practices in order to consider funding their projects. International accountability agencies and partnerships have emerged in recent years to formalize the process within the international community. Charity rating agencies are beginning to look at these types of partnerships or memberships and include ratings for INGO's accountability, which affects the amount of private and foundation funding.

In mid-2000, Fareed Zakaria, managing editor of Foreign Affairs, remarked that, "my concern is that governments will listen too much to the loud [NGO] minority and neglect the fears of the silent majority," and this would lead to "interested, unelected, unrepresentative and unaccountable NGOs" ${ }^{\prime 13}$. Zakaria's comments echoed the sounds of many other critics concerned that since INGOs were unelected, they were thereby unaccountable. If INGOs were going to play a pivotal role in international politics, Zakaria and other likeminded scholars and pundits outlined the need for INGOs to become more democratic and accountable.

This growing concern about accountability has not gone unnoticed within the INGO community. INGOs have focused more on accountability. Peer organizations competing for resources from donors force INGOs to formalize their monitoring and evaluation mechanisms and other TAB tools for accountability. As INGOs grow from supporting operations in one country to many countries, they are also pushed to formalize their processes, solidify their theories of change, and develop other learning mechanisms

\footnotetext{
${ }^{13}$ Zakaria's comments from The Spectator as cited in Anderson, Kenneth, "What NGO Accountability Means: And Does Not Mean,” The American Journal of International Law 10:13 (Jan. 2009): 173. 
Wardwell, Sarah

to continue their progress and impact. The maturity of this sector has led to the establishment of internal norms of accountability within INGOs, especially the larger INGOs who are in direct competition for financial resources. Unfortunately there has been more of a focus on TAB mechanisms and tools, though by focusing on developing their theories of change and furthering their organizational focus on learning is a SAB approach.

Chapter two will trace the rise of the accountability debate. It will frame the key terms and discussions behind the INGO accountability to beneficiaries debate including accountability (in general), INGOs and their role in global governance, accountability relationships for INGOs, and stakeholders and beneficiaries. This chapter will also outline the view that accountability to beneficiaries needs to be strategically designed so as to maximize program impact.

Chapter three will outline a model of accountability to beneficiaries. Beginning with an examination of who is to be held accountable and then carrying out a literature review of various types of accountability. For the purpose of this thesis, accountability to beneficiaries will be defined as the process through which an INGO justifies and is responsible for the manner and results of its projects and programs to any individual or group who is a member of the society whose interests they are intended to promote.

This chapter will look at the three questions that help to frame the discussion about how INGOs can be accountable to their beneficiaries: Accountable to whom? Accountable for what? Accountable how? Through these questions, the TAB and SAB approach will be compared. To connect the theoretical literature with real life examples, 
Wardwell, Sarah

the current situation in post-earthquake Haiti based on the author's field experience will be a theme throughout this thesis. The first question most scholars address in studies of accountability is who is to be held accountable? In this thesis, INGOs will be the parties examined at the level of the organization, from those implementing programs to the leaders. One presumption of this thesis argument is that all members of the organization should be held accountable to the agency beneficiaries. The question of "Accountable to whom" breaks open a discussion about who are the people and entities affected by an INGO project. The expanded definition used in a SAB approach goes beyond the direct, intended beneficiaries and considers all groups affected, present and future. This also begins the discussion of direct and indirect impacts of INGO activities and winners and losers in aid projects. While one of the goals of foreign aid intervention is to improve social and economic development, which is the focus of this thesis, this is not a linear path nor is it a standardized process across all states. Social and economic development occurs differently within each unique country context, and this process requires give and take, or winners and losers. This process also occurs over time, an important parameter that will be considered within this discussion.

The question of what INGOs are accountable for opens the debate about what particular actions affect the populations described in accountable to whom and then leads into the question of how transparency, participation, feedback and learning cycles, and complaint mechanisms can be used. A framework for measuring accountability to beneficiaries will be created in the "accountable how?" section. Finally, a section will be 
Wardwell, Sarah

included in chapter three that discusses how agencies measure their own accountability to beneficiaries, teasing out best practices as defined by the current literature on the topic.

Chapter four looks at internal (i.e. within-organization) methods an INGO can use to measure its own accountability to beneficiaries. Scholarly literature on strategic management systems for non-profits and how they can apply to international agencies will be examined, followed by a example of an example of an internal accountability assessment of Mercy Corps, an American INGO that works in humanitarian relief and community-led development. In February 2011 Mercy Corps surveyed all program staff in its 35 country programs specifically asking about accountability to beneficiaries practices, tools, barriers, and how staff felt the agency was doing in regards to accountability to beneficiaries. The author led a working group to conduct this research project and was responsible for all of the primary data analysis and report writing. Other members of the agency were involved in advising on the project, whose opinions are included in this section. First, an overview of this organization and the background to this research project will be provided. This discussion will outline the methodology used for completing this data analysis. Third, this example will be used to identify how Mercy Corps is currently framing and assessing the questions of accountable to whom and accountable for what. This chapter will conclude with a discussion about where Mercy Corps currently resides in its process of improving accountability to beneficiaries and recommended action steps. .

Finally, a summary of conclusions reached from this thesis will compose the fifth chapter. This chapter will establish a recommended protocol for INGOs to improve their 
Wardwell, Sarah

internal measurement of their accountability to beneficiaries. The conclusion will include recommendations for future research and acknowledge some of the limitations to this research project.

Survey questions from the Mercy Corps example are included in Annex A. There is also an annex of a brief overview of the World Bank and its attempts to improve accountability to beneficiaries. The World Bank is generally regarded as a donor, but they also carry out projects themselves, directly interacting with beneficiaries. This case study looks at the World Bank from the perspective of an organization to be held accountable by those they are directly serving. Additional annexes include a list of questions from the original Mercy Corps survey.

The question this thesis asks is how to formulate and implement effective accountability to beneficiary systems at a time when both the responsibilities as well as the demands on INGOs are increasing at a rapid rate. The findings here contribute in two ways to the understanding of INGO accountability to beneficiaries (AB). First, the concept of $\mathrm{AB}$ is expanded beyond traditional narrow understandings to encompass longer-term and multi-stakeholder perspectives. Secondly, the utility of internal assessment tools to advance $\mathrm{AB}$ is highlighted, providing a concrete example of what a strategic approach to $\mathrm{AB}$ looks like in practice. 


\section{Chapter 2. The Rise of the Accountability Debate}

\section{Part 1. The Debate on INGOs}

INGOs steadily expanded all over the world since the 1930s despite world wars, economic downturns, and the rise of antidemocratic states all over the world ${ }^{14}$. As INGOs have expanded in number, they have also increased their power. In 2004 after the Indonesian tsunami President Clinton advised INGOs, "with this heightened power and influence comes greater responsibility - NGOs must constantly examine not only what they are doing, but how they are doing it,"15. This section will highlight the most important moments and elements in the rise of the current debate around this topic and will conclude by looking at the different types of stakeholders and their role in holding INGOs accountable to the beneficiaries they serve.

Key moments in global politics help to explain the space created for INGOs in international affairs. The Peace of Westphalia in 1648 brought about the system of the nation-state, ending the system of kingdoms. The transfer in power from a kingdom ruled by a single family, to a nation-state with decentralized power, made space for entities outside of the government to have more influence and power. The development of the Red Cross in 1881 during the American Civil War, labor unions, women's organizations, and other civil society groupings were the precursors to NGOs. The expansion of the Red Cross and the Salvation Army into international outreach during the Second World War were early $20^{\text {th }}$ century precursors to contemporary INGO work.

\footnotetext{
${ }^{14}$ Ahmed, Shamina and David Potter, NGOs in International Politics (West Hartford, Connecticut: Kumarian Press, 2006), 22.

${ }^{15}$ Clinton, Bill, "Clinton to NGOs: With Great Power Comes Great Responsibility," InterAction (April 14, 2006). 


\section{Wardwell, Sarah}

The development of nation-states created a new international order including introducing borders that have created a new series of problems for leaders. The birth of the League of Nations in 1934 began the inclusion of international organizations in global governance. The 1980s and 1990s dominance of the neoliberal economic agenda associated with the Washington Consensus, further eroded the demand for the state, and made more space for other institutions to play a role in state actions, from corporations to INGOs. During this time, INGOs were both proponents of this structural changes and vociferous opponents to the dominance of these frameworks ${ }^{16}$.

Globalization has played a large role in the expanded abilities of INGOs to carry out their work around the world. Throughout the $20^{\text {th }}$ and $21^{\text {st }}$ centuries, the increased speed of communication and ease of access to information has created gateways for people to see the lives of others and has increased sympathy for human suffering from afar. The increased ease of ability to travel has further brought people together like never before in history. Globalization has benefited some and many others have seen their conditions sink deeper into chronic poverty. All of these factors are a part of globalization and have created the space and need for INGOs.

Along with the redefining of global politics comes an increase in demands for governance of those organizations. The increased growth in the number and size of INGOs, increased attraction of funds to INGOs, and their increased role in shaping public policy and unprecedented power have caused the question of INGO accountability to

\footnotetext{
${ }^{16}$ Lewis, David and Tina Wallace, ed., New Roles and Relevance: Development NGOs and the Challenge of Change (Connecticut: Kumarian Press, 2000), ix. 


\section{Wardwell, Sarah}

rise $^{17}$. "[I]NGO accountability became a central issue in large part after all because it was

linked to the question of whether and to what extent [I]NGOs should be seen as 'representative' of the world's peoples - as one half, in other words, of an equation about global governance." 18 .

Besides simply growing in numbers, INGOs have grown in importance to formally and informally shaping the global agenda. On the whole, INGOs and other civil society organizations have been treated with a secondary priority and their inputs have not been fully integrated into the policy process ${ }^{19}$. During the late 1990 's World Bank Group President James Wolfensohn increasingly consulted with INGOs and began aligning World Bank policies with the wishes of INGOs, further increasing the legitimacy and role of INGOs in global governance ${ }^{20}$. The World Bank has created several joint committees with INGO and civil society actors to hear their points of view in shaping decisions ${ }^{21}$. The Ottawa Treaty signed in 1997 banning landmines was primarily led by NGOs (local and international) and consequently dramatically increased

\footnotetext{
${ }^{17}$ Jordan, Lisa, and Peter Van Tuijl, ed., NGO Accountability: Politics, Principles, \& Innovations (Sterling, Virginia: Earthscan, 2006), 4. Havrda, Marek, and Petr Kutilek, "Accountability 2.0 - In Search of a New Approach to International Non-Governmental Organisations' Accountability." In Evaluating Transnational NGOs: Legitimacy, Accountability, Representation, edited by Jens Steffek and Kristina Hahn, 157-175. (New York: Palgrave Macmillan, 2010), 159.

${ }^{18}$ Anderson, Kenneth, "What NGO Accountability Means: And Does Not Mean," The American Journal of International Law 10:13 (Jan. 2009), 174.

${ }^{19}$ Scholte, Jan Aaart. "Civil Society and Democratically Accountable Global Governance." In Government and Opposition Ltd., edited by Held and Koening-Archibugi, 211-233. (Oxford: Blackwell Publishing, 2004), 216.

${ }^{20}$ Ibid.

${ }^{21}$ Scholte, Jan Aaart. "Civil Society and Democratically Accountable Global Governance." In Government and Opposition Ltd., edited by Held and Koening-Archibugi, 211-233. (Oxford: Blackwell Publishing, 2004), 226.
} 


\section{Wardwell, Sarah}

their legitimacy, more formally integrating them into the international community ${ }^{22}$. As

the role of INGOs in international politics matures, there will be increasing calls for accountability in order to increase their legitimacy ${ }^{23}$.

In recent decades INGOs have even become the preferred vehicles for delivery of many economic and political objectives ${ }^{24}$. Many of these activities may not initially appear political such providing food security or health care services. "There is almost always a political element to fighting poverty - it is rarely only about giving people things or knowledge ${ }^{25}$. Through the end of the twentieth century INGOs were generally regarded as good, but increasingly this image has dissipated and critics have begun to increase, arguing that NGOs undermine national sovereignty and lack a strong relationship with the public ${ }^{26}$.

By providing these services INGOs are duplicating and in some cases replacing the role of the government. Bypassing state governments undermines state authority and also makes INGOs accountable to actors outside of the host national government ${ }^{27}$. INGOs then are acting diplomatically on behalf of their government and intervening in another government's space. Both of these actions require slicing off part of the power of

\footnotetext{
${ }^{22}$ Anderson, Kenneth, "What NGO Accountability Means: And Does Not Mean," The American Journal of International Law 10:13 (Jan. 2009), 171.

${ }^{23}$ Lewis, David and Tina Wallace, ed. , New Roles and Relevance: Development NGOs and the Challenge of Change (Connecticut: Kumarian Press 2000), 13.

${ }^{24}$ Edwards, Michael and David Hulme, eds., Beyond the Magic Bullet: NGO Performance and Accountability in the Post-Cold War World (Connecticut: Kumarian Press 1996), 3.

${ }^{25}$ Ellerman, David P. Helping People Help Themselves: Towards a Theory of Autonomy-Compatible Help. Washington, D.C.: World Bank, Development Economics, Office of the Senior Vice President, 2001.

${ }^{26}$ Jordan, Lisa, and Peter Van Tuijl, editors. NGO Accountability: Politics, Principles, \& Innovations. Sterling, Virginia: Earthscan, 2006, 3.

${ }^{27}$ Ahmed, Shamina and David Potter, NGOs in International Politics (West Hartford, Connecticut: Kumarian Press, 2006), 128.
} 
Wardwell, Sarah

each government in order to acquire legitimacy and the power to act in these ways. The effects of INGO interactions may cause further political challenges or opportunities. If populations live longer and healthier lives, increase the average citizen's wealth, etc., governments will have to adapt their policies to meet the new needs of the populations.

Mass media has also taken to the work of INGOs, dramatizing and sharing information on both their successes and blunders and more importantly raising the visibility of these organizations with a larger audience. With the increase in publicity and legitimacy, came the increase of criticism of INGO actions. INGOs were increasingly called upon to deal with complex humanitarian emergencies, from the refugee and humanitarian situation in Kosovo, to the Rwandan genocide, to the Indonesian tsunami and the Haitian earthquake. INGOs increasingly became the most likely choice for responding to these emergencies. After each disaster, complaints were issued against INGOs from the populations they had sought to support. These complaints became more vocal and numerous throughout the 1990s. There is not one single moment in the history of INGOs that marks the beginning of the debate about INGO accountability, rather this debate has flared up with each of these humanitarian crises. Since the debate is most vociferous after these crises, the discussion often focuses solely on the way INGOs respond to emergencies. However, the discussion of INGO accountability to beneficiaries is much broader and applies to all functions of these agencies, most notably their response to emergencies and their role in social and economic development. Three highly-public cases mark when the issue of INGO accountability was brought to international attention - the case raised by Zakaria noted in Chapter 1, a confrontation 
Wardwell, Sarah

between a World Bank dam construction project and a small Berkley-based INGO, and the recent case of Greg Mortenson's INGO and his popular book “Three Cups of Tea”.

In 2003 journalist Sebastian Mallaby questioned the role of INGOs in a World Bank funded dam building project in Bujagali Falls, Uganda. He found that a small number of individuals in this Ugandan community were unhappy to be displaced from their homes in order to allow for the building of this dam. This small group of people, working with an INGO was able to bar millions of potential beneficiaries who would have received electricity from this dam ${ }^{28}$. Mallaby uses this example to highlight the same point being made here, that all INGOs and their projects are simply not equal. The range of INGO intentions and projected outputs and outcomes varies so widely that the general public, governments, and other institutional donors have become wary of antipoverty or development ideas. This harms INGOs not only in their ability to secure funds for their ideas, but sometimes other INGOs, such as the one from Berkley cited above, can even sometimes stop another anti-poverty group's project from happening. In other words, sometimes INGOs are their own worst enemy.

This account became an important point in raising awareness of INGO accountability to beneficiaries, a discussion that had been gradually building since the 1990's with the increased role of INGOs in international politics and global governance and the increase in NGO criticism. Following this incident, the World Bank became increasingly wary of NGOs who may try to block their projects. The World Bank

\footnotetext{
${ }^{28}$ Mallaby, Sebastian, The World's Banker, (New York, New York: Penguin Books, 2004), 7-9. Anderson, Kenneth, "What NGO Accountability Means: And Does Not Mean," The American Journal of International Law 10:13 (Jan. 2009), 170. 
Wardwell, Sarah

continued to propose similar projects in Uganda, and with each proposal came press releases saying the project was moving forward barring any NGO blocks ${ }^{29}$. This anecdote highlights three important factors in the debate about accountability to beneficiaries that are critical to understand in order to discuss this topic : the rise of NGOs, particularly INGOs and their role in international politics as previously discussed; the actions of these organizations, especially their interactions with the communities and states where they work; and the need to involve all stakeholders in the project process to ensure their feedback, positive or negative, is incorporated. Many scholars believe that accountability is a major source of vulnerability for the INGO sector ${ }^{30}$. One of the main supporting principles of this thesis is that accountability to beneficiaries is one way that an INGO can prove with some authority that they are doing no harm, helping donors and governments to choose wisely when selecting an organization to work with on a potential project.

A third case of media criticism of INGOs came about in 2011 regarding Greg Mortenson, CEO of the Central Asia Institute and author of the New York Times bestselling book, "Three Cups of Tea". Jon Krakauer, former supporter of the Central Asia Institute, accused Mortenson of falsifying information about his work for dramatic effect in his nonfiction book. These claims reach beyond literary critics and dig into the issues about INGO accountability to beneficiaries. Additional claims by Krakauer include a misuse of INGO funds by Mortenson, including private jets, and an exorbitant

\footnotetext{
${ }^{29}$ The Monitor, "Uganda; World Bank to Meet on Bjagali Dam", Africa News, April 2, 2007.

${ }^{30}$ Ahmed, Shamina and David Potter, NGOs in International Politics (West Hartford, Connecticut: Kumarian Press, 2006), 128. 
Wardwell, Sarah

salary for Mortenson; highlighting the discussion about stakeholders ${ }^{31}$. As noted in chapter one, INGOs are caught in between donors and beneficiaries. But there are additional groups that have an interest in the activities of INGOs beyond these simple two categories. This case illustrates the public interest from the home country of the organization, an important stakeholder for INGOs. Krakauer was concerned as a former private donor to the organization, but critics echoed his concerns in the media who had not given funds. This media pressure will also cause institutional donors to take a deeper look into the organization's affairs and could damage funding opportunities for the future. If local media in Pakistan and Afghanistan where Mortenson's projects were to hear these allegations, they could also make demands to look into the organization's inner workings or even pose security threats to Mortenson or his staff. All of these groups are affected by the actions of the INGO, making them all stakeholders in the INGO accountability discussion.

\section{Part 2. Getting Concepts and Definitions Straight}

One of the main challenges in studying INGO accountability to beneficiaries lies in the difficulty of defining the key terms involved. Scholars, practitioners, and policy makers toss around these terms, frequently employing different meanings of the terms that will be defined in this chapter: accountability (in general), INGOs, stakeholders, beneficiaries, and accountability to beneficiaries. This section will provide definitions for

31 Kristof, Nicholas, "Three Cups of Tea Spilled," The New York Times, (April 20, 2011). http://www.nytimes.com/2011/04/21/opinion/21kristof.html. Krakauer, Jon, Three Cups of Deceipt: How Greg Mortenson, Humanitarian Hero, Lost His Way. (California: Byliner, 2011), Kindle Single. 
Wardwell, Sarah

each of these terms and a justification for the wording of these definitions, beginning with the least controversial and working through to the most controversial terms. These definitions will set the foundation for the core arguments of this thesis. These are not intended to be definitive definitions for these terms, but rather concepts that are "intellectually and politically relevant to the context at hand" 32 .

\section{International Non-Governmental Organizations (INGOS)}

Civil society is the space in-between governments and private citizens that can act locally or globally through voluntary associations to shape the rules that govern social life, or "the arena outside of the state and above the individual,"33. One of these types of organizations is international non-governmental organizations (INGOs), which are a subset of non-governmental organizations (NGOs). INGOs essentially combine public service with private action, filling in social services that governments would like to provide but lack the resources to do so $^{34}$. The term NGO was first used in the UN Charter in $1946^{35}$. This marks a point in the history of NGOs when they were becoming more commonly accepted. Having already been strongly rooted in society and the term must have been commonly in use.

\footnotetext{
${ }^{32}$ Scholte, Jan Aaart. "Civil Society and Democratically Accountable Global Governance.” In Government and Opposition Ltd., edited by Held and Koening-Archibugi, 211-233. (Oxford: Blackwell Publishing, 2004), 213.

${ }^{33}$ Scholte, Jan Aaart. "Civil Society and Democratically Accountable Global Governance." In Government and Opposition Ltd., edited by Held and Koening-Archibugi, 211-233. (Oxford: Blackwell Publishing, 2004), 214. Ahmed, Shamina and David Potter, NGOs in International Politics (West Hartford, Connecticut: Kumarian Press, 2006), 30.

${ }^{34}$ Ahmed, Shamina and David Potter, NGOs in International Politics (West Hartford, Connecticut: Kumarian Press, 2006), 24. Edwards, Michael and David Hulme, eds., Beyond the Magic Bullet: NGO Performance and Accountability in the Post-Cold War World (Connecticut: Kumarian Press 1996), 2. ${ }^{35}$ Ahmed, Shamina and David Potter, NGOs in International Politics (West Hartford, Connecticut:
} Kumarian Press, 2006), 21. 


\section{Wardwell, Sarah}

For the purpose of this thesis, an INGO is defined as a not-for-profit organization $\underline{\text { separate from the government that seeks to advance a certain conception of the public }}$ interest through transnational activities. These organizations are voluntary in nature, operate in a global space and seek to advance core goals that are potentially transformative through normative commitments (mission statements, values, vision statements, theories of change, etc.) to improve the public good ${ }^{36}$. They may carry out a multitude of different types of activities, from bigger (multi-million dollar grants, multiyear implementation periods, national or even regional) to smaller (targeting one specific community or a minority population, budgets of less than $\$ 100,000 \mathrm{USD}$, etc.) in all of the same sectors that a government or developed state's private sector normally operates. For example, an INGO may offer health care programs in a state where the government cannot provide adequate health services. These programs could range from building hospitals to training health care professionals to developing innovative ways to improve maternal and child health in a particularly challenging environment, such as a war zone.

The term INGO can be difficult to understand because its very name explains mostly what it is not (non-governmental) rather than what it is. The term carries many different meanings from different vantage points. For some, it is synonymous with the "aid industry", as effective tools or channels for donors to provide international development funds to developing states. For others, they are seen as "vehicles for privatizing foreign assistance, making it less accountable to either government authorities

\footnotetext{
${ }^{36}$ Fogarty, Edward, "Nongovernmental Organization," Encyclopedia of Governance: http://www.sageereference.com/governance/Printn353.html 


\section{Wardwell, Sarah}

or local people because of a lack of clear governance structures for NGOs,"37. Still to others INGOs are grassroots organizations synonymous with community action, or service contractors working more efficiently than the government with limited legitimacy, and more recently they are seen as international policy actors, especially in the areas of human rights and environmental protection ${ }^{38}$. In recent years, INGOs have also come to be seen to provide more innovative solutions to past endemic problems, such as chronic poverty, than traditional bureaucratic political systems can offer.

These organizations voluntarily opt to use the term INGO. There are many types of organizations that fall outside the scope of this thesis in an effort to streamline the definition of the term, including religious organizations such as missionaries, educational organizations including universities, and professional or trade organizations.

INGOs play many different roles: humanitarian relief, social and economic development, advocacy and lobbying, public education and consciousness raising, agenda setting, and monitoring other transnational actors. Some scholars group these activities into "naming, framing, blaming, and shaming" 39 . The dominant INGOs are involved in most, if not all of these activities. This is because INGOs cannot function with stand-alone projects, in order to accomplish their bigger idealistic missions and achieve outcomes such as environmental protection or poverty alleviation; they must act

\footnotetext{
${ }^{37}$ Lewis, David and Tina Wallace, ed. , New Roles and Relevance: Development NGOs and the Challenge of Change (Connecticut: Kumarian Press 2000), $\mathrm{x}$.

${ }^{38}$ Ibid.

${ }^{39}$ Ahmed, Shamina and David Potter, NGOs in International Politics (West Hartford, Connecticut: Kumarian Press, 2006), 37.
} 
Wardwell, Sarah

on all possible levels, connecting with all actors involved ${ }^{40}$. Much of the debate on accountability to beneficiaries has focused on humanitarian relief work, but for this thesis, the role of INGOs in action, either through humanitarian relief or social and economic development will be focused upon since INGOs are directly interacting with beneficiaries the most in these roles.

INGOs carry out both projects and programs, while these terms are very similar it is worth a brief explanation of the difference. These terms differ mainly in the size of the activities carried out. A project means that fewer activities are carried out generally over a shorter period of time than a program, which includes a larger quantity of activities that tend to be more varied in scope and occur over a longer period of time. This thesis is interested in both and terminology choice will be based upon these definitions.

INGOs operate in a context of rapid change. The international political and economic environment is continually changing as well as attitudes towards the work carried out by INGOs. These organizations are forced to continually adapt and innovate to meet the changing world around them. They are at once being shaped by globalization, profiting from the space created by the new globalized political order, and contributing to the shifting shape of the new international arena. In order to justify the increased attention they have drawn and avoid the backlash of bad press than they receive, INGOs must improve their structures and procedures for being accountable to those they intend

\footnotetext{
${ }^{40}$ Lewis, David and Tina Wallace, ed. , New Roles and Relevance: Development NGOs and the Challenge of Change (Connecticut: Kumarian Press 2000), 10. 
Wardwell, Sarah

to serve ${ }^{41}$. As many INGOs focus on change, so must these organizations strive for change in their accountability systems and practices.

\section{Accountability in General}

The term accountability originates from the Latin word meaning "to count" and was first known to be used in $1794^{42}$. The term sprung from the literal sense that "a count" was necessary for monies left in one's care ${ }^{43}$. Later, the term took on a meaning as an abstract noun referring to both "the capacity of, and the obligation on, someone to produce an account" 44 . Public authorities were called to "respond" to their public about their conduct and actions, but were not held "accountable" until the 1980s. The word accountability doesn't exist in other languages; "responsibilité" is used in French, "responsabilidad" in Spanish, and "verantwortlichkeit" in German. Each of these terms has a closer relationship to the word "responsibility" in English.

In this thesis, accountability is defined as the ongoing process of justifying and being responsible for the manner and results of one's actions to relevant stakeholders. This definition intentionally includes the word "responsibility" to help clarify the relationship between the two words and acknowledge the intertwining relationship between them as is commonly used among most scholars ${ }^{45}$. Actions can be responsible, such as following a prescribed process and achieving an output, without being

\footnotetext{
${ }^{41}$ Lewis, David and Tina Wallace, ed. , New Roles and Relevance: Development NGOs and the Challenge of Change (Connecticut: Kumarian Press 2000), xii-xiii.

${ }^{42}$ www.merriam-webster.com

${ }^{43}$ Castiglione, Dario, "Accountability," Encyclopedia of Governance (2006). SAGE Publications. 28 April, 2011. http://www.sage-ereference.com/governance/Article_n1.html, 1.

${ }^{44}$ Ibid.

${ }^{45}$ Ahmed, Shamina and David Potter, NGOs in International Politics (West Hartford, Connecticut: Kumarian Press, 2006), 126.
} 
Wardwell, Sarah

accountable, providing the desired outcome. Accountability is critical thinking, reflecting whether those processes and outputs that are considered responsible are actually having the intended effect. An example helps clarify this; if a program manager decides to purchase and distribute 200 Aquatabs to a cholera-affected community he can be responsible and follow the organization's process for this purchase and distribution. However, to be accountable to the community requires going a step further and ensuring that these Aquatabs are distributed to those who need them most, that the recipients understand how to use them, and that the recipients have a plan to get clean water after the distributions end. In Chapter Three there will be more examples from the Haitian context that further explain and clarify the idea of accountability in practice. Accountability focuses on the process and the outcome, whereas responsibility more narrowly focuses on the process and the output.

In academia, there is tension between whether accountability is perceived as a process or an outcome; similar to how democracy is both a process and an outcome. Accountability is a series of ongoing negotiations among stakeholders rather than a strict definition or interpretation ${ }^{46}$. That is to say accountability is not an output, there is no magic equation of factors that can be put together to arrive at accountability. In this sense accountability is not purely procedural nor is it confined only to an end goal.

\footnotetext{
${ }^{46}$ Edwards, Michael and David Hulme, eds., Beyond the Magic Bullet: NGO Performance and Accountability in the Post-Cold War World, (Connecticut: Kumarian Press, 1996), 11. 


\section{Wardwell, Sarah}

It is also both an obligation and a willingness to act depending on the situation ${ }^{47}$.

In some cases accountability mechanisms may bind an organization or individual to be held to give an account of their actions. In others, an organization or individual may see benefits from willingly providing an account. Accountability implies the "rights of authority' in that those calling for an account are asserting rights of superior authority over those who are accountable, including the rights to demand answers and to impose sanctions, ${ }^{, 48}$.

Changes in political systems and management expectations have integrated the term accountability into American parlance. "Democracy is a continual correction of mistakes," and in this way democratic leaders are held accountable to their public by offering apologies, explanations, compensations and possible resignations for their actions $^{49}$. Since the public are directly involved in selecting and in some cases ousting leaders, the notion of accountability easily fits the democratic context; hence elections are often seen as a key method in democratic accountability.

Expanding the notion of accountability to global governance is a more difficult task. There is a nominal relationship between voters in democratic societies and then the actions of those representative bodies in global governance organizations, but this link is

\footnotetext{
${ }^{47}$ Bendell, Jem, Debating NGO Accountability, Geneva, Switzerland: UN Non-Governmental Liaison (NGLS) (2006), 1.

${ }^{48}$ Mulgan, Richard, “ “Accountability’: An Ever-Expanding Concept?” Public Administration 78:3 (2000): 555.

${ }^{49}$ Scholte, Jan Aaart. "Civil Society and Democratically Accountable Global Governance." In Government and Opposition Ltd., edited by Held and Koening-Archibugi, 211-233. (Oxford: Blackwell Publishing, 2004), 211.
} 
Wardwell, Sarah

weak in practice ${ }^{50}$. For example, citizens themselves are unable in most cases to take global organizations to court. The lack of accountability in this intermediary space between citizens, governments, and global governance has created space for civil society to represent the demands of citizens, especially minorities and vulnerable populations to be heard on the global stage. "To ask about accountability is not merely to ask whether [I]NGOs 'responsibly' exercise their power, but instead whether a basis exists for them to be invested with such power in the first place,"

Like many modern terms employed in politics such as sustainability or globalization, accountability seems to be leading down the path of becoming an essentially contested concept, a term that has become a placeholder for the greater debate it encompasses. If accountability does become an essentially contested concept, it would lose its meaning, and the lively debate around it right now would diminish. One way of avoiding this situation is to tack on additional words to the original term, adding depth. For example, "political globalization" or "cultural globalization" provides more information than the term "globalization" by itself. Likewise, the term "accountability to beneficiaries" provides more insight into the intended meaning.

Another way of further defining accountability is into functional/procedural accountability and strategic/substantive accountability. Practical accountability refers to the bureaucratic and internal functions of an organization, "accounting for resources,

\footnotetext{
${ }^{50}$ Scholte, Jan Aaart. "Civil Society and Democratically Accountable Global Governance." In Government and Opposition Ltd., edited by Held and Koening-Archibugi, 211-233. (Oxford: Blackwell Publishing, 2004), 211.

${ }^{51}$ Anderson, Kenneth, "What NGO Accountability Means: And Does Not Mean," The American Journal of International Law 10:13 (Jan. 2009), 176. 
Wardwell, Sarah

resource use, and immediate impacts" ${ }^{, 52}$. It answers the questions: Are they acting in a prudent, careful manner? Are they transparent with their spending? Are they keeping accurate records of their activities and spending? Strategic accountability looks deeper into the outcomes and impacts of the organization, accounting for the impact from the organization and it's actions on the wider environment ${ }^{53}$. It asks are they spending their funds appropriately? This thesis is primarily interested in strategic accountability, while recognizing the contributions of practical accountability to that end.

\section{Stakeholders and Beneficiaries}

Accountability can be a nebulous and unmanageable term unless the stakeholders to whom the individual or organization is to be held accountable to are identified. Each stakeholder brings their own set of expectations, making it difficult for individuals operating within an organization to decide how to best manage all of these in a way that maximizes impact. For the purpose of this thesis, a stakeholder is defined as any individual or group who has a legal obligation, moral, or material interest in the actions of the NGO. Generally, the list includes the donor (private, public, or corporate), government from the donor country, host national government, host local government, affected community (which can be further disaggregated by interests such as gender, age, disabled, poor, entrepreneurs, etc.), INGO board and other leadership, partner agencies (such as Southern NGOs), peer agencies, and the program staff. These forces are depicted

52 Edwards, Michael and David Hulme, eds., Beyond the Magic Bullet: NGO Performance and Accountability in the Post-Cold War World (Connecticut: Kumarian Press, 1996), 8.

${ }^{53}$ Edwards, Michael and David Hulme, eds., Beyond the Magic Bullet: NGO Performance and Accountability in the Post-Cold War World, (Connecticut: Kumarian Press, 1996), 8. 
Wardwell, Sarah

below in the diagram ${ }^{54}$. All of these groups are diverse and can be further broken down by special interests depending on the actual program, which is why a specific stakeholder analysis for each program is a necessary first step in developing an accountability to beneficiaries framework ${ }^{55}$."Since the relative importance of the relationships is context and case-specific, the INGO must review all the relevant legal, moral, ethical, and political claims made on them and make a strategic decision about which claim carries the most weight." ${ }^{, 56}$. All stakeholders play a monitoring role in the activities of the NGO depending on their interest in the activities.

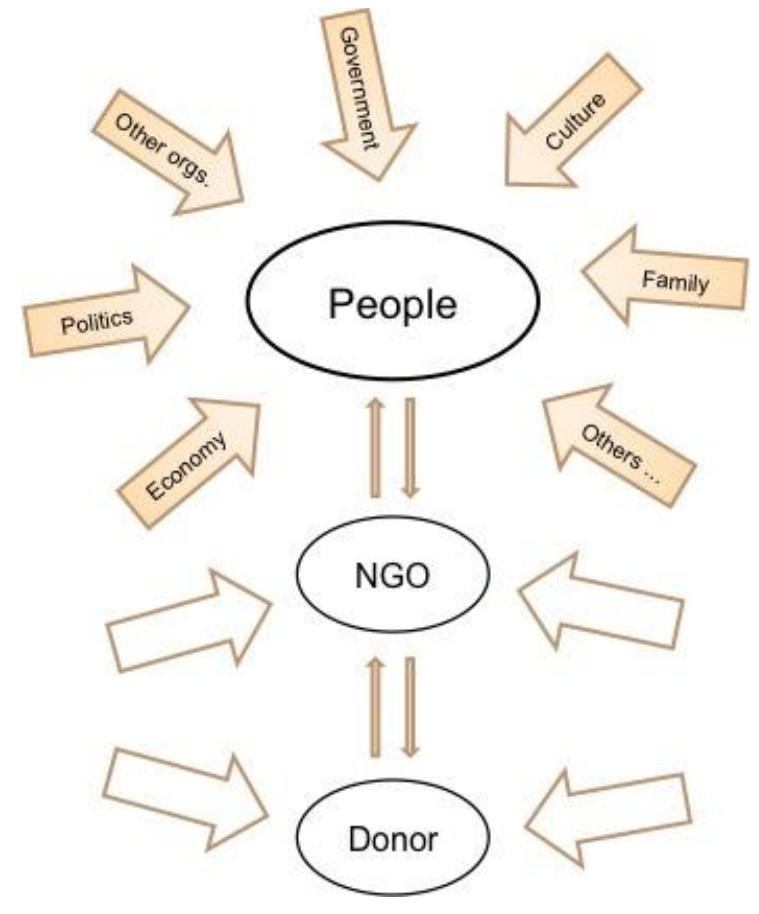

Figure 2. INGO Stakeholders

54 Jacobs, Alex, "Five Pillars: Improving Quality and Impact," (April 19, 2011,) www.NGOperformance.org.

${ }^{55}$ Cavill, Sue, and M. Sohail, "Increasing Strategic Accountability: A Framework for International NGOs," Development in Practice 17:2 (April 2007), 240.

${ }^{56}$ Szporluk, Michael. "A Framework for Understanding Accountability of International NGOs and Global Good Governance.” Indiana Journal of Global Legal Studies 16:1 (Winter 2009): 341. 


\section{Wardwell, Sarah}

Not all stakeholders will see positive benefits from the actions of an INGO. With most INGO interventions, there will be tradeoffs, or moresimply put, winners and losers. With most foreign interventions, a fundamental question related to accountability is: who enjoys the benefits and may suffer consequences ${ }^{57}$ ?

Beneficiaries are a specific subset of stakeholders as they are the persons most likely to be directly affected by an NGO program activities, or outputs. In social and economic development, these individuals tend to be significantly economically and/or socially disadvantaged, and living in a developing state. For this thesis, they are the primary stakeholder, whose perspective is being studied. A beneficiary is defined in this thesis as any individual or group who is a member of the society whose interests the project or program is intended to promote.

Beneficiaries who are living in poverty have unique limitations that present particular problems to holding organizations accountable. These groups tend to be unaccustomed to having a voice in local governance. In many developing countries police and other systems intended to protect people require fees that may block individuals from accessing these services when they have complaints or concerns. Many vulnerable groups are even afraid of voicing their concerns since it could only worsen their situation.

\footnotetext{
${ }^{57}$ Lewis, David and Tina Wallace, ed. , New Roles and Relevance: Development NGOs and the Challenge of Change (Connecticut: Kumarian Press 2000), 54. 
Wardwell, Sarah

These definitions will set the stage for developing an accountability to beneficiaries definition in chapter three and will build the bedrock of the arguments this thesis puts forward. As this chapter has shown, a great part of the challenge in measuring accountability lies in first arriving at a common meaning for each term, a challenge that the larger international community has yet to, and may never, overcome. 


\section{Chapter 3. Defining Accountability to Beneficiaries}

As chapter two has identified, holding INGOs accountable to their beneficiaries is a principle that should be implemented in a way so as to ensure that projects are effective and impactful in a positive way. Although sometimes written off as too idealistic, principle-based, or academic, this thesis contends that with concrete practices and systems to measure accountability to beneficiaries, beneficiaries themselves can become an important component of measuring the impact, and ultimately success, of a project or organization. This chapter sets apart the concept of strategic accountability to beneficiaries (SAB) from traditional approaches to this concept, or traditional accountability to beneficiaries (TAB). TAB practices include the mechanisms and tools that INGOs currently employ without seeing overall improvements in their impact. Standard tools used by INGOs to measure their results and progress, such as the logframe that organizes the activity with indicators of achieving the goals or intended outcomes of the project, may not lead to accountability in the SAB sense because they can lead staff to focus too heavily on studying only the indicators they have decided to study and could miss other impacts their project is causing, either positive or negative. This type of TAB tool shall be discussed later on in this chapter.

SAB practices make up a framework that allows leaders to incorporate mechanisms and tools into their projects and operations throughout their organization, improving not only outputs but also outcomes of their work. The information gained through SAB mechanisms and tools help leaders make strategic decisions to align their organizational mission and values better with the projects and activities they carry out. 
Wardwell, Sarah

$\mathrm{SAB}$ also differs from $\mathrm{TAB}$ in that it holds all members of the organization to account for their behavior and actions, rather than just select project or program leaders.

Haiti is an example of the struggle for INGOs to be accountable to the beneficiaries they intend to serve. In a 2011 Rolling Stone article quoting President Clinton's experience in the impoverished nation, "For too long the West has embraced 'development for development's sake,' throwing money at poor countries without demanding either accountability or results. ${ }^{, 58}$. Using the case of Haiti, this chapter will walk through the theoretical arguments from the debate about accountability to beneficiaries, further differentiating between $\mathrm{TAB}$ and $\mathrm{SAB}$ approaches, mechanisms, and tools. The definitions developed in chapter two will be used in this chapter to open the foundational questions in the debate, beginning with assessing who is to be held accountable. Next, this chapter will discuss the different directions of accountability before focusing on accountability to beneficiaries and delineating what is meant by the term. The heart of the theoretical aspect of this debate will then be explored by responding to these three core questions: Accountable to whom? Accountable for what? Accountable how? A related annex attached to this thesis includes a brief examination of how the World Bank has taken steps towards increasing accountability to beneficiaries when they act as a project implementer.

\section{Who is Accountable}

Chapter two highlighted the many different stakeholders involved in any INGO intervention, from intended beneficiaries to local government to multi-national donors.

\footnotetext{
${ }^{58}$ Reitman, Janet, "Beyond Relief: How the World Failed Haiti,” Rolling Stone, August 4, 2011. 
Wardwell, Sarah

The first step in moving towards an accountability framework is to determine which of these stakeholders are to be held accountable.

For the bulk of academic research, large institutional donors and western governments are held accountable for the success and failures of international development activities over the past half century. "Accountability is too often skewed to the most powerful of stakeholders, that is, those who provide financial resources." Many of these arguments rely on colonialist and neo-colonialist theories. There is some merit in these arguments as these institutions are holding the purse strings to most largescale development activities. However, these arguments are weak from the perspective that these institutions rarely implement activities

USAID, the United States Agency for International Development, sets up offices all over the world to hold their experts and administrative staff. However the main function of these field offices are to ensure program quality and vet implementing partners and not to actually carry out programs themselves. Ensuring program quality and ensuring effective disbursement of funds all too often amounts to little more than reviewing annual reports ${ }^{60}$. In a 2010 interview with a USAID Chief of Mission in Vietnam, he candidly confessed making fewer visits to the field than he would have liked. When pressed to come up with a frequency, he lamented that he usually tries to get

\footnotetext{
${ }^{59}$ Havrda, Marek, and Petr Kutilek, "Accountability 2.0 - In Search of a New Approach to International Non-Governmental Organisations’ Accountability,” In Evaluating Transnational NGOs: Legitimacy, Accountability, Representation, edited by Jens Steffek and Kristina Hahn, 169. New York: Palgrave Macmillan, 2010.

${ }^{60}$ Havrda, Marek, and Petr Kutilek, "Accountability 2.0 - In Search of a New Approach to International Non-Governmental Organisations' Accountability,” In Evaluating Transnational NGOs: Legitimacy, Accountability, Representation, edited by Jens Steffek and Kristina Hahn, 169. New York: Palgrave Macmillan, 2010.
} 
Wardwell, Sarah

out of the office to visit a project quarterly, but also admitted that the logistics involved in arranging such a visit often slow down the actual number of visits he can take in a year ${ }^{61}$. This example is from Vietnam during a period of peace and stability where logistics are much simpler than in a country such as Haiti, which remains volatile and has much worse infrastructure to facilitate such visits. While INGOs need to place an increased importance on the perceptions and input from their beneficiaries, in order for INGOs to effect an accountability system to their beneficiaries, they will need the input and relationship with their donors in which to do so. Achieving an INGO accountability to beneficiaries system will be closely linked to donors recognizing the importance of such a system $^{62}$.

The second most-cited party held accountable in the literature is the government of the country receiving aid. This argument has slightly more credibility since these governments will be left with the remains of whatever projects enter their country. In development best-practice the government is often referred to as a partner in development activities. However, in reality, often organizations find it easier to achieve their projected project outputs by simply informing the government of their activities or altogether bypassing them. This has been a particular problem in Haiti where many INGOs are spending private funding they raised after the earthquake. Since these funds are less restricted by their donors, the agencies are not obligated to involve the government in the project in the same way they would be if they were receiving institutional funding.

\footnotetext{
${ }^{61}$ Personal Observation, 2010.

${ }^{62}$ Ebrahim, Alnoor, NGOs and Organizational Change: Discourse, Reporting, and Learning, Cambridge: Cambridge University Press ( 2005), 149. 


\section{Wardwell, Sarah}

Therefore they can implement activities that they believe are benefitting the community irrespective of what the appointed government leaders believe is needed. This has led to numerous cross-over activities by organizations carrying out similar, duplicative or even counter-productive projects at the same time. In 2011 in Saint-Marc, Haiti, the mayor has attempted to tackle this problem by asking all NGOs (local and international) to meet once a month and discuss their projects. NGO leaders are asked to give overviews of their projects and the mayor and the other NGO leaders give input on projects ${ }^{63}$.

Corruption is also cited frequently as a barrier to holding the aid-recipient government accountable for INGO activities. Transparency International's Corruption Perception Index, which is published annually, roughly aligns with where western governments are putting their aid dollars ${ }^{64}$. Countries such as Afghanistan and Somalia rate among the highest levels of corruption worldwide according to this metric, and they historically and continually receive some of the largest sums of humanitarian and development aid amounts the world over. Haiti is rated 1.8 on this scale of $0-10$ where zero is very corrupt and ten is very clean, making it the $9^{\text {th }}$ most corrupt country as measured on this index (ranking 175/182 with 5 sources reporting and a confidence range of $1.6-2)^{65}$. In late 2011 the mayor of Saint-Marc came to the Mercy Corps office to inquire about project progress, then he informed the Head of Office that he was planning a housing development that would be "très chic" including a golf course. Perhaps, he

\footnotetext{
${ }^{63}$ Personal observation, September 2011, Saint-Marc, Haiti.

64 “Corruption Perceptions Index 2011," Transparency International, http://cpi.transparency.org/cpi2011/results/

${ }^{65}$ Ibid. 


\section{Wardwell, Sarah}

suggested, this would make more suitable housing for INGO management ${ }^{66}$. It can be difficult to say the government is the focal point for INGO accountability when they are facing their own series of challenges from mismanagement, fund misappropriation, to being out of touch with their communities. In Haiti the latter challenge is particularly clear with the elitist divide between the ruling class and "pèp la" or general population. In other non-democratic societies this disconnect between government and public is well documented in democratic theory literature.

For this thesis, the INGO as a whole, herein referred to as "the organization", will be the focal point of accountability. Since the INGO is the actor carrying out the majority of the activities themselves, it is the most appropriate actor to say "the buck stops here". Further, choosing the INGO as the actor who is responsible for accountability to beneficiaries also puts the INGO in the driver's seat of improving their results and impact. INGOs will have a more research-backed claim to impact by following a SAB approach. As this thesis contends, it is expected that when an INGO takes initiative to carefully consider and analyze their actions in response to how accountable to their beneficiaries these actions are, that the actions will on the whole lead to a more positive impact. A TAB approach to AB would focus only on one part of the agency, whereas the SAB approach considers every decision made within the agency by all actors.

In a SAB approach, holding the organization accountable involves the actions of everyone in the agency. Just as democratic accountability requires all actors within the society to be accountable, INGO accountability to beneficiaries requires the actions of all

${ }^{66}$ Personal observation, Saint-Marc, Haiti, November, 2011. 
Wardwell, Sarah

members of an INGO to be held accountable ${ }^{67}$. Cavill and Sohail term this "collective accountability", holding every member of the organization liable for the organization's conduct $^{68}$. The organization decisions made at the top of organization, such as which countries to work in, down to decisions about project implementation.

Much academic literature treats INGOs as entities, but as these organizations are run by many individuals simultaneously making decisions all over the globe, in a SAB approach it's necessary to think about how accountability to beneficiaries will impact and infiltrate every one of those decisions. Cavill and Sohail refer to this as "individual accountability", where each member of the organization's actions as they contribute to the organization's conduct as a whole are measured ${ }^{69}$. Figure three below shows a SAB approach to this question where each individual is responsible for a different aspect of the organization's accountability, depending on their unique role. These roles are designed to fit any INGO structure. Starting with the bottom left corner, all INGOs have administrative staff, often referred to as operations staff, who are accountable for ensuring compliance with all formal procedures are complied with. This includes upwards accountability measures such as stipulated by the grant agreement, local and international laws, and internal policies and procedures. The bottom right corner is the producer/executive, who oversees the entire INGO mission or operation. These people usually have titles such as Country Director, Mission Director, Head of Office, or

${ }^{67}$ Bendell, Jem, Debating NGO Accountability, Geneva, Switzerland: UN Non-Governmental Liaison (NGLS) (2006), 3.

${ }^{68}$ Cavill, Sue, and M. Sohail, "Increasing Strategic Accountability: A Framework for International NGOs," Development in Practice 17:2 (April 2007), 233.

${ }^{69}$ Cavill, Sue, and M. Sohail, "Increasing Strategic Accountability: A Framework for International NGOs," Development in Practice 17:2 (April 2007), 234. 
Wardwell, Sarah

Operations Manager/Director. These individuals ensure accountability, looking at the economy, efficiency, and effectiveness of the project implementation. This has a lot to do with budget controls and operations management, but also includes working with project teams to ensure they have found the optimal way to carry out their project activities.

\section{Change}

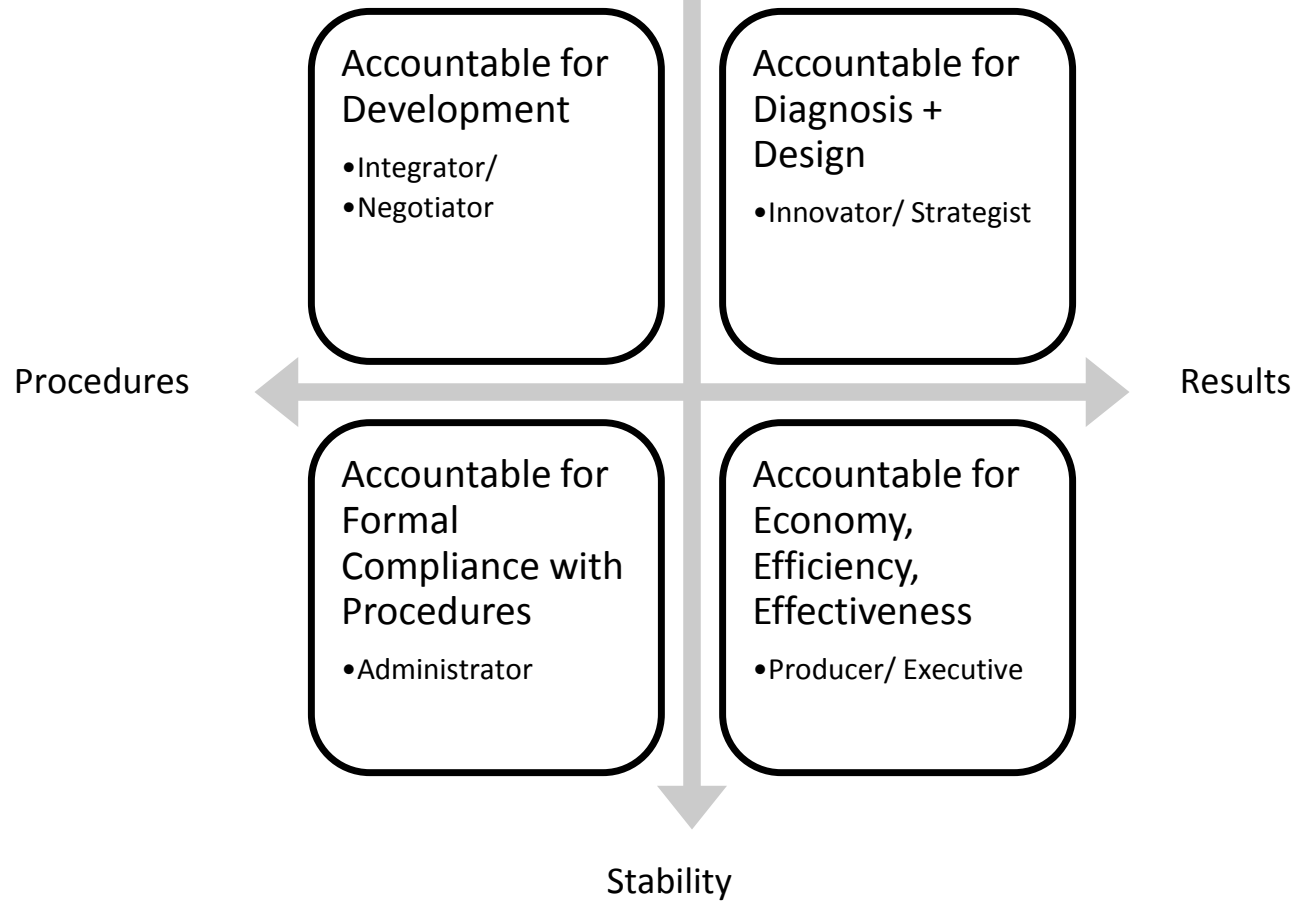

Figure 3. Who's Accountable? ${ }^{70}$

The top right hand corner is led by the innovator or strategists within the organization. These individuals tend to sit on the programs side of the organization creating new projects. They are not necessarily in a senior position, but most INGOs will have someone like this in a senior-level and then others at a mid-level working on

\footnotetext{
${ }^{70}$ Cavill, Sue, and M. Sohail, "Increasing Strategic Accountability: A Framework for International NGOs," Development in Practice 17:2 (April 2007), 234, 244. 
Wardwell, Sarah

country-specific new projects. As innovators and strategists, they are accountable for the diagnosis and design of the organization's interventions. The individuals in the top left corner are the integrators and negotiators who carry out the projects. These individuals are the ones left with the actual accountability for development outcomes as they are the ones directly implementing the project activities. When producer/executives are accountable for the 3 E's (economy, efficiency, and effectiveness) and the administrators are accountable for compliance, the organization will have stability. When the integrator/negotiators are accountable for the development/project implementation and administrators are accountable for compliance, there will be procedural accountability achieved. When the producer/executives are accountable for the 3Es and the innovators/strategists are accountable for their diagnosis of the problem and project design, there should be measurable results, or outputs. To achieve change, all of these actors need to be held accountable for their individual aspects, but most importantly the innovators/strategists must have properly diagnosed the problem and be held accountable for their implementation design and the integrator/negotiators must be held accountable for the development and implementation of the project. This figure helps to break apart individual roles and responsibilities and their specific accountability relationship within the larger concept of accountability to beneficiaries.

\section{Accountability Compass}

There are three main purposes of accountability as defined by the scholarly literature - to whom, for what, and how? These questions help identify the type or direction of accountability in question. As discussed in chapters one and two, 
Wardwell, Sarah

accountability can be a rather vague term unless it is qualified by adding the direction or affected population. As such, accountability can be imagined as a compass, spun to point in the direction of the "to whom" population in question.

Accountability to whom identifies the group or individual who the accountable party wants their actions to be held accountable to. This seemingly straight-forward question has caused a great deal of debate amongst scholars and practitioners and highlights the gap between theory and practice. In theory many INGOs aspire to have their actions be held accountable to the populations they serve, but in reality, they are held more tightly to their donors by more rigorously developed monitoring and evaluation mechanisms and finances. Simply put by one field worker, "“There is an ongoing battle between being accountable to the people you work with and for, versus the people who give you the money to do that work.",71.

Since INGOs occupy a middle position in the chain of foreign aid spending, INGO accountability can be broken down into upwards and downwards accountability. Upwards accountability describes the relationship between the INGO and donors, board of trustees, and the host government or the relationships that "face up the aid chain" Downwards accountability, rather, focuses on the relationship between the INGO and beneficiary, or the relationships that "face down the aid chain"73. These relationships also

\footnotetext{
${ }^{71}$ Survey respondent as cited in Cavill, Sue, and M. Sohail, "Increasing Strategic Accountability: A Framework for International NGOs," Development in Practice 17:2 (April 2007), 239.

72 Jacobs, Alex, and Robyn Wilford. "Listen First, a Pilot System for Managing Downward Accountability in NGOs." Development in Practice 20:7 (2010): 798. Cavill, Sue, and M. Sohail, "Increasing Strategic Accountability: A Framework for International NGOs," Development in Practice 17:2 (April 2007), 233.

73 Jacobs, Alex, and Robyn Wilford, "Listen First, a Pilot System for Managing Downward Accountability in NGOs," Development in Practice 20:7 (2010): 798. 
Wardwell, Sarah

exemplify the transitions of power from one actor to another. There are two additional directions accountability relationships flow: horizontal and strategic/inward. Horizontal accountability is where members of the organization hold one another accountable for their actions, also known as "professional accountability" 74 . Within a traditional hierarchical management structure, this is a similar system of upwards accountability internally. Using more innovative management structures such as a team map helps visualize and encourage team members holding each other accountable for their decisions and actions. Competition between individuals can present problems with this type of accountability and warrant at least one other form be used. Lastly, there is strategic or internal accountability, which similar to horizontal accountability holds INGOs accountable to their organizational mission and values and for working within established societal norms and expectations ${ }^{75}$.

The second question, "accountable for what?" identifies the actions for which the accountable party wishes to be held accountable for. Accountability can be understood as the "management of expectations"76. The party that will be held accountable has the opportunity to decide which of their actions they wish to be held accountable. This is not to say that their wishes will always be followed, a public can hold a democratically elected official accountable for their personal actions that are not overtly recognized in

Cavill, Sue, and M. Sohail, "Increasing Strategic Accountability: A Framework for International NGOs," Development in Practice 17:2 (April 2007), 233.

${ }^{74}$ Cavill, Sue, and M. Sohail, "Increasing Strategic Accountability: A Framework for International NGOs," Development in Practice 17:2 (April 2007), 233. Mulgan, Richard, “ 'Accountability': An Ever-Expanding Concept?" Public Administration 78:3 (2000): 559.

${ }^{75}$ Cavill, Sue, and M. Sohail, "Increasing Strategic Accountability: A Framework for International NGOs," Development in Practice 17:2 (April 2007), 233.

${ }^{76}$ Mulgan, Richard, “'Accountability’: An Ever-Expanding Concept?” Public Administration 78:3 (2000): 559. 
Wardwell, Sarah

their position description. As chapter two discussed, INGOs carry out a multitude of activities that affect different populations in differing direct and indirect manners. At this point accountability can be split into two directions: practical and strategic. Practical accountability relates to the use of inputs, policies, and decision making to deliver outputs $^{77}$. This type of accountability focuses heavily on the day-to-day operations and financial management of the INGO. Cynics of INGO accountability to beneficiaries downplay the importance of this type of accountability as supporting only the continued existence and reproduction of the organization. However, for an organization to implement a strong accountability system - both upwards and downwards, this function of accountability must be included. Strong operational and finance systems are essential to the smooth implementation of a program. When operations and finance staff are consistently thinking about accountability with each decision, and being involved and questioning the decisions made by the program teams, accountability takes on a more robust form.

Strategic accountability, or more specifically SAB, which is the focus on this thesis, examines how the INGO performs in relation to their mission ${ }^{78}$. While some scholars see these as two distinct forms of accountability, they are closely linked and in practice often indistinguishable. As this thesis has discussed previously, the whole INGO is to be held accountable. This holistic approach to accountability asks each member of the organization to be dedicated to the mission and values of the organization.

\footnotetext{
${ }^{77}$ Cavill, Sue, and M. Sohail, "Increasing Strategic Accountability: A Framework for International NGOs," Development in Practice 17:2 (April 2007), 234.

${ }^{78}$ Cavill, Sue, and M. Sohail, "Increasing Strategic Accountability: A Framework for International NGOs," Development in Practice 17:2 (April 2007), 234. 
Wardwell, Sarah

Additionally, practical accountability plays in when considering the daily activities that lead towards strategic accountability. This is not necessarily a cause and effect relationship, but rather a process, whereby practical accountability coupled with a strong sense of the mission and values leads to a vibrant accountability structure.

The third question, "accountable how?" helps to clarify the specific mechanisms and steps an interested party can take to measure and improve their accountability. Mechanisms vary widely depending on the responses to the first two questions. This is also the most highly contested area around accountability. "Accountability to clients should be a major emphasis since most INGOs' missions emphasize serving the community in various ways. However, most communities lack mechanisms for holding INGOs accountable, especially poor communities."79. Scholars and practitioners have proposed mechanisms for the past few decades only for another to find that their mechanism can be in fact counterproductive to accountability. A general example of this is monitoring and evaluation (M\&E) systems. As the INGO sector has matured, $\mathrm{M} \& \mathrm{E}$ has become a bedrock of INGO best practices. Modern scholars are questioning the effectiveness of M\&E at holding INGO activities accountable to the populations they serve. Some even find it to be a barrier to accountability.

"Measurement is, arguably, the most challenging aspect behind the principles of aid effectiveness," ${ }^{, 80}$. Monitoring and evaluation (M\&E) systems are mechanisms intended to measure INGO output and impact achievement. Donors rely heavily on

\footnotetext{
${ }^{79}$ Ahmed, Shamina and David Potter, NGOs in International Politics, (West Hartford, Connecticut: Kumarian Press, 2006), 127.

${ }^{80}$ Goody, Allison, “International Development: The Aid Effectiveness Debate,” Library of Parliament (24 June, 2009), 14. 
Wardwell, Sarah

results of regular monitoring results and final evaluations of projects to assess the impact of their funds. In 2011 USAID began an increased effort to conduct more external final evaluations on projects they have invested large sums in since this type of evaluation eliminates a level of bias. M\&E systems increase upward accountability because they increase the flow of information from the project to the donor. However, M\&E systems are not necessarily a way to increase downward accountability. Given the complexity of beneficiary populations and the many activities for which INGOs are to be held accountable to these populations, measurement systems must take on a more holistic approach to understanding and measuring not only the outputs, but also the outcomes of a project in a SAB system. There is an additional danger of evaluations in that there is pressure from the donor and the organization to show that the work was well done and problem areas can be glossed over ${ }^{81}$.

M\&E systems are often based around logical frameworks (commonly referred to as a log frame), 4 x 4 matrices that specify the goal, purpose, outputs and inputs of a project, and objectively verifiable indicators that these outputs were met. Sometimes these indicators can be too narrowly focused so that "only that which is measurable should be measured and other phenomena are thus not considered important" ${ }^{\prime 22}$. Often key issues can be lost in M\&E log frames. For example, Mercy Corps published a learning document discussing the positive and unexpected benefits to women in rural Tajikistan from a food assistance program. These effects were not measured in the log

${ }^{81}$ Cavill, Sue, and M. Sohail, "Increasing Strategic Accountability: A Framework for International NGOs," Development in Practice 17:2 (April 2007), 239.

${ }^{82}$ Davies, 2001 as cited in Bendell, Jem, Debating NGO Accountability, (Geneva, Switzerland: UN NonGovernmental Liaison (NGLS), 2006), 17. 
Wardwell, Sarah

frame, but their effects on the community were notable and worth sharing internally and externally. Additionally, sometimes donors require such a large quantity of information that it can become cumbersome on project managers. An example from a Aga Khan rural development project in India where they were asked to track 89 different indicators. Reams of data were generated from these indicators, but the project managers found that the data they were not asked to report on was actually the most useful to the project's success $^{83}$. Ebrahim argues against the idea that the more rigorous the performance measurement, the better it is and instead suggests "focusing on measures that make a difference rather than measures that are countable, and that this would make the work more accountable to the interests of intended beneficiaries, who, of course, have an interest in being benefited, not just being reported on, " ${ }^{84}$. Therefore M\&E systems alone are not sufficient to measure accountability.

Accountability mechanisms can be grouped into: internal (organization-wide) initiatives, external (independent) initiatives, and external peer or sector initiatives ${ }^{85}$. Internal mechanisms can be implemented by the organization themselves, including organization-wide surveys, frameworks, toolkits, accountability advisors, and M\&E systems. These mechanisms are the main focus of this thesis as they are steps any member of an organization can take action on to improve the accountability of their actions and decisions.

\footnotetext{
${ }^{83}$ Bendell, Jem, Debating NGO Accountability, (Geneva, Switzerland: UN Non-Governmental Liaison (NGLS), 2006), 17.

${ }^{84}$ Ebrahim, 2003, as cited in Bendell, Jem, Debating NGO Accountability, (Geneva, Switzerland: UN NonGovernmental Liaison (NGLS), 2006), 17.

${ }^{85}$ Cavill, Sue, and M. Sohail, "Increasing Strategic Accountability: A Framework for International NGOs," Development in Practice 17:2 (April 2007), 234-236. 


\section{Wardwell, Sarah}

External (independent) initiatives include the range of actions for actors in the external environment in which INGOs operate that hold them accountable for their actions and decisions. Some of these actors include the local civil society, media, host government, and individuals from the home or host country of the INGO. These individuals and groups can use a variety of mechanisms to hold the INGO accountable primarily by demanding information, voicing complaints, raising concerns via media outlets, protesting, and refusing to conduct business with the INGO (mostly through private sector actors). This type of initiative also includes legal regulations such as those set by the United Nations (UN), local laws, policy agreements, and a growing body of common law and court cases from international courts. INGOs can be bound by quasilegal measures such as contracts and memorandums of understanding. These external initiatives and forces acting upon INGOs affect how INGOs select internal accountability to beneficiaries mechanisms, but are outside the scope of this thesis.

The third group of mechanisms includes more controversial ideas about INGOs holding each other accountable for their actions. These include associations such as the Active Learning Network for Accountability and Practice (ALNAP) and the Humanitarian Accountability Partnership International (HAP-I). All of these organizations are optional for INGOs to join, but once they are members they are obliged to make significant progress on their accountability mechanisms as the association outlines. These are steps that senior leaders within INGOs can choose to take towards improving accountability, but are outside the scope of this thesis since this thesis looks 
Wardwell, Sarah

more at the actions that each member of the organization can take to improve accountability rather than just decisions senior leadership can make.

\section{Locating Accountability to Beneficiaries within INGO Activities}

A foundational argument in this thesis is that accountability to beneficiaries increases INGO impact. Within the organization as a whole there are many different activities that each individual carries out and for which she must be held accountable for. This section will look at this question from a slightly different angle, examining the different components of INGO work and how each contributes to accountability to beneficiaries.

As stated in chapter two, this thesis defines beneficiaries as any individual or group who is a member of the society whose interests the project or program is intended to promote. The definition of accountability to beneficiaries is constructed by combining the definitions of accountability and beneficiaries. As stated in chapter one, accountability to beneficiaries will be defined as the process through which an INGO justifies and is responsible for the manner and results of its projects and programs to any individual or group who is a member of the society whose interests they are intended to promote. Focusing on this type of accountability encourages the organization to stay aligned with their mission and values, and theoretically increase impact. It's difficult to say that accountability to beneficiaries mechanisms will always result in increased impact due to the numerous and highly varied forces acting upon any single project and the actors involved. INGOs know all too well how difficult documenting and claiming results 
Wardwell, Sarah

of their projects can be. Causal relationships in this sector are nearly impossible to draw, at best INGO actions can be included as corollary to a perceived impact.

The figure below breaks down the concept of strategic accountability to beneficiaries by each main component of what the organization is accountable for. This diagram looks at the actions and activities of the organization from a bigger picture point of view, beyond just the life cycle of a project, calling specific attention to the parts and details of each larger component. 


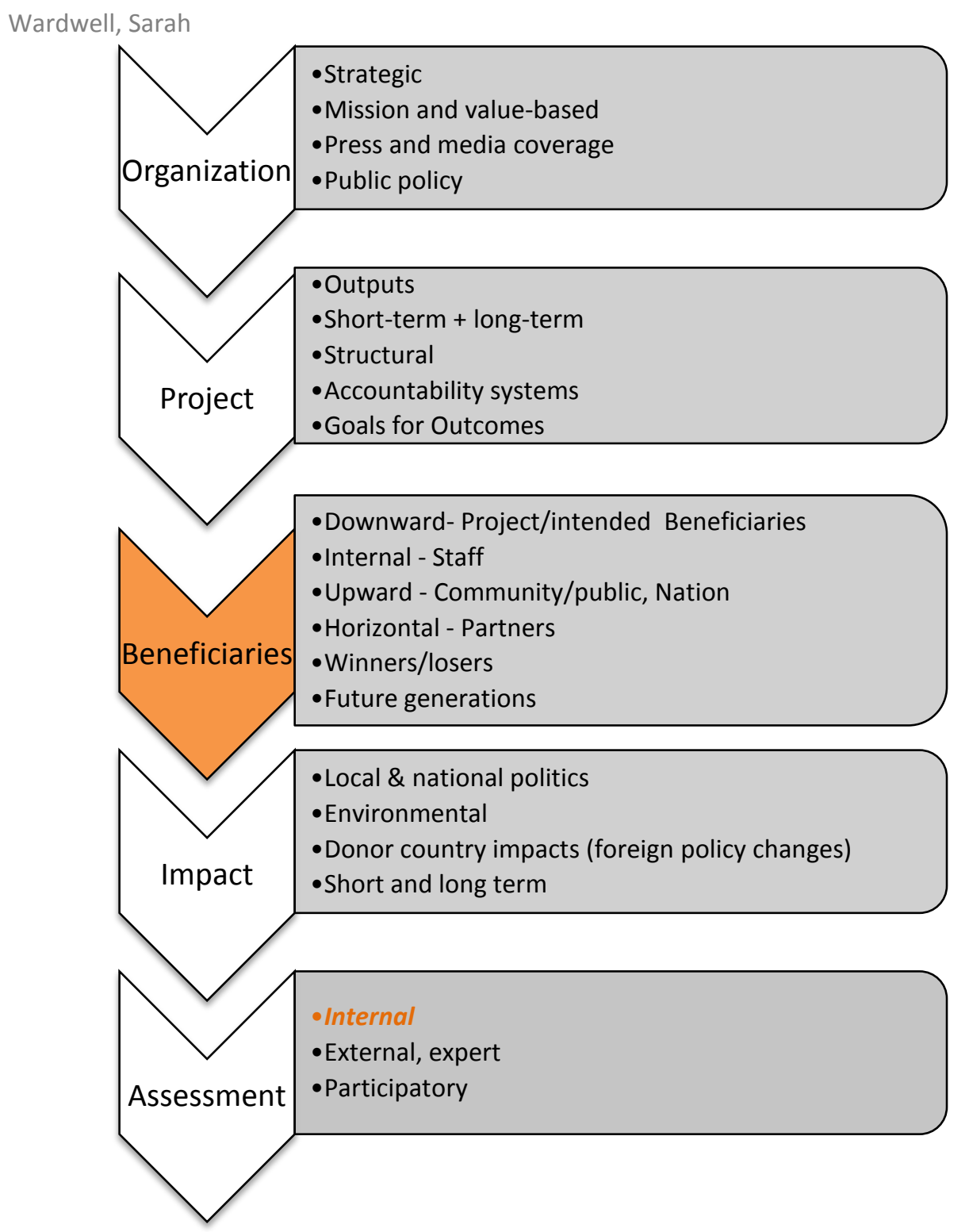

\section{Figure 4. Accountability to Beneficiaries Components}

First, there is the organization, which encompasses all individual actions and also includes those actions not directly associated with implementing a project. Accountability should be a part of the organization's overall strategy. For example having a strategic framework in place that guides the organization and encourages accountability practices, is a good start towards achieving accountable project outcomes. The organization, could 
Wardwell, Sarah

have an accountability framework and possibly a toolkit of accountability mechanisms, that the individual project chooses which specific tools fit the needs of the context at hand. The mission and values of the organization are closely linked to strategic accountability. If the organization hopes to achieve their mission and act in alignment with their values, they must implement accountability practices. Press and media coverage are usually handled, at least in part, by the organization's headquarters, and thus are represented in this section. Individual projects may also use the media as accountability tools, but for the whole organization's actions, this is placed here. Linked also the organization is public policy changes, where the policy section of an INGO may work with their home government or international governing actors, such as the UN to affect policy change.

Secondly, there is the project, which is where most practitioners focus their time and energy on when considering accountability. This is a logical place to start, as this is the main point of action. The project will work towards achieving outputs during the entire cycle, from assessment to final evaluation. The time period where stakeholders will be affected is in both the short and long term, depending on the activity. The project is where individual project-specific accountability systems should be introduced. The project also has goals for bigger picture outcomes, such as poverty alleviation, food security, or environmental protection.

The next step is beneficiaries, as a key part of the downward accountability system, this group includes the intended beneficiaries from the project. Beneficiaries also include the staff, or internal beneficiaries as part of internal accountability. Upwards 
Wardwell, Sarah

accountability includes the community, general public, or the greater nation in which the INGO is working who will be affected in some way by the actions of the project. Beneficiaries may also be horizontal, as in partner or local organizations that will be affected by the project. Sometimes these partners may look different from the traditional sub-grant concept. For instance, during an Local-Regional Procurement food security project (LRP), local vendors will supply the food that USAID gives beneficiaries the money to purchase. In this type of project, the vendors are the horizontal beneficiaries. Beneficiaries may be affected in a positive manner, and those who are possibly affected negatively. Lastly, there is the effect on future generations that must be considered when discussing beneficiaries of a project. The lifetime of an INGO intervention may be only a few months or a few years, but its effects may last for several generations. These effects may morph over time from a positive to negative sense.

Next, is the impact step of accountability. The four main dimensions of impact are local and national politics, environmental effects, donor country impacts, and time considerations. Local and national politics can be either positively or negatively affected by the project and the beneficiaries' view of the project. The environment will be altered in some way by any type of foreign intervention. USAID has recognized this and with certain projects, they now require an environmental assessment be conducted before and after each intervention. In a project in Tajikistan called the Tajikistan Stability Enhancement Project (TSEP), an individual was hired specifically to monitor these impacts from each activity within the multi-year project ${ }^{86}$. Each project will also have

${ }^{86}$ Personal observation, Tajikistan, 2010. 
Wardwell, Sarah

effects back in the donor country, largely affecting foreign policy decisions. For example, USAID funded projects working in the area of HIV/AIDS prevention could have affects on US foreign policy to affected areas or on future foreign aid spending in this sector. INGO project impact may also affect foreign policy decisions through donor-country impacts. The impacts of a project or an INGOs interventions may vary over time, but time is again an important consideration.

Lastly, is assessment, which may take place at the project level or the organization level of analysis. Since the organization is the focus of this thesis, organizational assessments are the level of study. This thesis will discuss three types of assessments: internal, external, and participatory, looking at how they each relate to accountability to beneficiaries systems. While assessments occur before, during, and after a project, it is listed here as a final stage because this is where information is recorded before it gets cycled back to the organization for use in either informing future project decisions or designing new projects. While many evaluations include participation from project beneficiaries (intended beneficiaries), a participative assessment in this sense includes all stakeholders, even those not directly benefiting from an INGO intervention.

\section{Accountable to whom?}

In the discussion of accountability to beneficiaries, this thesis has already established that the group of individuals that will be affected by an INGO project, the "beneficiaries", is larger than those intentionally targeted by the project in a SAB approach. Defining the beneficiaries is more complicated than just considering the group of intended project beneficiaries because INGO projects have ripple effects beyond their 
Wardwell, Sarah

intended consequences. A TAB approach to accountability to beneficiaries would consider only the direct project beneficiaries. The question of accountable to whom, can also be rephrased as "which beneficiaries are we accountable to?" As the SAB approach has defined beneficiaries, this group consists of: project participants (intended beneficiaries), the general community/public, national/state government, future generations (10 years, 30 years, so on), and local partners. Within this group there will be those who see positive effects and those who are affected negatively - simply put, winners and losers. This section will give more detail on each of these groups. There is a distinction between stakeholders and beneficiaries. Stakeholders are those that have an interest in the program, but they can be interested from any number of angles. Beneficiaries are a specific group of stakeholders who are either direct or indirect recipients of aid, affected either positively or negatively. This is a fine line of distinction and not a definition accepted across all agencies. When most INGOs discuss beneficiaries they are only discussing the direct recipients of the intervention. One reason the term beneficiaries has been chosen to encompass all of these different groups is to get away from the upward accountability connotation of the term stakeholders and hone in on those voices from individuals and groups on the receiving end of the funding, even if not affected directly receiving the funds or benefits. All of these groups have in common that their ideas, concerns, and questions are often unmentioned and unheard at the donor level. The dam example from Uganda highlights the dangers of only focusing on the small group defined by the INGO as beneficiaries when there may be a larger consortium of people who's information should be used to inform the decisions of the INGO. 


\section{Wardwell, Sarah}

The term "beneficiaries" carries a positive tone, but under this expanded definition, all individuals affected by the project are included. Not all beneficiaries will be impacted in a positive manner. INGO impact is not black and white. INGOs struggle to measure results of their work. For donor reports and media relations, INGOs highlight signs of positive impact on the communities they have worked in. For this reason, external evaluations have been recommended by major international institutional donors more in the past decade.

Time is an important factor in terms of INGO accountability and impact that is often skipped in a TAB approach. TAB looks primarily at how direct project beneficiaries will perceive the work in the near future. For example, if a community is surveyed and says their primary concern is food insecurity and the INGO chooses to distribute food, this would be considered accountable under a TAB approach. In a SAB approach, a better intervention would be to address the root causes of food insecurity such as job creation or improved farming techniques. Due to the short-term nature of development assistance, INGOs rarely measure the affects of their work years after the end of their project. INGOs work with people and people change over time. Individual or government priorities may change, the environment may change, and other changes can happen in a community that will alter the effects of a project. Individuals who were once positively affected by a project could later be negatively affected by that same intervention and vice versa. For example, providing and improving access to education is always touted as an INGO activity that has a positive impact. However, if the population becomes educated rapidly, and the government and economy cannot provide jobs for 
Wardwell, Sarah

those individuals when they are ready to enter the workforce, the population could rise up against the government and overthrow the same government that helped improve access to education. This complicated scenario highlights the many different factors and forces operating on any INGO project and the impact of time on all of these actors.

The most obvious group of beneficiaries is the project's intended participants or recipients. Most of the time when INGOs use the term "beneficiaries" this is the group they are referring to. Beneficiaries have a distinct interest in the activities that the INGO is carrying out because the INGO intends to provide some sort of benefit to this group regardless of how large or small the group is and regardless of the longer term impact. Most social and economic development projects intend to fight poverty in some form or another. Since these programs are generally targeted at poor populations, these individuals have a different capacity to question or complain about the activities of the INGO.

In the rebuilding of Haiti after the 2010 earthquake, citizens sometimes complain that INGOs are building houses without latrines, while simultaneously claiming that the Haitian people need to improve their sanitation to fight cholera and other disease ${ }^{87}$. In Haiti, citizens are accustomed to fighting the government through protests. In 2011 citizens held protests against INGOs (local and international) in Port au Prince and Mirebalais, a mid-size town in the Central Plateau of Haiti, and against the UN Stabilization Mission in Haiti (MINUSTAH) in Saint-Marc ${ }^{88}$. In Port au Prince numerous protests have been held for a myriad of reasons related to INGOs and the UN. In

${ }^{87}$ Personal observation, January 2012, Port au Prince, Haiti.

${ }^{88}$ Personal observation, October 2011-January 2012, Haiti. 
Wardwell, Sarah

Mirebalais protestors reportedly wanted more funding for local NGOs and more jobs for Haitians, fewer for expatriates. In Saint-Marc they reportedly wanted MINUSTAH to pay damages to citizens affected by cholera, which the UN Mission has been charged with bringing to Saint-Marc and has spread throughout Haiti. In each case, the citizens' demands were not met. INGOs in Haiti have taken some steps towards improving feedback and complaint mechanisms, but the fact remains that in nearly every society, the poorest of the poor are familiar with a tradition of quiet acceptance of imposed rules and regulations on them. In an effort to communicate with beneficiaries in Haiti after the earthquake, many INGOs established committees within camps and communicated directly with those committees. While the intent of this approach was good, as one beneficiary stated, "Even if we want to say something, we don't have the chance; only the committee has the right." 89 .

Nicholas Kristof and Sheryl Wu Dunn write a dramatic story of a young woman in Pakistan who tries to report abuse from authorities and ends up further abused ${ }^{90}$. Participation, feedback, and complaint mechanisms are all key factors in accountability to beneficiaries and will be further discussed in the section "accountable how".

The community where an INGO operates its project or head office is also impacted by their activities. As the case of Mirebalais highlights, jobs with INGOs are one way the community is affected. Currently in Haiti, INGO operations are scaling back, which means reducing staff and returning many Haitians to a stagnant or even shrinking

${ }^{89}$ Humanitarian Accountability Partnership, “The 2010 Humanitarian Accountability Report," (Geneva, Switzerland), 92.

${ }^{90}$ Kristof, Nicholas and Sheryl Wu Dunn, Half the Sky: Turning Oppression into Opportunity for Women Worldwide, (New York, New York: Vintage Books), 2010. 
Wardwell, Sarah

employment market. Communities can also be directly affected by the outputs of a project, or indirectly. If one community receives a benefit, such as the dam building example in Uganda, another community may be negatively affected. More indirectly, communities not receiving benefits of a project may have similar needs that they are left to find solutions to on their own. For example, if an organization builds a school in one village, a neighboring village may also need a school, but will be forced to find a way to build it on their own. These are give and takes that all INGOs consider before selecting a location for their projects. Selection criteria and the role of community members in this process varies widely, but is a factor of accountability.

The host country where the INGO is operating, including national and local governments are other beneficiaries. In order to carry out operations in a foreign country, INGOs must liaise in some way with the host country government. Often, governments require NGOs to go through a registration process and in some cases INGOs must submit reports of their work. How closely an INGO works with the government depends on the organization, the nature of the project, and the country they are working in. Aid has flooded into Haiti post-earthquake. Many organizations have chosen to subvert the government to carry out their projects. This type of behavior is unaccountable to beneficiaries because the government will remain in the country long after the INGO has gone.

In some cases, INGOs will work directly with local NGOs to implement their projects. Working through partners helps build local organization's capacity and can help with long-term sustainability of the work. These organizations are part of the group of 
Wardwell, Sarah

beneficiaries since they can receive direct financial and capacity building support from the INGO. Local NGOs can either collaborate and receive benefits from an INGO or find themselves in competition with INGOs for limited funding, as the Mirebalais protests exemplify.

\section{Accountable for what}

The long-term impacts are ultimately the "what" that INGOs are to be held accountable for. This goes beyond the narrow "participatory" accountability approach currently employed by many INGOs and digs deeper into M\&E data (not just that which is collected to report on specified indicators, but also the complaint and beneficiary stories, local staff observations) on the outcomes of projects and interventions and thus holds the INGO accountable to the great silent majority of present and future citizens. The what is the effects on populations that have been trapped in endemic poverty cycles, unaccustomed to having their voice heard by their government or the authorities put in place in theory to protect them, such as the police or military. INGOs often say they want to focus on helping these people, but in their haste to implement projects that will improve their situation; they often fail to truly listen to what these people are saying or asking for. A TAB approach would focus solely on the ouputs of the individual project or program that is being implemented, whereas a SAB approach looks at the outcomes of each project and asks if the organization is staying in line with their own mission and values. Accountable for what asks what INGOs need to be listening for and then accountable how will look at how INGOs can improve their listening skills to these vulnerable populations. 


\section{Wardwell, Sarah}

There's a common logic model international development practitioners are familiar with below ${ }^{91}$. This model looks like a linear model, as though if all of the right materials can be found, the end result can be accurately predicted. Except that development work happens a) with people and b) in unpredictable, rapidly changing environments.

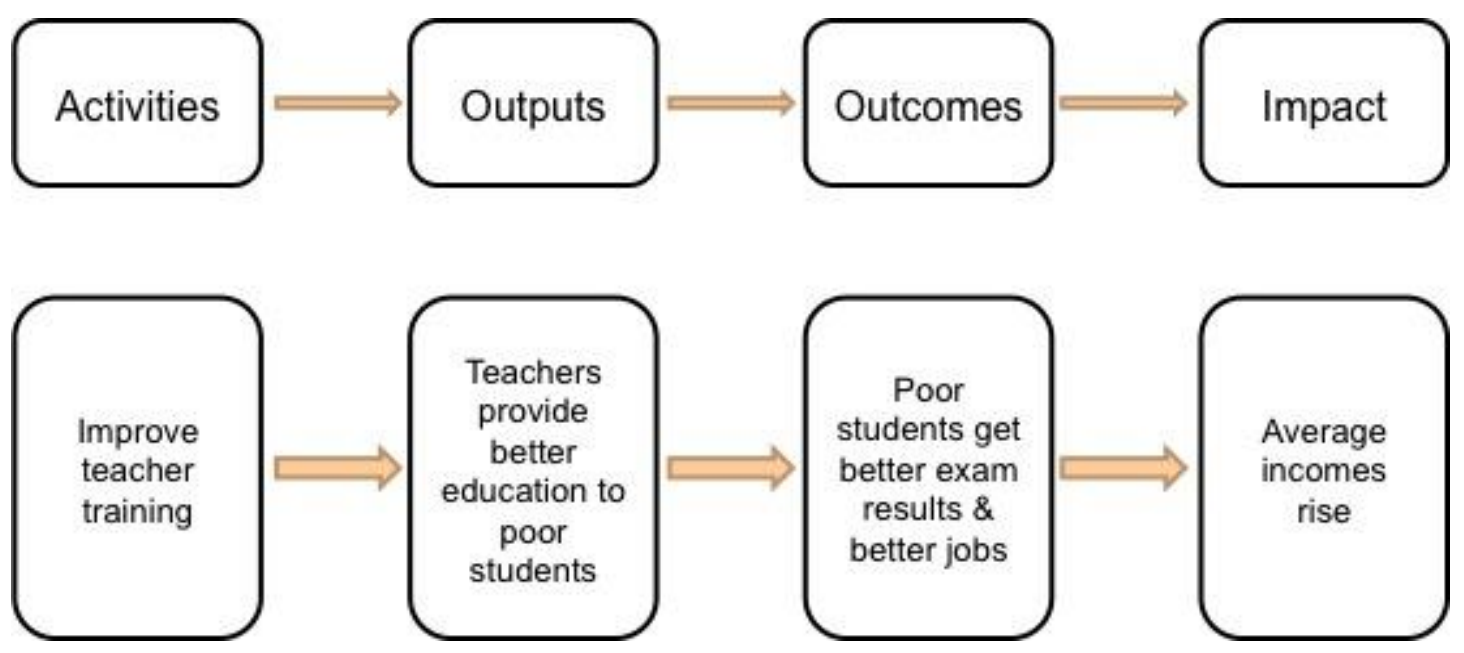

Figure 5.1 Traditional View of an INGO Project Pathway

The above model oversimplifies the work of an INGO project and leads the reader to believe that impact is a sure final step in the process, when history shows that it clearly is not (i.e. poverty alleviation has not happened in wide scale across Sub-Saharan Africa despite billions of dollars of foreign aid assistance being sent over with this intended impact). The model below is a more modern project management system. This one is set up by an organization that focuses on designing models of project management for INGOs.

\footnotetext{
91 Jacobs, Alex, "Five Pillars: Improving Quality and Impact," (April 19, 2011,) www.NGOperformance.org. 


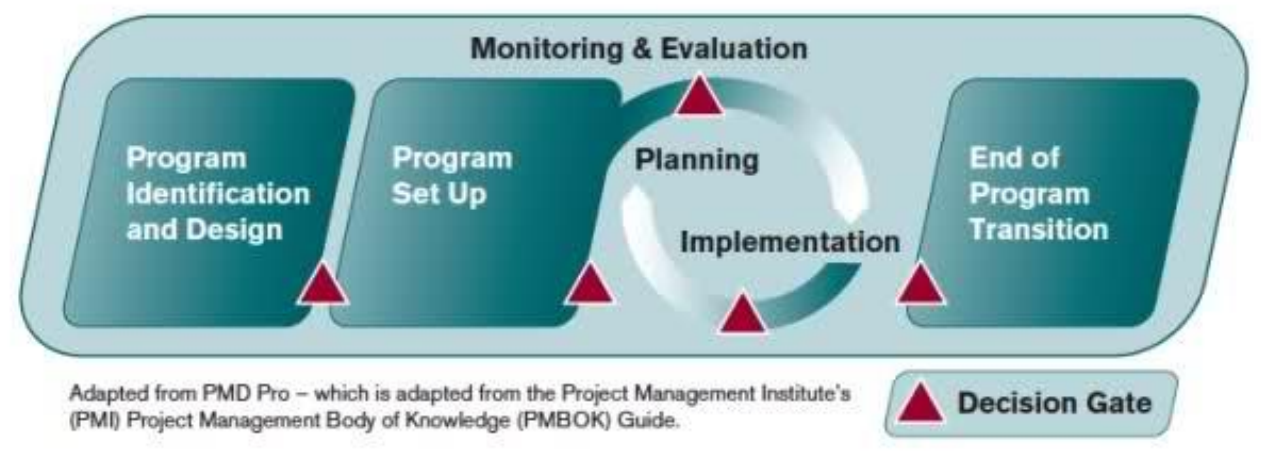

Figure 6. Modern Project Management ${ }^{92}$

This model looks at feedback loops and acknowledges that behavior change and INGO impact does not happen in a straight line. This is a confusing point for many local INGO staff because the project they are given and their job functions are frequently designed in a linear fashion without built in feedback loops, unless the program manager specifically requires these and takes the time to discuss this with staff. For example, project job functions are often divided into three broad categories of project implementing staff responsible for carrying out the project activities, M\&E staff responsible for collecting and recording data, and operations staff responsible for arranging all of the logistical and bureaucratic functions and ensuring activities are carried out in compliance with donor and organization standards.

Within each step of the project cycle, there are many individual decisions that are made by numerous decision makers. Strategic organizational accountability looks at each of these innumerable decisions along the entire project cycle and holds each individual actor accountable for all of these decisions. The diagram above uses decision gates to

${ }^{92}$ Mercy Corps. 2011 Project Management Manual. 
Wardwell, Sarah

identify the key decisions that the organization wants to be held accountable for. In reality, even seemingly small daily decisions made by INGO staff can impact their accountability to beneficiaries.

For example, an INGO project in Haiti had a large M\&E department with more than 30 monitoring staff all collecting data plus data entry staff to enter the information, and the information was then shared with the $\mathrm{M} \& \mathrm{E}$ advisor and other management staff. After the end of the project, some of the M\&E staff admitted that they were afraid to collect information that showed some of the beneficiaries were not completely satisfied with the activities of the INGO because they feared that reporting complaints from beneficiaries could threaten the jobs of the whole team ${ }^{93}$. In a country like Haiti where jobs are scarce and INGO jobs are well known to pay well even if they are not guaranteed for a long period of time, it is important to consider the biases of local staff. Further, these staff need to be well trained to understand how and why they are collecting this data to ensure they are properly collecting it and sharing the right information with the communities about why the data is being collected. Overlooking this important step can lead to data errors. To ensure objectivity of data collectors, M\&E staff report to someone more objective about the success of the project, someone other than the program manager.

\section{Accountable How?}

When INGO managers discuss accountability, the conversation quickly turns to the question of how to be more accountable? Practitioners want solutions they can

${ }^{93}$ Personal observation, January 2012. 
Wardwell, Sarah

quickly implement. As Bendell points out, "The question of organizational accountability is often seen as a bureaucratic hurdle at best, and at worst a threat to achieving an NGOs aims, ${ }^{, 94}$. In order to effectively integrate accountability measures into practice, measures must be low-cost and require limited time and resources to implement, ideally matching up with systems and tools the organization and project are already using. At the same time, a SAB approach asks that managers select tools that help them see past the immediate outputs of the project and help them gain insights into the outcomes of the project. As such, there cannot be a standardized set of tools that will work for every project or program, even within one specific country context.

The humanitarian and development sectors are notorious for searching in vain for "the magic bullet". As Ebrahim and Rangan argue, it is not feasible nor even desirable for all organizations to develop metrics at all levels on the logic chain ${ }^{95}$. The mechanisms proposed can be broken down into two categories: tools and processes. Accountability tools are discrete devices or techniques used to achieve greater accountability that can be applied over a limited period of time, can be tangibly documented, and can be repeated. ${ }^{96}$ Process mechanisms, "emphasize a course of action rather than a distinct end-result,". 97 These types of mechanisms are less tangible, not bound to a specific time frame, are more broad or multi-faceted, and may involve a set of tools. In this section, the different mechanisms an INGO can use to hold their actions accountable will be examined -

\footnotetext{
${ }^{94}$ Bendell, Jem, Debating NGO Accountability, (Geneva, Switzerland: UN Non-Governmental Liaison (NGLS), 2006), xi.

95 Ebrahim, Alnoor and V. Kasturi Rangan, "The Limits of Nonprofit Impact: A Contingency Framework for Measuring Social Performance,” Harvard Business School Working Paper 10-099 (2010), 4.

${ }^{96}$ Ebrahim, Alnoor, “Accountability in Practice: Mechanisms for NGOs," World Development 31:5 (2003), 815.

${ }^{97}$ Ibid. 
Wardwell, Sarah

narrowing from the overarching change of mindset to more specific changes that can be made before, during, and after a project.

\section{Accountable How: Tools}

Accountability mechanisms are essentially about control $^{98}$. In a democracy, people want to have control over the decisions and actions of their elected officials. With an INGO, donors have created clear mechanisms for leveraging control over the actions of the implementing organization. Yet, these mechanisms are much less developed for beneficiaries to affect the behavior of the organization. Accountability is a fine balance of allowing the beneficiaries and the donor to determine what actions are appropriate for the INGO, while still allowing the INGO sufficient room for their own expertise and input. Within a democracy, accountability mechanisms include: separation of powers, federalism, constitutionalism, judicial review, the rule of law, public service codes of conduct, and so on ${ }^{99}$.

There are four main dimensions of accountability to beneficiaries: transparency, participation, complaints, and feedback and learning. All of these four dimensions have significant overlap, and when they all overlap, the middle is accountability to beneficiaries, as displayed in the figure below. As Jacobs argues, systematically improving collaboration will lead to improved quality and impact of INGO actions within

\footnotetext{
${ }^{98}$ Mulgan, Richard, “ ‘Accountability’: An Ever-Expanding Concept?” Public Administration 78:3 (2000): 563.

${ }^{99}$ Mulgan, Richard, “ ‘Accountability’: An Ever-Expanding Concept?” Public Administration 78:3 (2000): 563. 
Wardwell, Sarah

each of these four mechanisms ${ }^{100}$. In reality, time is also a very important factor in accountability to beneficiaries and to account for this graphically, would require imagining this figure in 3-D and these concepts being stretched over time. Of these four dimensions, three are processes, which are more multifaceted and less tangible or timebound than tools. Process dimensions focus on the course of action rather than the distinct end-result, making the means as important as the ends themselves ${ }^{101}$. While complaints may seem out of place here as not being a process, it is an important tool for accountability to beneficiaries that is often overlooked and under-utilized by INGOs.

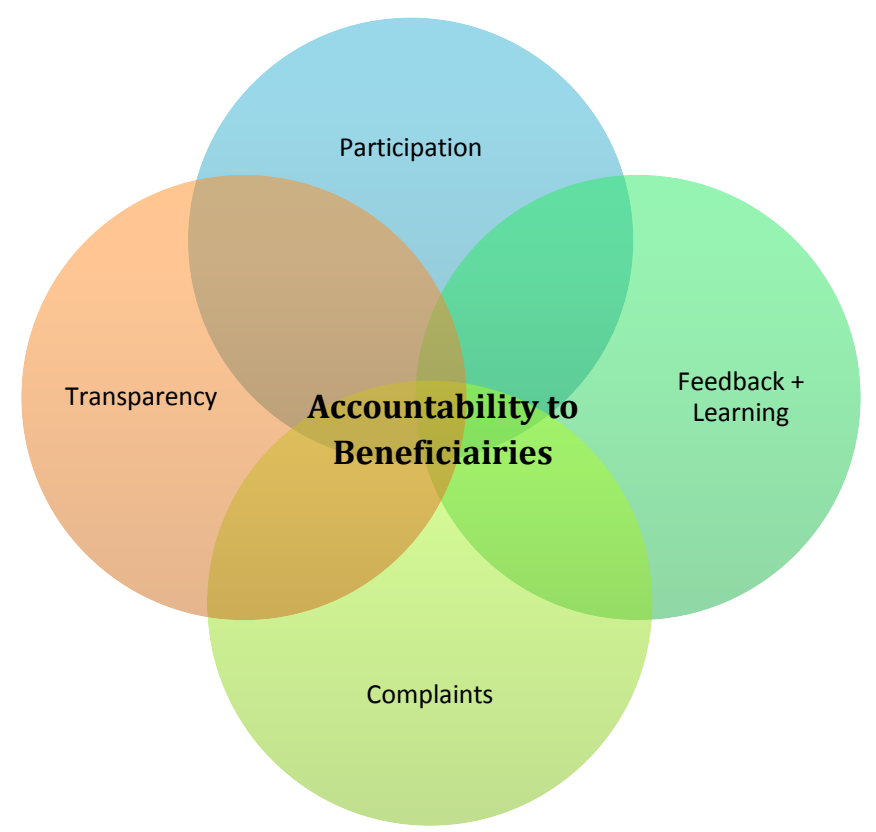

Figure 7. The overlapping dimensions of Strategic Accountability to Beneficiaries

100 Jacobs, Alex. "Five Pillars: Improving Quality and Impact." (April 19, 2011,) www.NGOperformance.org.

${ }^{101}$ Ebrahim, Alnoor, “Accountability in Practice: Mechanisms for NGOs," World Development 31:5 (2003), 816. 
Wardwell, Sarah

"There is a need to engage in more participatory approaches because even in poor countries, people understand the issues and can take action to improve development outcomes,"102. In some way or another, all INGOs, donors, and literature on international development acknowledge that participation is integral to any external intervention. For many, if not most, INGOs, their mission statement involves something related to helping people help themselves, a key principle in modern international development theory. As Ellerman states, this means that "any external intervention must be sensitively informed by local people's preferences and priorities at every stage of planning, implementation and review, as a cornerstone of success,",103.

Participation is especially important to hold an organization accountable for itself and its actions, provided that meaningful ways exist for those being represented to exercise participation in and, ultimately, control over the organization ${ }^{104}$. Participation may occur in many different levels. At its most basic level, participation overlaps with transparency - people having access to information is a rudimentary aspect of participation. Building on that, is public involvement in the actual process of the project. This can be as simple as direct beneficiaries being involved in the project, such as a cash for work project where citizens are selected to help clean up after a disaster or maintain public goods. This would be an example of the traditional approach to accountability to

\footnotetext{
${ }^{102}$ Worthington, Sam, moderator. "The Aid System: Does 'Mutual Accountability' Encourage Outcomes?" Panel Discussion at the Civil Society Forum at the World Bank and IMF Board of Governors Meeting, (Istanbul, Turkey), October 4, 2009.

${ }^{103}$ Ellerman, (2005) as cited in Jacobs, Alex, "Creating the Missing Feedback Loop," IDS Bulletin 41:5 (2010): 56-64.

${ }^{104}$ Anderson, Kenneth, "What NGO Accountability Means: And Does Not Mean," The American Journal of International Law 10:13 (Jan. 2009), 175. 
Wardwell, Sarah

beneficiaries. Or, this can be a more involved type of participation where a variety of stakeholders are involved in the entire project process from assessment and design all the way through to the final assessment and disseminating project results. This latter example is part of the third tier of participation, the ability of citizens to bargain over decisions with NGOs or state agencies ${ }^{105}$. The fourth tier of participation is where the idea for the project itself comes from the community themselves and the project proceeds independently of INGO and state sponsored projects ${ }^{106}$. This tier of participation is the type of project ownership that many INGOs strive to see happen after the initial project is carried out by the INGO.A SAB approach would strive to achieve the fourth tier of participation.

A fundamental assumption of the importance of the first two tiers of participation is that poverty can be eliminated by access to resources and services ${ }^{107}$. Therefore, little decision making and project ownership is needed for certain types of foreign intervention to achieve these outcomes. These types of projects include building or improving infrastructure and providing direct services. In this sense, participation is largely symbolic. As Najam points out, in this sense "the sham of participation translates into the sham of accountability,". 108

Transparency is often mistaken for accountability. In essence, transparency is disclosure and sharing of information across stakeholders. Control over information is a

\footnotetext{
${ }^{105}$ Ebrahim, Alnoor, “Accountability in Practice: Mechanisms for NGOs," World Development 31:5 (2003), 818 .

106 Ibid.

${ }^{107}$ Ebrahim, Alnoor, “Accountability in Practice: Mechanisms for NGOs,” World Development 31:5 (2003), 818.

${ }^{108}$ Najam, 1996 (pages 346-347) as cited in Ebrahim, Alnoor, “Accountability in Practice: Mechanisms for NGOs," World Development 31:5 (2003), 818. 


\section{Wardwell, Sarah}

lever of power for both INGOs and donors ${ }^{109}$. A variety of mechanisms can ensure transparency of information and results across the project cycle. Transparency allows outsiders to make their own judgments on many activities INGOs carry out, including future project proposals, so that all stakeholders in cases such as the Uganda dam project can have the opportunity to participate ${ }^{110}$. This is the area of overlap between participation and transparency, simply sharing information can be a basic form of participation and also a basic form of transparency.

Supreme Court Justice Louis D. Brandeis famously wrote in 1913 that "sunlight is said to be the best of disinfectants." But in the cynical world, companies and political groups often deflect that light or diffuse it into 1,000 incomprehensible components ${ }^{111}$. This is to say that transparency in and of itself is not accountability. INGOs will produce a plethora of information throughout the lifecycle of a project, but which information is selected to be shared must be carefully selected depending on the context at hand.

An example from outside the realm of INGOs helps clarify the selection process for transparency. The recent restaurant grading system in New York City helps diners make informed decisions about the quality of the food preparation of the establishment they are going to select. The information is clearly displayed in a simple manner (grades are $\mathrm{A}, \mathrm{B}$, and $\mathrm{C}$ ). This type of transparency carefully selects the information relevant to

\footnotetext{
${ }^{109}$ Ebrahim, Alnoor, NGOs and Organizational Change: Discourse, Reporting, and Learning. Cambridge: Cambridge University Press (2005), 144.

${ }^{110}$ Anderson, Kenneth, "What NGO Accountability Means: And Does Not Mean," The American Journal of International Law 10:13 (Jan. 2009), 177.

111 Miller, Jed, "If Transparency Leads Nowhere," New York Times, January 25, 2012. http://www.revenuewatch.org/news/blog/nyt-op-ed-if-transparency-falls-forest
} 
Wardwell, Sarah

the intended population, accomplishing the output goal of the shared information helping customers make informed decisions, with the intended outcome of improving food service quality in NYC. They didn't have to ask businesses to share information they wouldn't really be comfortable sharing, such as their financial records in order to accomplish their goal.

When the word "transparency" comes up within the INGO community there is sometimes an ill feeling that they'll be forced to share information they don't necessarily want to share. At the same time though, INGOs realize that there is a need to coordinate better with other INGOs, local NGOs, businesses, and the government, which would require increased transparency. Much of the information that is currently shared by INGOs focuses too heavily on products produced by the INGO, or their project outputs, rather than the processes they are following ${ }^{112}$. The type of information collected by the organization will directly affect the type of decisions made by the organization. Much of the information collected by INGOs comes in the form of monitoring and evaluation systems (M\&E). The organization then has the choice about which and how much of this information to share with which stakeholders. A TAB approach would focus merely on collecting the information, whereas a SAB approach would ensure that the information collected is then also shared back to the communities where the information was taken from to ensure learning happens with all stakeholders through the dimension of transparency.

\footnotetext{
${ }^{112}$ Ebrahim, Alnoor, NGOs and Organizational Change: Discourse, Reporting, and Learning. Cambridge: Cambridge University Press (2005), 81. 


\section{Wardwell, Sarah}

Feedback and learning systems are a systematic approach to collecting the views of the beneficiaries and other key stakeholders about the quality and impact of INGO activities, offering the possibility of significantly boosting impact by creating incentives for staff to focus on beneficiaries' priorities ${ }^{113}$. These systems provide the moments of pause during a project, where staff re-group and discuss the information obtained through M\&E and other staff observations. This primarily happens through meetings, but can be an ongoing process as well and the information supplied from M\&E and staff observations will feed into each future decision. M\&E data, once collected and recorded, should be shared widely with staff and back with the community as well. Many communities have become tired of constantly responding to questionnaires without seeing the analysis that follows. When an INGO collects information, many communities also see this as a promise of future benefits. If the INGO collects information and then never follows through with a project or activities in the area, communities are often become outraged with the organization. Similarly, in some countries communities have become wary of INGOs collecting data on them because they fear they are spying on them and are part of a rebel movement. This is a particular challenge faced by INGOs operating in conflict zones such as Afghanistan where INGOs now struggle to collect information from beneficiaries.

Project monitoring can be a method of obtaining feedback if the information is shared within the project and operations team. Unfortunately, due to the time restraints and plethora of demands upon program and M\&E staff, this information is often collected

\footnotetext{
${ }^{113}$ Jacobs, Alex. “Creating the Missing Feedback Loop.” IDS Bulletin 41:5 (2010): 56-57. 
Wardwell, Sarah

but not shared widely. A TAB approach would consider that simply collecting the information allows the project to be considered accountable to beneficiaries. In order for this information to be usable for program and operations teams, the data needs to be analyzed and boiled down into meaningful points and action items. Taking the time to do this would be an excellent step towards creating projects that are more accountable to beneficiaries. This information can also be used to inform the country program, regional program, or organization's strategy as well and may influence other actors in the region if the information is shared.

Complaints are a specific part of feedback from beneficiaries that is necessary to call special attention to for accountability to beneficiaries. The populations that are often the direct beneficiaries of an INGO project are usually unaccustomed to having their voice heard, and when they do raise their concerns via the local authorities or media, their situation can be made worse. A local government official in rural Haiti told an INGO in 2010 that he didn't want their specific project in his community because it didn't address what he saw as the most pressing needs. He also said that he realized if he didn't accept this project, he would be jeopardizing his chances for future projects in his community ${ }^{114}$. Complaints must not only be recorded, but the organization must have a clear and simple reporting system and way to show the community that they are acting on their complaints under a SAB system.

Within the four main dimensions of accountability to beneficiaries there are many different tools that can be used. A toolbox for accountability would be useful for

${ }^{114}$ Personal observation, 2010. 


\section{Wardwell, Sarah}

organizations to share, or even a unique toolbox for one organization would benefit all of their different country programs. Dubnick categorized three types of account giving tools - reporting, mitigating, and reframing ${ }^{115}$. He uses the figure below to establish the differences between the role and relationship of the principal (donor) versus the agent $(\text { INGO })^{116}$. This section will review a few of the tools that are representative of the reporting and reframing categories and are either frequently employed by INGOs or becoming commonly accepted as "best practices" within the sector: participative evaluations, external final evaluations, benchmarking, and internal assessments. Mitigating tools are less common with INGOs than in the public sector, where Dubnick's research is focused. In the international development sector there are two main tools used for mitigating, monitoring systems and complaint tools. Both of these are accountability processes rather than discrete accountability tools and will be discussed further in the section about accountability processes.

\footnotetext{
${ }^{115}$ Dubnick, Melvin, "Accountability and the Promise of Performance: In Search of the Mechanisms," Public Performance \& Management Review 28:3 (March 2005), 383.

${ }^{116}$ Dubnick, Melvin, "Accountability and the Promise of Performance: In Search of the Mechanisms," Public Performance \& Management Review 28:3 (March 2005), 384. 


\begin{tabular}{llc} 
Reporting & Mitigating & Reframing \\
\hline $\begin{array}{c}\text { Principal } \\
\downarrow\end{array}$ & Agent $\longleftrightarrow$ Principal & Principal \\
Agent & & $\downarrow$ \\
& & Agent
\end{tabular}

Figure 8. Forms of Account-

Giving Relationships

First, two types of reporting tools will be reviewed, participative and external evaluations. In recent years participative evaluations have become increasingly popular $\mathrm{TAB}$ tool. In this type of evaluation, beneficiaries are actively involved in the measurement of the project, usually in the form of surveys and focus groups. Depending on the specific circumstance, additional mechanisms have been employed for this type of evaluation including innovative usages of technology. However, these evaluations often fall short of measuring the impact on all stakeholders because most evaluators lack the time to properly assess the beneficiary and stakeholder population. Furthermore, these evaluators are tasked with providing specific information that the donor is looking for and therefore don't have the time and resources to examine questions specifically related to how accountable the project was to the populations they were serving. Unless the INGO can provide the evaluator with a robust stakeholder and beneficiary analysis and specifically asks for information on accountability to beneficiaries, this information will not necessarily be collected and thus the evaluation will not be a strong SAB tool.

At the end of the project, an external evaluator is increasingly called in to conduct an assessment of the project's performance and impact. An external evaluator improves the evaluation process by reducing bias about project results. A complaint against external evaluators is that they sometimes lack the local context. When the donor requires an external evaluation of the project, as with the 2010 USAID Forward reforms, the 


\section{Wardwell, Sarah}

INGO still has the option to choose the evaluator and will be heavily involved in the evaluation documentation. Again, simply conducting the evaluation is only a TAB tool. In order to use this type of tool in a SAB system, the evaluation would need to feed into the organization's learning, informing the future decisions of the organization and its strategy. The evaluator should ask questions about how the project aligned with the organization's mission, goals, country and/or regional strategy, and values. A TAB evaluation focuses heavily on standard M\&E tools such as a logframe to measure progress of the project against intended goals. However, as previously noted, this type of system can focus too heavily on pre-defined indicators and miss some of the external or tangential pluses and minuses of the project. For example, a post-earthquake project was evaluated in Haiti and the evaluator focused on the impact to the intended direct beneficiary community. Even when informed by project staff of the positive benefits the local vendors saw from the project he refused to include these results as they were not in line with the project's intended outcomes ${ }^{117}$.

The next two types of tools reviewed are reframing tools, where the agent takes the opportunity to "transform how the problematic situation is defined and perceived" Strategic dashboards are a tool that can be useful in ensuring alignment with an organization's goals and mission. Benchmarking along the dashboard is a tool organizations can use to stay aligned with their mission and goals. Accountability to beneficiaries can be marked as a specific point on the dashboard and progress can be

\footnotetext{
${ }^{117}$ Personal observation, June 2011.

${ }^{118}$ Dubnick, Melvin, "Accountability and the Promise of Performance: In Search of the Mechanisms," Public Performance \& Management Review 28:3 (March 2005), 389. 
Wardwell, Sarah

measured against this indicator over time. The strategic dashboard concept comes from business, but can be applied to an INGO as well by measuring performance against their own selected indicators, such as accountability to beneficiaries. Defining accountability to beneficiaries as an indicator on the strategic dashboard would mean breaking up the concept into it's four dimensions and selecting specific goals to reach within each dimension. The general idea of a strategic dashboard is to condense strategy into simple key points to measure performance against throughout the year. Just like in a car, there are indicators the driver easily reads while using the car, a strategic dashboard helps leaders review their progress on indicators. The dashboard will be expanded upon in the following chapter when the balanced scorecard approach is elaborated and the role of internal assessments further noted.

Assessments are a primary starting point for a strategic dashboard; just as a car starts at zero MPH, the assessment calibrates the organization's performance to zero so that measurement is made possible. Just as with the project cycle, the first step is to conduct an assessment and from there the next steps to be taken to improve accountability can be taken. These assessments can take place at the agency level or at the country-program level. This accountability tool allows the agency or country program to establish areas of focus (which mechanisms need more attention), see which tools are being employed already, and set an accountability framework. Since this type of tool is a starting point of measuring and improving INGO accountability to beneficiaries, it is the focus of this thesis. 


\section{Wardwell, Sarah}

Internal assessments are able to measure staff perspectives of their work, asking staff to critically review their own work. Assuming that staff have decided to work for an INGO because they believe in the organization's mission and have a true desire to improve the situation of others, then this type of assessment can be beneficial for staff to compare their perspectives against those of their peers within the agency. This sort of internal discussion within the agency encourages learning and growth. As INGOs are working in a rapidly changing context, this type of pause for reflection needs to happen frequently, generally around moments of strategic planning. An internal assessment won't offer concrete results about how the INGO is performing in regards to their actual outcomes. Perspectives can of course vary from reality. After standardized tests students across several countries were asked how they performed, American students had the highest level of confidence in their work despite lower scores than students in other countries. Many INGO staff who have worked in the field for a long period of time tend to have a more cynical perspective of their work than newer staff. Thus, the amount of time a staff member has worked in the field could affect their perception of their work and change the data collected by an internal assessment.

\section{Accountable How: Processes}

Accountability tools are individual steps within an integrated accountability process. This section will review the over-arching processes within an accountability to beneficiaries system.

Being accountable to beneficiaries primarily requires a change in mindset of all those working directly on an INGO project. This includes not only the program/project 
Wardwell, Sarah

team, but also the support and operations staff involved, including the finance officers all the way to the Country Director. The first accountability mechanism the organization can benchmark against is their mission and values. The fundamental goals and purpose that the organization claims are directly related to how the organization wants to be held accountable. The actions and outcomes the organization is striving to produce are exactly what the organization should be held accountable for. If an organization claims to improve the health of children, or reduce domestic violence, then the organization can be measured against these goals. Many large INGOs have broader goals that may seem more difficult to measure against, but by asking the organization to start with the goal in mind of being measured against their mission statement; this should push the organization to define their mission in clear and measurable terms.

From there, the organization can integrate accountability into the rest of their programmatic systems and cycles. After the widely criticized response by the US Federal Emergency Management Agency (FEMA) to Hurricane Katrina in 2005, the agency adopted a more integrated preparedness cycle as illustrated below. An integrated approach such as this is what a SAB system ideally should look like. 


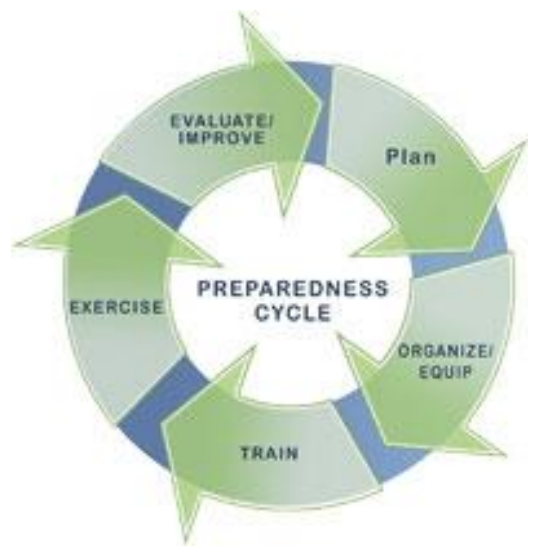

Figure 9. FEMA Emergency Preparedness Cycle $e^{119}$

The headquarters staff will need to support this mindset, largely through adopting and creating a culture of a learning organization. The concept of a "learning organization" has been somewhat in vogue for the past decade with businesses and has caught on within the INGO sector more recently. This concept of a learning organization is based around the idea that organizations can learn, which happens in two ways. The first, is through individuals who learn under the context of the organization they work for. This idea includes on the job training and other skills individuals can learn within an organization. The second way organizations learn is when a concept is understood and accepted within the organization, such as this thesis is interested in $^{120}$. The type of organizational learning that will lead to improved accountability to beneficiaries is when the organization develops and adopts a concept, then ensures that individuals within the organization learn about the concept. Cook and Yanow define organization learning as, the capacity of an organization to learn how to do what it does, where what it learns is

\footnotetext{
119 "Preparedness." http://www.fema.gov/prepared/

${ }^{120}$ 11. Cook, Sccott D. N. and Dvora Yanow, “Culture and Organizational Learning.” Journal of
} Management Inquiry (1993): 401. 


\section{Wardwell, Sarah}

possessed not by individual members of the organization but by the aggregate $\operatorname{itself}^{121}$. A

learning organization is one that takes the time to analyze results of ongoing activities and completed activities, and then, most importantly, the organization uses these lessons learned in establishing a feedback cycle to inform future decisions.

Organizational change is born of tension and succeeds best when it aims for alignment of purpose and action and attunement of the internal and external environment. It is impossible to avoid conflict, inertia and confusion in this process; the only option is to make sure of these forces by being aware of their potential. If a development organization makes it possible for its staff and partners to thrive on change, then it will be, in essence, a learning organization. $^{122}$

Cook and Yanow focus their studies on the private sector, and admit that organizational learning does not necessarily imply observable change $e^{123}$. This is a fundamental point about accountability to beneficiaries, while there is evidence that furthering the organizations understanding of accountability and establishing practices to be held accountable to the organization's beneficiaries will increase impact, the goal of the organization, there is no guarantee this will happen since INGOs work in such a rapidly changing context where their results are dependent on a large and varied number of external factors beyond their control.

Measuring accountability to beneficiaries within a robust organizational learning culture is sometimes referred to as "double-loop learning" because it requires first taking a moment of introspection at the work being done and then incorporating it into the

${ }^{121}$ 11. Cook, Sccott D. N. and Dvora Yanow, “Culture and Organizational Learning.” Journal of Management Inquiry (1993): 403.

${ }^{122}$ Scott-Villiers, 2002 as cited in David, Mancini, and Guijt p. 133

123 11. Cook, Sccott D. N. and Dvora Yanow, "Culture and Organizational Learning," Journal of Management Inquiry (1993): 403. 
Wardwell, Sarah

system, and then repeating ${ }^{124}$. This type of learning is rare in organizations and individuals. Single-loop learning may lead to standardized processes, but won't function as well in the unstable, rapidly changing context in which INGOs work. Rather, a doubleloop system where learning can be triggered by a multitude of factors, including from beneficiaries, changes in local government, changes in local economics, etc. will help INGO projects achieve their larger goals such as accountability ${ }^{125}$. A double-loop learning system produces changes in people's assumptions and theories about cause-andeffect relationships $^{126}$. This type of learning system incorporates more perspectives and works on a strategic level rather than an immediate decision-making level, such as financial data allows.

Peer or horizontal mechanisms are the final category to be covered in this section. This is a growing category of mechanisms. While they fall slightly outside the scope of this thesis since they are not internal mechanisms, if an organization chooses to bind themselves to one of these types of mechanisms, it could be a part of their overall accountability framework. These types of frameworks have two main pitfalls. First of all, they are new and offer only weak consequences for organizations that break the standards. Secondly, while these organizations and standards seek to improve accountability at multiple levels, including to beneficiaries, they offer weak mechanisms for inclusion and participation of beneficiaries. In a study conducted by the Listening Project of the CDA Collaborative Learning Projects showed that beneficiaries think aid

\footnotetext{
${ }^{124}$ Ebrahim, Alnoor, NGOs and Organizational Change: Discourse, Reporting, and Learning. Cambridge: Cambridge University Press (2005), 149.

125 Ibid.

${ }^{126}$ Chris Argyris in Kaplan, Robert S. and David P. Norton, "Using the Balanced Scorecard as a Strategic Management System,” Harvard Business Review July-August (2007): 158. 
Wardwell, Sarah

agencies should work with each other, but still want to emphasize their own central role in the "working together" approach ${ }^{127}$.

Havrda and Kutilek propose a global regulatory system to track performance in a more transparent manner using the internet. In their proposed tool, donors and peer agencies would be able to review actions of INGOS. Global regulatory systems seek to better synchronize standards for all NGOs (local an international), globalizing the approach to accountability and helping to define NGO accountability, preventing "illegitimate and malevolent government interference" ${ }^{\prime 28}$. In this way, they seek to add benefits to the whole system from organizations to donors, but beneficiaries, especially those from disadvantaged positions will see little direct involvement in this type of approach.

Three major frameworks or guidelines have emerged in recent years to establish minimum standards for INGO conduct in emergencies with some ties to long-term development activities. Input from major INGOs was heavily included in the design of each of these and has resulted in a relatively wide acceptance rate amongst INGOs and their implementing staff. These frameworks include the Do No Harm framework, which was designed to help NGOs consider the impacts of foreign aid on conflict situations. The framework follows a similar rubric to the accountability framework proposed here by asking questions about the assistance needed Why? Where? What? When? With whom?

\footnotetext{
127 Anderson, Mary, "Listening to Improve Accountability." Monday Developments (InterAction) (December 2007), 12.

${ }^{128}$ Havrda, Marek, and Petr Kutilek, "Accountability 2.0 - In Search of a New Approach to International Non-Governmental Organisations' Accountability," In Evaluating Transnational NGOs: Legitimacy, Accountability, Representation, edited by Jens Steffek and Kristina Hahn, 163. New York: Palgrave Macmillan, 2010.
} 
Wardwell, Sarah

By whom? And How ${ }^{129}$ Their seven-step approach follows an accountability design, including a feedback loop. This system lacks sufficient input from beneficiaries (participation) and doesn't require transparency, making it an insufficient framework for accountability to beneficiaries. The organization who designed this framework seems to have realized these weaknesses and has embarked on a more recent initiative they call the "Listen Project" where they are working on improving INGO inclusion of beneficiary voices.

The SPHERE project and the Good Enough Guide outline minimum standards for NGOs operating in an emergency context. The Good Enough Guide considers transparency, participation, feedback, and a continually evolving approach to programming in emergencies ${ }^{130}$. This framework mandates strong coordination and consultation with beneficiaries, but fails to particularly call attention to complaints.

In the case of all three frameworks and guidelines, it is optional for staff to follow these and there are weak binding mechanisms or forms of punishment for the INGOs who choose not to follow them. Additionally, the organization must commit their own resources to ensuring all staff participating in an emergency response are trained in these standards. While there are some applicable lessons from these guidelines to longterm development, not enough effort has been put into writing and studying how these can be adapted.

\footnotetext{
129 Anderson, Mary. Do No Harm: How Aid Can Support Peace - or War. Colorado: Lynne Rienner Publishers, 1999.

${ }^{130}$ Davidson, Sara, Good Enough Guide, The Emergency Capacity Building Project, (2006), 1-2. 
Wardwell, Sarah

The Accountability, Learning and Planning System (ALPS) has the strongest link to ownership from aid recipients ${ }^{131}$ ALPS has beneficiaries at the core of its principledriven system, calling for increased accountability to beneficiaries through long and short term initiatives, as represented in the graphic below. One of their unique initiatives is to reduce reports to $\mathrm{HQ}$ and instead find increasing ways to communicate results with beneficiaries and primary stakeholders ${ }^{132}$. They also focus on the process of accountability, rather than trying to make it an output or result. The project launched in 2001. Results so far have been increased internal coordination of agencies from finance to marketing teams, and also the beginning of a power shift from donors and wealthy countries to the beneficiaries and poor communities requesting assistance ${ }^{133}$. This organization still has limited access to operating INGOs and donors have not taken a strong affinity to the project either, limiting its potential impact across the sector.

131 Adams, Laurie. "International Accountability Frameworks". Newsletter of the IASL Community, ActionAid, www.actionaid.org.

${ }^{132}$ David, Rosalind, Antonella Mancini and Irene Guijt, "Bringing Systems into Line with Values: The Practice of the Accountability, Learning, and Planning System (ALPS)," In Relationships for Aid, edited by Rosalind Eyben, 133-153, (UK: Earthscan, 2006),137.

${ }^{133}$ David, Rosalind, Antonella Mancini and Irene Guijt, "Bringing Systems into Line with Values: The Practice of the Accountability, Learning, and Planning System (ALPS)," In Relationships for Aid, edited by Rosalind Eyben, 133-153, (UK: Earthscan, 2006),139, 144. 


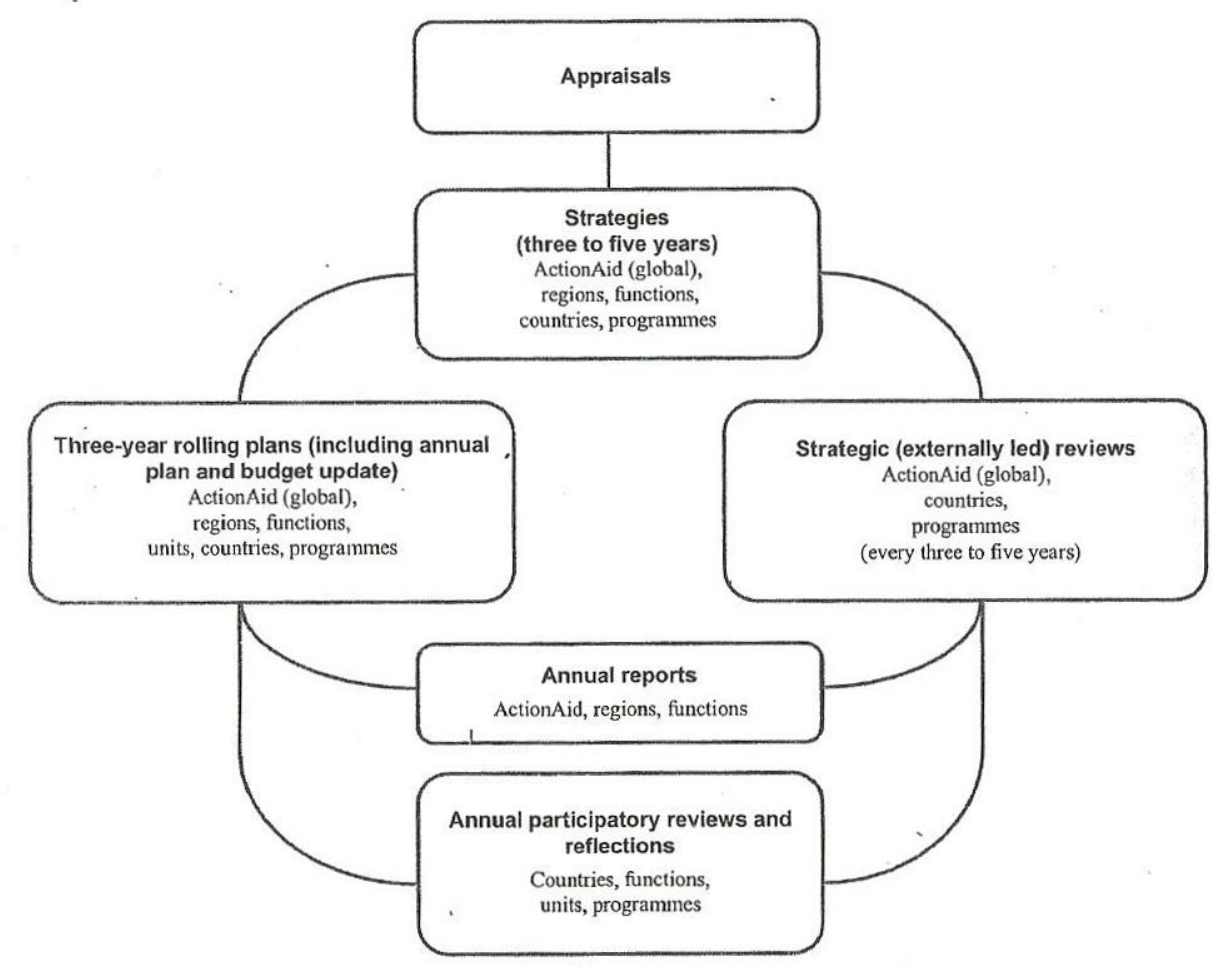

Source: ActionAid, 2000

Figure 7.1. Core elements of the Accountability, Learning and Planning System (ALPS)

\section{Figure 10. ALPS System ${ }^{134}$}

In 2003 leading university and practicing INGOs from a wide range of backgrounds came together to outline the first INGO Accountability Charter. In 2006 the Charter was officially adopted by eleven INGOs who are now committed to regular reporting requirements by the Charter ${ }^{135}$. The Charter looks at INGO actions not only in emergencies, but also in long-term development projects. One of the reporting requirements of the Charter is an assessment from the organization's leadership about

${ }^{134}$ David, Rosalind, Antonella Mancini and Irene Guijt, "Bringing Systems into Line with Values: The Practice of the Accountability, Learning, and Planning System (ALPS)," In Relationships for Aid, edited by Rosalind Eyben, 133-153, (UK: Earthscan, 2006),137.

135 "About the Charter," www.ingoaccountabilitycharter.org 
Wardwell, Sarah

compliance with the Charter's standards, including addressing stakeholder complaints and participation ${ }^{136}$.

Similarly, the Humanitarian Accountability Project -International (HAP-I) has worked to design standards of accountability and quality management for INGOs. They are seeking to certify most humanitarian organizations. As of 2010 they had increased membership to 64 INGOs $^{137}$. Many INGOs have decided against this framework fearing that it limits actions of INGOs too much, forcing a standard of action that may not be applicable to all situations and reducing the ability for local groups and beneficiary input to be heard ${ }^{138}$. In response to the 2010 Haitian earthquake, HAP-I published a lengthy report on the accountability of actors involved in the response. They published results of evaluations of the actors and their coordination efforts in the emergency response and also conducted an assessment of perceptions from beneficiaries and other stakeholders of the response, and a workplan for HAP members accountability implementation in coming years. One of their key findings was that INGO efforts to improve quality and accountability are "disjointed". Haiti currently more INGOs operating within its jurisdiction than any other state in the world. Despite efforts to coordinate INGO activities, HAP-I finds that there are too many agencies carrying out too many overlapping and un-coordinated efforts ${ }^{139}$.

\footnotetext{
${ }^{136}$ Adams, Laurie. "International Accountability Frameworks". Newsletter of the IASL Community, ActionAid, www.actionaid.org.

${ }^{137}$ Humanitarian Accountability Partnership. "The 2010 Humanitarian Accountability Report”. Geneva, Switzerland, 15.

${ }^{138}$ Adams, Laurie. "International Accountability Frameworks". Newsletter of the IASL Community, ActionAid, www.actionaid.org. p. 4.

${ }^{139}$ Humanitarian Accountability Partnership. "The 2010 Humanitarian Accountability Report”. Geneva, Switzerland, 54. 
Wardwell, Sarah

There are additionally several other organizations that have emerged in recent years to measure and benchmark INGOs, including the One World Trust which publishes an accountability study, Transparency International and the Emergency Capacity Building Project, amongst others. One of the problems with the growing number of agencies trying to measure and coordinate efforts within INGOs is that these agencies themselves are not coordinated. It is time and resource consuming for an INGO to become a compliant member of these organizations, thus forcing INGOs to select amongst the various options. 
Wardwell, Sarah

\section{Chapter 4. Internal/Staff-Based Assessment Tools}

This chapter will look at how internal staff assessment tools can give organizational leaders a closer look at their own accountability to beneficiaries. Each previous chapter has taken the concept of accountability and become more specific on this theme. Chapter one looked briefly at the history of accountability, chapter two took a closer look at the actors involved and defined specific terms to be used throughout this thesis, chapter three looked deeper into what accountability to beneficiaries really means, now chapter four will look at how internal staff assessment tools can give organizational leaders a closer look at their own accountability to beneficiaries. From the concept of accountability to beneficiaries, this thesis will now narrow its focus to strategic management tools, continuing to differentiate between SAB and TAB. Within this specific theme, now this chapter will look specific at internal/staff assessment tools and provide a theoretical response to the first question of this thesis: How can an INGO use internal assessments to effectively measure their own accountability to beneficiaries? The response to this question relies on strategic management tools such as the balanced scorecard approach. An internal or staff survey is a tool that can be used as part of a strategic management system that supports the SAB theory posited by this thesis. The second part of this chapter will analyze an internal staff survey completed by an INGO, Mercy Corps in 2011 as an illustration of this type of SAB tool. 


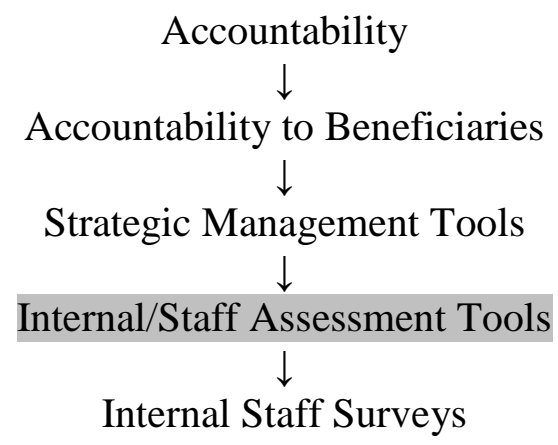

Measuring accountability to beneficiaries is part of a healthy, robust organizational learning culture, as discussed in chapter three. One part of this is developing an organizational strategy that prioritizes accountability to beneficiaries. Having built-in, regular internal assessments are a feedback and learning tool to encourage the organization to keep learning about its work and impacts. Improved understanding about the impacts of an INGO's work helps guide leaders to make strategic decisions that will improve impact of their work.

Using a SAB approach to accountability to beneficiaries helps align the organization's mission and values with the activities they carry out. Accountability to beneficiaries is often understood in various ways by the different decision makers in the $\operatorname{organization}^{140}$. SAB helps the organization establish a coherent approach within the organization overcoming this challenge. SAB is a part of strategic management, as both are concerned with short, medium, and long term performance. Strategic management tools such as the balanced scorecard allow leaders to put an emphasis on accountability to

\footnotetext{
${ }^{140}$ Brock and Pettit 2007 as cited in Jacobs, Alex and Robyn Wilford "Putting New Approaches to NGO Accountability into Action", 803. 
Wardwell, Sarah

beneficiaries and measure progress against it as the organization strives to attain their mission and work in line with their values.

In contrast, $\mathrm{TAB}$ approaches the question of accountability to beneficiaries by solely looking at the opinions and feedback of those outside of the organization. SAB, however, recognizes that some of the best informed individuals on the project and its impact within a community may be the staff directly executing the project. A SAB approach utilizes tools such as internal assessments to record and share this information within the organization and inform future decisions.

Tools and mechanisms to measure INGO impact, especially in regards to accountability to beneficiaries is still in its infancy and draws heavily in academic writing on business and the public sector. Tools developed for these sectors will be evaluated here as they apply to measuring strategic downward accountability within INGOs.

\section{Balanced Scorecards and Internal Strategic Management Tools}

The ability to take information and transform it into a strategic vision is a key element for an INGO to effect change in a turbulent environment. Just as businesses include data beyond financial information when developing their strategies, so must INGOs. For an INGO to carry out their mission and vision, including improving accountability to beneficiaries and ultimately positive impact, organizations need to have tools to measure their accountability. These tools must be able to provide relevant information that can be used to create a strategy that enhances accountability and positive impact. 


\section{Wardwell, Sarah}

A balanced scorecard is a tool that was introduced in 1992 by Robert Kaplan and David Norton, revolutionizing how businesses thought about performance metrics ${ }^{141}$. In addition to measuring organizational performance by analyzing traditional financial measures, this tool includes three additional perspectives: customers, internal business processes, and learning and growth ${ }^{142}$. This innovative practice links long-term vision directly with short-term actions so organizations can operationalize their mission and vision. The balanced scorecard introduces four new processes. The first is translating the vision into measurable and meaningful statements. The second is communicating and linking, where managers communicate their strategy throughout the organization and link it with individual departments and objectives. Third, is business planning where the organization integrates their business and financial plans. This is where an accountability to beneficiaries initiative would be linked into the strategic plan for an INGO. The fourth process is feedback and learning, where organizations create space for "strategic learning", monitoring input from the perspectives of finance, customers, internal business processes, and learning and growth. Just as feedback and learning is an important component of a project improving its accountability to beneficiaries, an organization improves its real-time learning by incorporating regular feedback and learning from the top-down of the organization. The balanced scorecard approach has accountability builtin, as it closely mirrors the framework for accountability outlined in chapter three -

\footnotetext{
${ }^{141}$ Kaplan, Robert S. and David P. Norton, "Using the Balanced Scorecard as a Strategic Management System,” Harvard Business Review July-August (2007): 151.

${ }^{142}$ Ibid. 
Wardwell, Sarah

soliciting feedback from beneficiaries (customers), feedback and learning, and transparency (communicating and linking).

This system is backed by strong results in the business sector where businesses report being able to transform their companies so that every employee focuses on achieving the long-term strategic objectives. As one corporate executive claimed, "The balanced scorecard is both motivating and obligating." 143 This type of system would help overcome the most common barriers INGO workers cite towards implementing accountability to beneficiaries practices - they are either too cumbersome or not binding enough. If accountability to beneficiaries was built in as a priority for INGOs to achieving their strategic visions, and if the organization's strategic vision was clearly communicated with all employees, they would theoretically be able to improve their overall results.

The balanced scorecard can also be used to set minimum thresholds for organizational and employee performance. Just as some organizations and academic writers proposed to define minimum standards for INGOs to improve accountability, using a balanced scorecard, each organization could be allowed to define how they wish to set standards and measure progress against these, thus overcoming some of the objections posed against sector-wide minimum standards presented in chapter three.

Once an organization has decided to place an emphasis on accountability to beneficiaries and link it to their strategic vision, the balanced scorecard can be used to define and measure the concept. An internal assessment is a tool that can be used to

\footnotetext{
${ }^{143}$ Kaplan, Robert S. and David P. Norton, "Using the Balanced Scorecard as a Strategic Management System," Harvard Business Review July-August (2007): 154. 
Wardwell, Sarah

measure employee perceptions of accountability to beneficiaries and this data can then be used as a benchmark for accountability uptake within the organization. The data from the internal assessment is a feedback and learning mechanism, complimenting efforts of a balanced scorecard.

Measuring accountability to beneficiaries within an INGO is similar to making public policy decisions within a democratic government. The government is presented with many different priorities and must find a way to select which issues to actually prioritize. Governments use many tools to make these tough decisions including utilitarian approaches, ethical weighting, cost-benefit analysis, and economic systems analysis, to name a few. The balanced scorecard applies to governments, INGOs, nonprofits, and businesses because it can consider all of the factors that the organization themselves prioritizes. A utilitarian approach focuses more heavily on the financial aspects of the decision and ignores many of the less tangible components and factors related to the issue. INGOs have perhaps relied on this type of decision making tool enabling them to overlook the important, difficult to measure information coming from the beneficiaries themselves, leading to some of the complaints today. Ethical weighting helps organizations such as INGOs and governments prioritize their decisions based on political beliefs. Within a government these principles may come from the ethical principles held by incumbents. A cost-benefit analysis helps organizations compare decisions using a mixture of quantitative and qualitative data, quantifying information into discrete, easily comparable numbers. If an organization is trying to decide whether to incorporate an accountability to beneficiaries system, this information, these tools would 
Wardwell, Sarah

be useful. But a balanced scorecard approach is a better tool to help an organization integrate the principle into their strategic plans.

An internal assessment helps an organization establish a baseline. It has the additional benefit of being cost-effective as it is internally conducted and doesn't require a lot of staff time, thus reducing strain on internal capacity. There is a significant body of literature on best practices in conducting surveys for research purposes that survey writers and data analyzers can draw upon for their assessment. When staff members from the organization conduct the survey they are more familiar with the organization's culture, challenges and opportunities they face, so they can ask questions in a more directed manner to their colleagues. Respondents are also more likely to give uninhibited information since they are reporting this information only to their colleagues, especially if the information is collected anonymously. Lastly, those charged with analyzing the data will be able to present results in a more frank manner since their motivation is primarily to report the findings as is. While there is still room for bias, results are reported in a less biased way than an external evaluator who has their own motivation that may vary from the organization's.

\section{Building the Mercy Corps Accountability System}

This thesis will now use the example of Mercy Corps, an INGO, which has taken steps towards internally measuring their accountability to beneficiaries, to illustrate the principles and ideas put forth in this thesis. This section will present data from the internal survey about accountability at Mercy Corps conducted in February 2011. These results will be analyzed and related to scholarly theory about how to best measure an 
Wardwell, Sarah

organization's accountability to beneficiaries - how to take the most accurate and honest "pulse" of the organization's progress on this issue. First, this section will provide an overview and justification of the selection of Mercy Corps and provide some relevant background on the organization. Secondly, it will discuss the methodology of the survey and its limitations. Then, it will divide up the survey answers to respond to the three core questions about accountability to beneficiaries: accountable to whom, accountable for what, accountable how.

\section{Background to the Mercy Corps Survey}

In 1979 Dan O'Neill was a young man struck by the horror of the genocide inflicted upon the Cambodian people by the Khmer Rouge regime. Dan wanted to help so he set out to start a fundraising effort he named the "Save the Refugees Fund". Over 30 years later that small relief effort aimed at supporting survivors and refugees of the Cambodian crisis evolved into a multi-million dollar organization operating in more than 40 countries across the globe, now called Mercy Corps. By the time Mercy Corps entered the playing field there was already a core group of "major" American-based INGOs Save the Children, Care, Catholic Relief Services, and World Vision, to name a few. These aid agencies commanded the majority of USAID grants for INGOs and combined they covered most of the developing nations in the world. As Mercy Corps has expanded into more countries and grown in budget size, it has established expertise in humanitarian 
Wardwell, Sarah

disaster response and relief, with a strong focus on the mobilization of civil society $\operatorname{actors}^{144}$.

The Mercy Corps internal survey was chosen for this thesis since the author contributed to the analysis and report writing of the analysis of the internal survey about accountability to beneficiaries, carrying out global discussions throughout the agency regarding the results. The author's position within the agency allowed for a wide range of feedback from those involved in carrying out the daily activities of the organization. The data presented here was collected and analyzed by the author, with feedback from a working group established by Mercy Corps to analyze this issue.

In 2003 Mercy Corps became a founding member of the Emergency Capacity Building Project (ECB) that began by convening a forum of seven INGOs who consistently respond to global crises to discuss the major obstacles in emergency response delivery. The group recognized the importance of accountability to beneficiaries in emergency response. The Mercy Corps ECB representative has been an agency focal point in the effort to improve accountability to beneficiaries. He led the 2011 survey and originally limited it to a focus only on accountability during emergencies, but discussions within the agency made it clear that the initiative needed to be expanded to all aid delivery.

In 2007 Mercy Corps acknowledged that more emphasis needed to be placed on accountability. Accountability has become a buzzword within the industry and it can be heard used throughout Mercy Corps' headquarters, from the finance department, to the

\footnotetext{
144 “About Mercy Corps," mercycorps.org 
Wardwell, Sarah

executive floor, to program officers and even web designers. A brief survey was conducted that was similar in structure to the 2011 one, but with fewer questions and a more limited scope, focusing more on accountability in general. Significantly fewer individuals responded to this survey, and results were only minimally analyzed, but the data was enough to support the leadership team's acknowledgement that more attention needed to be given to the issue. The 2007 survey results were discussed with Mercy Corps' senior leadership and a plan was developed to implement an improved accountability plan, but the price tag attached to this combined with the slumping market in 2008 led to the plans being pushed aside, but not forgotten ${ }^{145}$. The intent of the 2011 survey was to measure how staff perceive the internal accountability to beneficiaries systems currently in place.

The 2007 staff survey showed that a majority of respondents believed that "Mercy Corps' strength in terms of accountability to beneficiaries" was "limited"146. Though several field offices have independently instituted means to ensure and track accountability to beneficiaries, Mercy Corps has not yet embraced a global accountability framework. Under the Emergency Capacity Building (ECB) Project, Mercy Corps has committed to create and adopt such a framework. However at present, the organization remains one of two out of the seven ECB agencies that do not have a formal framework in place or hold a membership in the Humanitarian Accountability Project, which also requires the adoption of an accountability framework. The rejection of a Mercy Corps bid

\footnotetext{
${ }^{145}$ Informal interview with Richard Jacquot, Mercy Corps Global Emergency Operations (GEO) Team Leader, 2010

${ }^{146}$ Mercy Corps. “Accountability Study.” 2007. 
Wardwell, Sarah

in a recent call for proposals from a major international donor was explained by the donor to be in part due to Mercy Corps' lack of an accountability framework - underscoring the growing importance of such mechanisms in the INGO community ${ }^{147}$.

The absence of a formal accountability framework has hampered Mercy Corps' ability to recognize and leverage the tools and practices that would be accompany such a system. Appreciation for the state of accountability within the organization has shown to be lacking from the analysis of project reports, program evaluations and field visits. To address this problem, the Mercy Corps ECB Accountability and Impact Measurement advisors created the Accountability to Beneficiaries (AB) initiative and formed its core working group $^{148}$.

Mercy Corps was also chosen for this thesis since it has a relatively robust organizational learning department (OL). In order for accountability to beneficiaries to become an internalized concept, the agency will need to develop its own unique knowledge and know-how of the concept ${ }^{149}$. As such, accountability to beneficiaries will move beyond being not only a philosophical debate, but also a series of practical implementation and measurement tools.

In the summer of 2009 the author participated in a seminar conducted on the internet discussing the concept of accountability within the Design, Monitoring, and Evaluation (DM\&E) unit of the organization. At that time, many different ideas were shared regarding the definition of the concept, but it was clear that the agency lacked a

\footnotetext{
${ }^{147}$ Mercy Corps. "Accountability to Beneficiaries TOR.” 2010.

${ }^{148}$ Core Working Group members include Brian Atkinson, Jenny Hanley, Richard Jacquot, Shagufta Jeelani, and Sarah Wardwell.

${ }^{149}$ Cook, Sccott D. N. and Dvora Yanow, "Culture and Organizational Learning," Journal of Management Inquiry (1993): 404. 
Wardwell, Sarah

shared understanding of the concept ${ }^{150}$. From the results of the qualitative questions in the 2010 internal survey, it was evident that Mercy Corps still lacked a clear definition accepted within the organization. When the agency wrote the survey, they based questions around the definition of accountability to beneficiaries from the Good Enough Guide, a Humanitarian Best-Practices guidebook that Mercy Corps contributed to the writing of. The goals of the Good Enough Guide are similar to those of Mercy Corps and an accountability to beneficiaries focus, "making sure that the women, men, and children affected by an emergency are involved in planning, implementing, and judging our response to their emergency too. This helps ensure that a project will have the impact they want to see."151

In the survey analysis and report, the group used the following definition, "Accountability is most basically the process of justifying and being responsible for the manner and results of one's actions to relevant stakeholders." 152 Later in 2011 the agency conducted a brief survey comparing the different definitions it has used in publications during the recent decade and found that most staff agreed with the definition supplied by the following sources as shown in the pie chart below ${ }^{153}$. As the pie chart shows, the definition used in the Accountability to Beneficiaries Study was most in line with the staff's own views, next to a mixed group of "other" definitions.

\footnotetext{
${ }^{150}$ Personal Observation, 2009

${ }^{151}$ Good Enough Guide, p. 4

${ }^{152}$ Mercy Corps Accountability to Beneficiaries Internal Assessment

${ }^{153}$ Insert the definitions for each of these if Dr. G decides to keep this. 


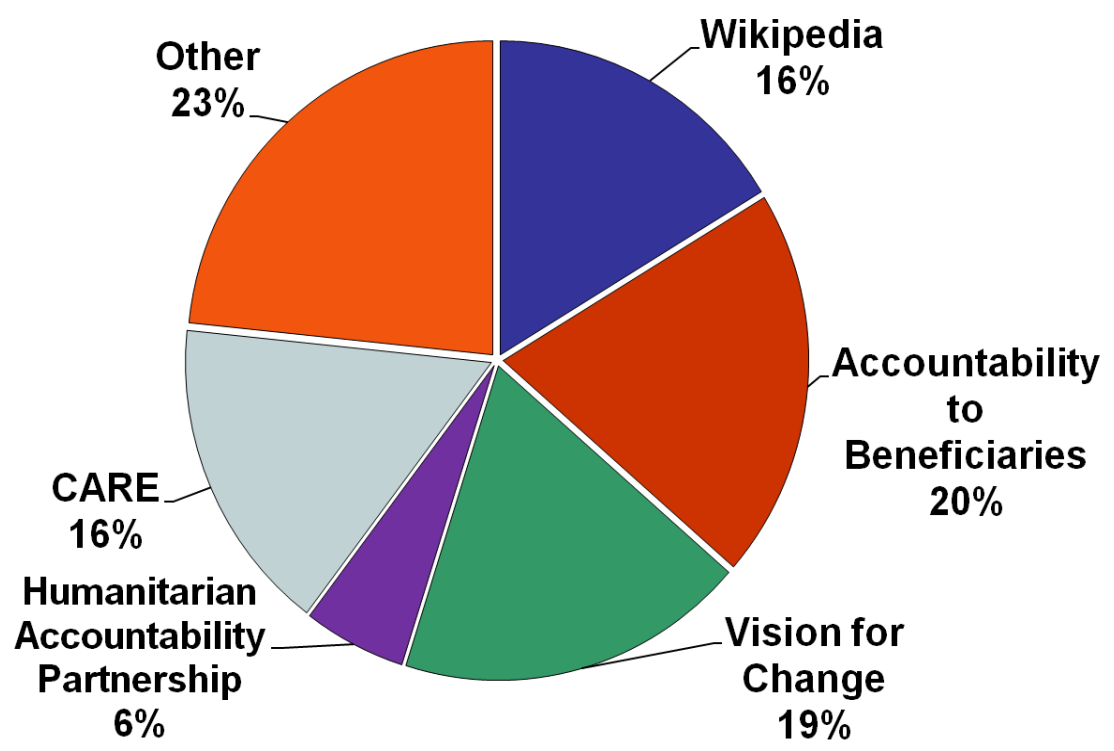

Figure 11. Mercy Corps Definitions of Accountability

\section{Methodology}

In February of 2011 the survey was sent out to all Mercy Corps employees via three internal electronic information platforms: weekly email sent to all staff called "The Globe", the agency intranet called the "Hub", and a web-based information sharing portal that all employees have access to called "Clearspace". Even in remote field offices, Mercy Corps staffs usually have internet access and leadership believe staff are likely to connect with at least one of these platforms during the week. All expatriate and headquarters staff are provided a Mercy Corps email and within field offices, most fulltime regular national employees are also supplied with email addresses and internet access. Mercy Corps Human Resources estimates that the organization currently employs approximately 4,800 staff in 41 countries $^{154}$.

${ }^{154}$ Beth Hill, Mercy Corps Human Resources, email to author, March 26, 2012. 


\section{Wardwell, Sarah}

The stated goal of the survey was to establish a baseline of the state of accountability to beneficiaries within the agency, to identify accountability tools, knowledge and practices currently used by the field staff, and to collect and disseminate those throughout the organization. The questions were modeled after the Good Enough Guide, a humanitarian practitioners handbook to emergency response that Mercy Corps collaborated with other INGOs to create. For this reason many of the questions have an emergency focus that may have caused some confusion among respondents. Questions were developed with field staff in mind or those with significant field experience, but it's not possible to break down the data by those who have field experience and those who do not. Mercy Corps headquarters is composed of both former field staff and staff who perform fundraising and administrative tasks who do not necessarily have field experience. Some reliability issues related to these questions are that they were only posed in English, so interpretation and translation could account for some nuances in the data interpretation. Other factors that may have affected reliability could be related to events happening within Mercy Corps programs, such as grant close-outs or project startups that could potentially affect responses. With the wide sample range this aspect of reliability seems null. Otherwise there were no major global events during the period of the survey that would have dramatically affected response reliability.

Ninety-two respondents completed all of the quantitative questions, with significantly fewer choosing to respond to open-ended questions (results per question vary so this information accompanies each of these data points). A majority of the 
Wardwell, Sarah

respondents were from the field (i.e. outside of one of the US or European headquarters locations) and national staff (i.e. not expatriates) had a strong response rate.

Quantitative questions were analyzed using Microsoft Excel. A content analysis and verbatim quotation selection was completed for all qualitative questions. For quantitative questions that included a qualitative response section, only a verbatim quotation selection accompanied the quantitative analysis. The initial results of this survey were posted on Mercy Corps internal information sharing site, Clearspace for staff feedback.

Seventy-nine percent of respondents are national staff, which nearly mirrors Mercy Corps' global ratio of national to expatriate staff (globally Mercy Corps employs 95\% national staff). $80 \%$ of respondents work in programs, which was the intended audience. $85 \%$ of respondents have had at least occasional contact with beneficiaries and $39 \%$ spend more than half of their time working directly with beneficiaries. $15 \%$ of respondents had no contact with beneficiaries and this breakdown was nearly identical when the data was disaggregated by national staff. Since the survey was anonymous, it is not possible to know what type of work these individuals were doing (i.e. they may have previously worked in a program with beneficiaries but changed jobs; they may work in operations not directly dealing with beneficiaries, etc.). Ninety-two staff completed the quantitative questions out of 138 respondents who started the survey. Qualitative questions had significantly weaker response counts, ranging from 32 to 75 . Due to its design, the survey was accessible only to English speaking staff that had access to a computer and the Internet, which is too imprecise to generate a response rate. 


\section{Wardwell, Sarah}

Additional limitations of this survey are: questions that lack clarity affecting response validity, questions don't elicit responses with specific tools even though this is the intended goal of the designers, no breakdown by geographic region or country, and limited to only English speakers. Results cannot be said to be representative of the organization as a whole due to the low response rate. Since the survey was only offered in English and required a computer and access to the Internet, the potential audience was less than the entire organization's staff. If this survey is repeated, translation into different languages and, additional methods of interacting with field teams are recommended in order to reach a wider audience and gather more in-depth information about SAB operations.

The use of a Likert scale of "never to always" limits results to be somewhat vague (different interpretations of each term are possible) and therefore affects the validity of response analysis. It is difficult for most respondents to estimate how frequently they actually use certain practices and tools, especially when they work with multiple programs.

"I think it would have been helpful in the survey to also include a selection, such as not often or almost never, something like that. This was a little skewed $\mathrm{b} / \mathrm{c}$ there were several times that I felt the answer was less than "sometimes", but not "never" and there was no selection for that, so I had to answer one of those two, which wasn't exactly accurate," survey respondent.

Additionally, the survey never specifically asked what tools teams currently use, which means that additional steps will need to be taken in order to find them. 


\section{Wardwell, Sarah}

This survey was anonymous in order to encourage respondents to leave open and honest comments. Relatively few strong, negative comments were received though, so little would probably be lost in terms of honesty if the survey asked for country affiliation so that a regional breakdown of results could be made and then more targeted action would be possible. If respondents were given the option to write in their name, it would be possible for the surveyors to follow-up on specific responses, such as tools and practices being used in certain field offices and then share these with the rest of the organization.

\section{Survey Analysis: Accountability Barriers}

Often, the author has observed that when opening discussions about accountability to beneficiaries with humanitarian workers the conversation begins by enumerating the reasons why it is difficult to ensure accountability. "Just delivering the program with limited support from logistics, admin etc., is a mammoth undertaking in itself," survey respondent. For this reason, the survey analysis will begin at this point looking at why it is difficult to ensure accountability to beneficiaries at a practical implementation level. Also, in order to reach the agency's goals of improving accountability to beneficiaries, an understanding of the current challenges staff face in improving accountability to beneficiaries is necessary.

The survey asked respondents to describe the barriers they face in being more accountable to their beneficiaries. Since responses varied widely, they were grouped into categories with the top three being: 1) workload/time/resource restrictions, 2) security/managing sensitive information, and 3) uneducated beneficiaries. Table one 
Wardwell, Sarah

outlines all categories that were mentioned at least twice by respondents. These categories were made through a qualitative content analysis. Within each response these key words were looked for and recorded in the table. Multiple categories could have been mentioned in each response. These categories can be more generally grouped into four general themes: context-specific barriers, beneficiary barriers, structural (external) barriers, and structural (internal) barriers.

\begin{tabular}{|l|l|l|}
\hline Accountability Barriers & Times Mentioned & Percentage \\
\hline Workload/time/resources restrictions & 12 & $16 \%$ \\
\hline Security \& sensitive info. & 10 & $14 \%$ \\
\hline Uneducated beneficiaries & 7 & $10 \%$ \\
\hline Government & 6 & $8 \%$ \\
\hline None & 6 & $8 \%$ \\
\hline Many, mixed beneficiaries & 5 & $7 \%$ \\
\hline Other & 5 & $7 \%$ \\
\hline Donors & 4 & $5 \%$ \\
\hline Logistical challenges & 3 & $4 \%$ \\
\hline Partners & 3 & $4 \%$ \\
\hline Gender & 2 & $3 \%$ \\
\hline Lack of participation & 2 & $3 \%$ \\
\hline Language & 2 & $3 \%$ \\
\hline Local policy & 2 & $3 \%$ \\
\hline Project design & 2 & $3 \%$ \\
\hline Staff capacity & 2 & $3 \%$ \\
\hline Total & $\mathbf{7 3}$ & $\mathbf{1 0 1 \%}$ \\
\hline \hline
\end{tabular}

Table 1. Content analysis from qualitative responses to: What barriers to Accountability to Beneficiaries do you face? 61 total responses, some responses included multiple barriers.

Context-specific barriers: These barriers are specific to the particular environment in which the project operates. Logistical challenges include physical barriers that are specific to a project, country, or region, like poor road conditions, that make meeting with beneficiaries difficult. Security and language challenges can also be grouped into this 
Wardwell, Sarah

category since they are similarly specific to the region. One survey respondent stated that there is often a "Limitation to share sensitive information. Often beneficiaries think that we hide something,". An example of the type of information that is sometimes intentionally not shared with beneficiaries is beneficiary selection criteria so that field teams can gather more accurate community information and offer programs that benefit their intended population.

Language could also be considered a structural (internal) barrier since it relates to staff capacity, but most responses discussed language issues as problems relating to the particular context in which they were operating (this example highlights the challenge of reducing categories into broader themes for analysis, since many categories could fall into two themes). As often as possible, Mercy Corps employs local staff and expatriate staff who bring with them language skills, in keeping with standard best practices within the industry. Still, in rural areas especially there may be language barriers even between local staff.

Beneficiary barriers: Another possible theme looks at specific problems in interacting directly with beneficiaries. Gender was mentioned as a specific concern in conservative cultures where respondents raised issues meeting with women and girls. For example in rural areas of Tajikistan, newly married women are not allowed to visit anyone outside of their immediate family until they are pregnant.

The difficulty of meeting the demands of the large and varied group of stakeholders is represented in this category. This is a central issue to the question of assessing and improving NGO accountability to beneficiaries. As one survey respondent 
Wardwell, Sarah

noted, "There are many peoples in the community with different attitude and different level of understanding and we have to face problems making them equal accountable for the responsibilities,".

The large "uneducated beneficiaries" category covers feedback that beneficiaries often don't demand accountability from Mercy Corps because they are illiterate and/or uninformed about how to interact with the agency. Respondents mentioned that this problem can lead to a misuse of information or gossip within certain communities that has presented particular accountability challenges.

Structural barriers (Internal): Within the structure of Mercy Corps and the unique set-up of each project, there are specific challenges to accountability. The “donors" category includes concerns that donors don't require accountability measures, which limits the importance respondents place on ensuring it. One survey respondent explained that there is a , "Donor-driven mentality and lack of expectation that beneficiaries should be actively involved in program design and evaluation. Unfortunately, as a program officer I can think of very few cases where beneficiaries have been asked to contribute to program design, monitoring or evaluation,". Respondents also feel that they receive inadequate information from donors about accountability measures or expectations.

Program design and a lack of time/workload/resources also fall into this theme, the area where most responses were grouped. This category includes responses that discuss feeling as though they don't have enough time to create accountability measures, they are too busy to work on this, or they lack the proper resources in order to enact such 
Wardwell, Sarah

measures. Respondents reported feeling a lack of organizational commitment and support for accountability measures, leading them to place less of an emphasis on this in their own work. The quotes cited from survey respondents highlight the time dilemma that respondents feel when completing a project, which is heightened during an emergency.

Working with partner organizations also presents challenges to accountability to beneficiaries since it involves another layer of information coordination and expectation management (this barrier is also project-specific, but is a structural problem that best fits into organizational barriers). This issue is similar to the challenge the World Bank faces ensuring accountability to beneficiaries when they often work through NGOs to implement their projects. Mercy Corps also implements programs through local organizations.

Structural barriers (External): Certain realities exist in country and regional contexts that present particular challenges to accountability: governments, insurgencies, armed conflict, local governments and policies, and US government regulations and foreign policy decisions. Each of these categories shape how respondents interact with their beneficiaries and the unique opportunities and restrictions faced by each project. All of these barriers are generally beyond the control of the agency.

These challenges above all else highlight the need for a clear stakeholder analysis in order to develop a comprehensive framework for strategic accountability to beneficiaries. Program teams need to be able to quickly identify whom they are accountable to and then be able to select tools that will allow them to engage beneficiaries. Other strategies and tools, such as improved communication around the 
Wardwell, Sarah

topic would also help, but these would need to follow suit of a strong stakeholder analysis and generally strong understanding of the cultural context of each intervention planned.

\section{Accountable to whom? Which beneficiaries are we targeting?}

Defining the beneficiary population(s) is the first step in accountability practices.

All project interventions will have ripple effects beyond the project target group, so in order to understand the current state of accountability to beneficiaries, a large and diverse group of beneficiaries who will be affected by any interventions must be defined. While this may seem fairly obvious, the challenges involved in this exercise are highlighted in chapters one and two of this thesis.

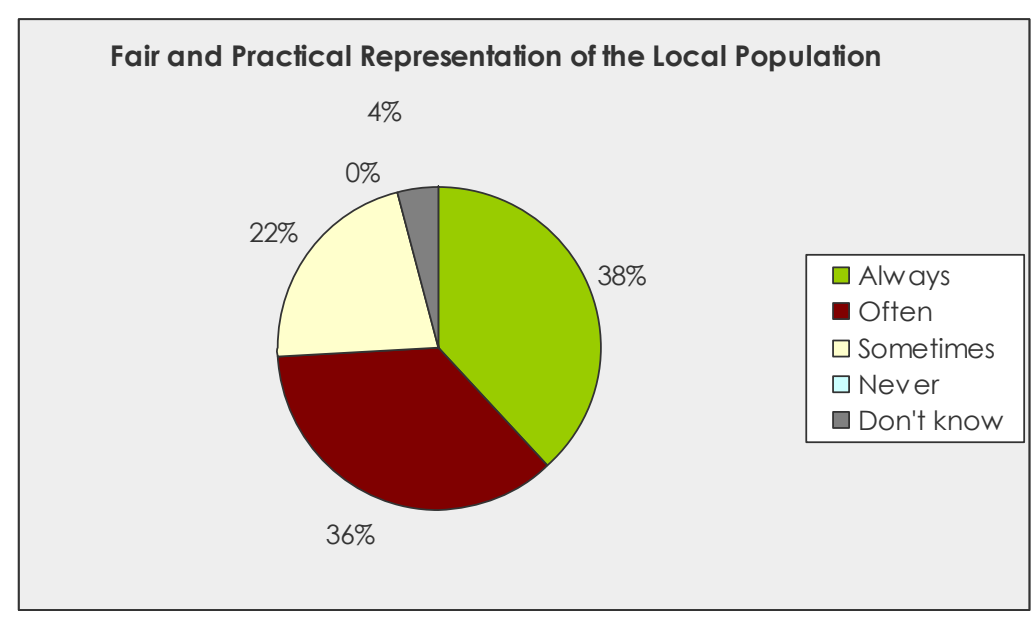

Figure 12. Responses to the question: To what extent does your team include a fair and practical representation of all the groups that are members of the local populations? 92 total responses.

$38 \%$ of the survey respondents reported that teams try to include a "fair and practical representation of all groups that are members of the local population" "always". Another $36 \%$ of respondents stated that they do this "often". Combining these two categories shows a clear majority making strong efforts to include a fair and practical 
Wardwell, Sarah

representation of the local population. A flaw in the design of this question is that it doesn't look deeper into determining whether staffs ideas about what constitutes a "fair and practical representation" are in fact accurate. Mercy Corps walks a fine line in attempting to stay neutral in their activities and human resources decisions. Certain contexts make this particularly challenging, as noted in the accountability barriers section above.

In specific projects, it may not be possible or desirable to include an even representation of all groups in the community - for example if the project has a focus on local government, some of the most vulnerable groups may not be targeted and information on how the project affects them may not be collected. It may be more important to consider this latter percentage for this reason. No one reported that they "never" try to include a fair representation of all groups. This is not surprising since equal opportunity to benefit from aid delivery is a general humanitarian and human rights principle (as cited in the SPHERE guidelines, HAP guidelines, UN Universal Declaration of Human Rights).

Women and girls are a particularly vulnerable group, often left out of the formal economy and other social structures. They also account for approximately half of any community, making them a significant group of beneficiaries in any project. When asked about maintaining a gender balance, $32 \%$ of respondents reported that they do so always; slightly more reported often maintaining a gender balance (33\%). Many of the barriers previously mentioned about working with women in conservative cultures were again 
Wardwell, Sarah

mentioned as challenges to maintaining an equitable gender balance. As one survey respondent also noted,

"Gender balance is a tricky issue. Do you mean numbers? $50 \%$ men and 50\% women? That does not necessarily represent gender equality... In the project I run, we have a base majority of men as beneficiaries; however, we guarantee gender balance by carefully including a gender perspective in all our activities."

In the Mercy Corps 2010 Internal Gender Assessment 23\% of respondents reported "always" collecting gender disaggregated data, 32\% reported "frequently" doing so and $23 \%$ reported "frequently" collecting this data (the Gender Assessment had approximately 300 responses. Questions 12-14 were used from this survey in this report). The slightly higher rate of respondents stating they "always" collect gender data could be a function of the small rate of response to the accountability survey, or other systematic error. In Mercy Corps' internal gender assessment, respondents were asked why they choose to collect this information with the majority (66\%) reporting doing so because of donor requirements with significantly fewer reporting because country leadership requires it $(39 \%)$ or because program implementers think it is important even if it isn't required $(34 \%)$. This survey showed that the largest barrier to collecting gender disaggregated data is a lack of training.

Transparency is another important component of accountability, which means conducting operations in a way that is open to inspection and feedback from beneficiaries. Respondents reported that teams establish basic profiles of the population from primary and secondary sources in a transparent manner most consistently for 1) gender, 2) vulnerability, and 3) ethnicity (based on percentages of respondents that they 
Wardwell, Sarah

"always" do this). Political affiliation and religion were most likely to "never" be used in creating a profile of the community. As one survey respondent stated, "Why we never ask our beneficiaries for ethnicity, religion and political affiliation, because we are non religion non governmental organization. We just want secure and just productive community."

Beneficiaries are a constantly changing group, part of the complexity of measuring accountability to beneficiaries. Thirty-five percent of the respondents report that beneficiary information is always updated and analyzed periodically by teams, while $7 \%$ of the respondents reported never updating or analyzing beneficiary information.

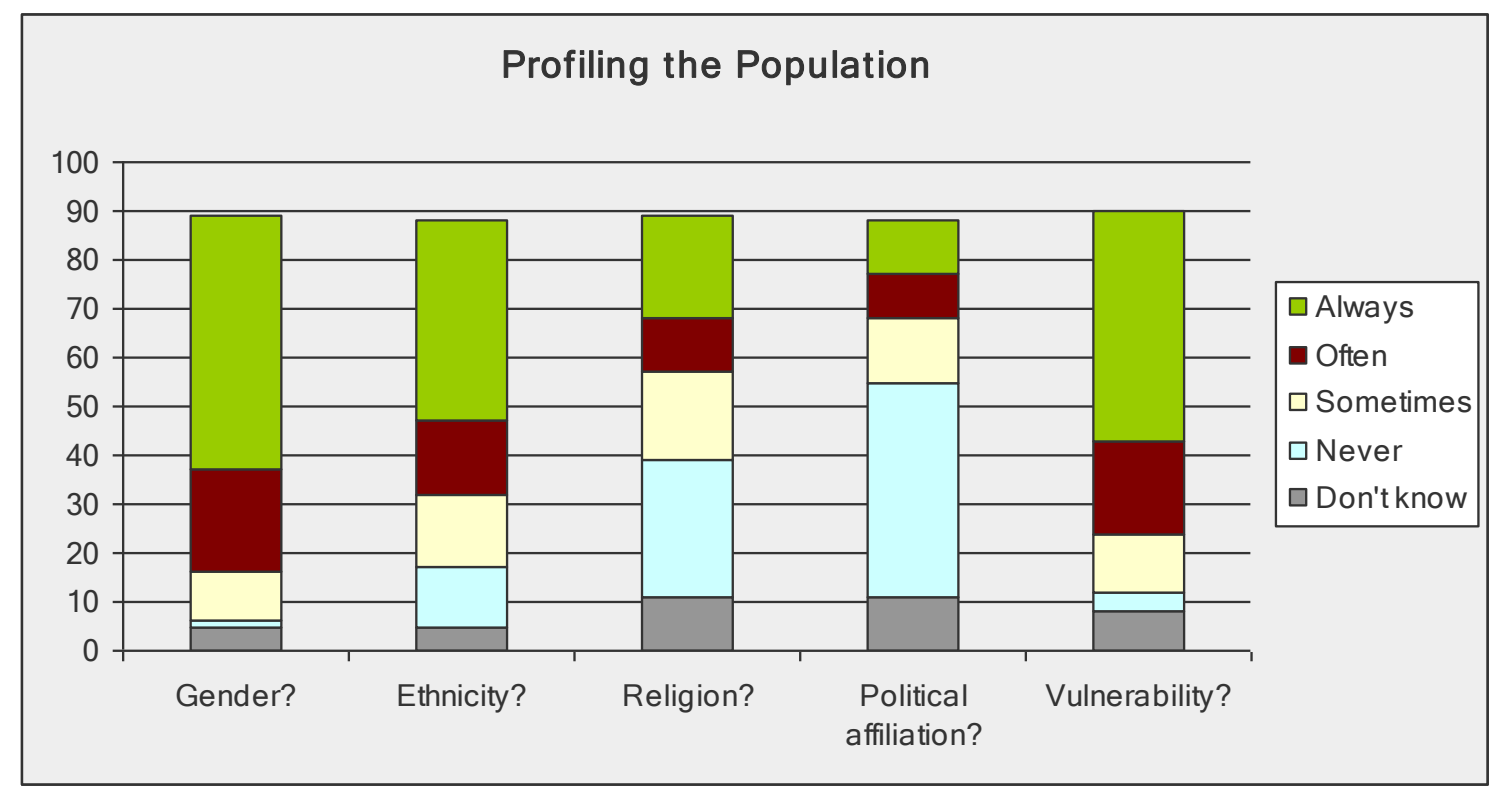

Figure 13. Responses to the question: To what degree does your team establish a basic profile of the population from primary and secondary sources in a transparent manner including: gender, ethnicity, religion, political affiliation, vulnerability? 90 responses.

\section{Accountable how? Sharing Information with Beneficiaries}

One of the goals of this survey was to gauge how accountable respondents currently believe they are to the populations they serve. Sharing information with 


\section{Wardwell, Sarah}

beneficiaries is one important aspect of accountability which is why one survey question specifically addresses this. Overall, $26 \%$ of respondents feel that they are making "strong efforts" to share information with beneficiaries (Figure 13). A majority of respondents (51\%) believe they are making "adequate" efforts" to share program information with beneficiaries and $23 \%$ think they make "limited" or "poor" efforts in this regard. When disaggregating the data by national staff, a slightly higher percentage of respondents $(31 \%)$ report that they make strong efforts to share information with beneficiaries.

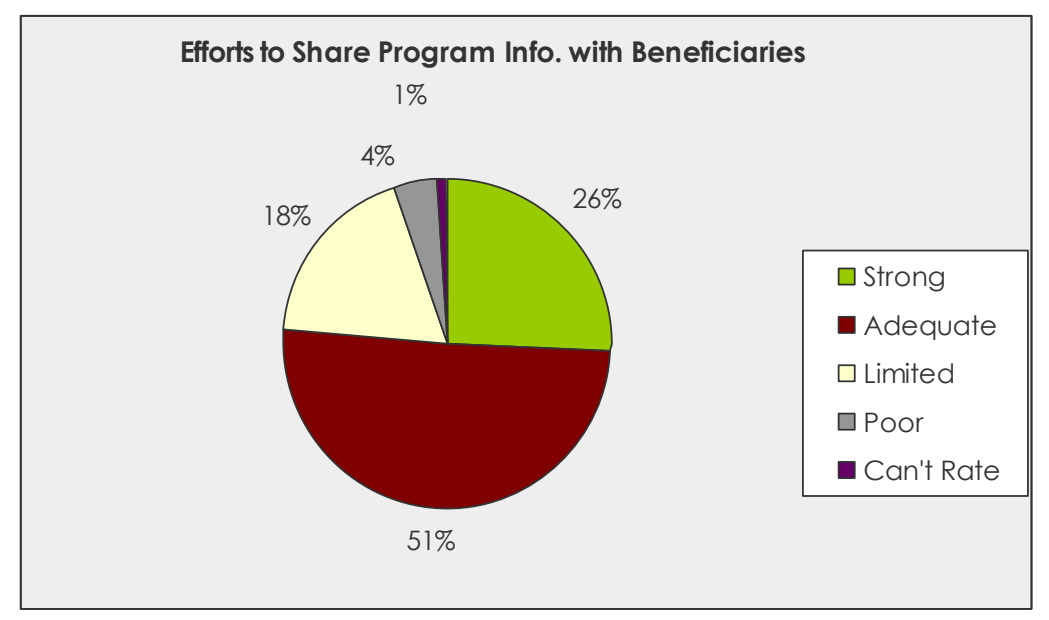

Figure 14.Responses to the question: Overall, how would you rate your program's efforts to share program information with beneficiaries?

One way to interpret these results is that a majority, $77 \%$ are content with the amount of information currently being shared with beneficiaries during Mercy Corps projects (combining strong and adequate). Another angle, is to focus on the $18 \%$ that view efforts to be "limited" and the $4 \%$ who rate it as "poor". It would be interesting to pose a follow-up question to this one in a future survey that asks why or to explain the specific program circumstances that allow them to rate their response this way. 


\section{Accountable for what? Participation}

As discussed in chapter three, participation and when the INGO chooses to include beneficiaries is a component of $\mathrm{AB}$. What actions that the INGO carries out could relate to $\mathrm{AB}$ ? Breaking down accountability in this way helps facilitate the discussion on measurement tools in the upcoming "accountable how?" section. The survey analyzed this aspect of accountability by asking which phases of the project cycle beneficiaries were likely to be involved in, when project information is shared with beneficiaries and when are they asked to participate in the selection criteria.

Participation in this section refers to beneficiary inclusion in various steps in the project cycle. Respondents reported that they are most likely to involve beneficiaries 1) during the implementation of activities, 2) the initial assessment, 3) the evaluation, and 4) the monitoring of the project. Beneficiaries are least likely to be involved in the design of the project. Figure 14 below depicts the full findings from the survey on this point.

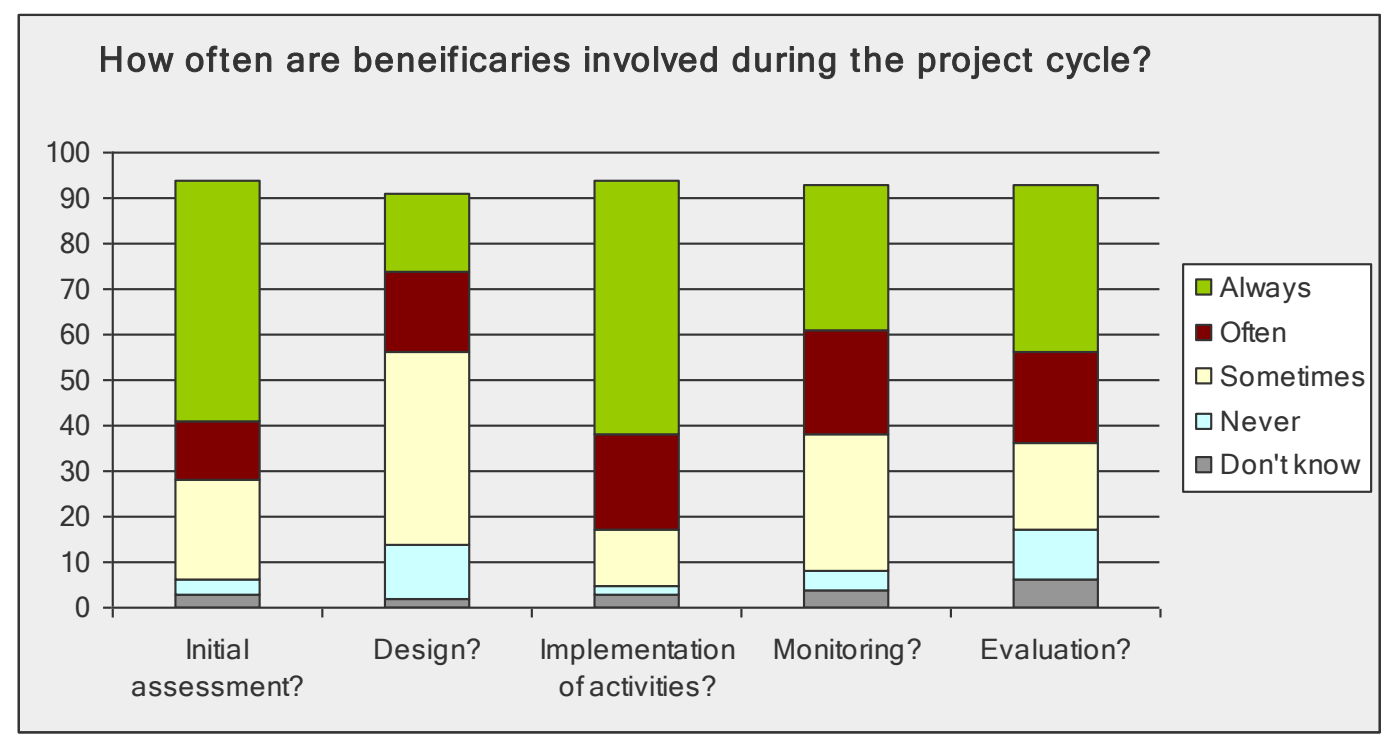

Figure 15. Response to the question, how often does your team involve beneficiaries during the following phases of the project. 94 responses. 


\section{Wardwell, Sarah}

Respondents are most likely to meet with beneficiaries to explain the kind of assistance Mercy Corps can provide, who Mercy Corps is, and the roles the community plays in program implementation during the assessment and design phases. Sources of funding are least likely to be shared with beneficiaries during these phases. Percentages for sharing information about all of these subjects was above $50 \%$ when combining the “often" and "always" categories. Figure 15 above displays the full report.

When input and inclusive participation is used to direct beneficiary selection, input is most likely to be sought from community leaders and community representatives before most vulnerable groups, although only by a small margin. The table below details the "always" and "often" categories from this question on the survey.

\begin{tabular}{|l|l|l|l|}
\hline Who do we solicit information from? & & & \\
\hline & Always & Often & $\begin{array}{l}\text { Combined } \\
\text { Total }\end{array}$ \\
\hline Community Representatives & & & \\
\hline Community Leaders & $53 \%$ & $26 \%$ & $79 \%$ \\
\hline Most Vulnerable Groups & $38 \%$ & $27 \%$ & $81 \%$ \\
\hline
\end{tabular}

Table 2. Response to the question, When creating beneficiaries selection criteria, to what extent does your team include input and inclusive participation from. 94 responses. 


\section{Wardwell, Sarah}

Lastly, 49\% of respondents reported "always" informing beneficiaries about program changes. Only $2 \%$ reported that "never" share this information and $25 \%$ say they only "sometimes" discuss changes with beneficiaries. This question didn't explain what specific type of program changes they were referring to, leaving some space for confusion in responses. The assumption in this analysis is that the question was interpreted to mean "major changes" in the program.

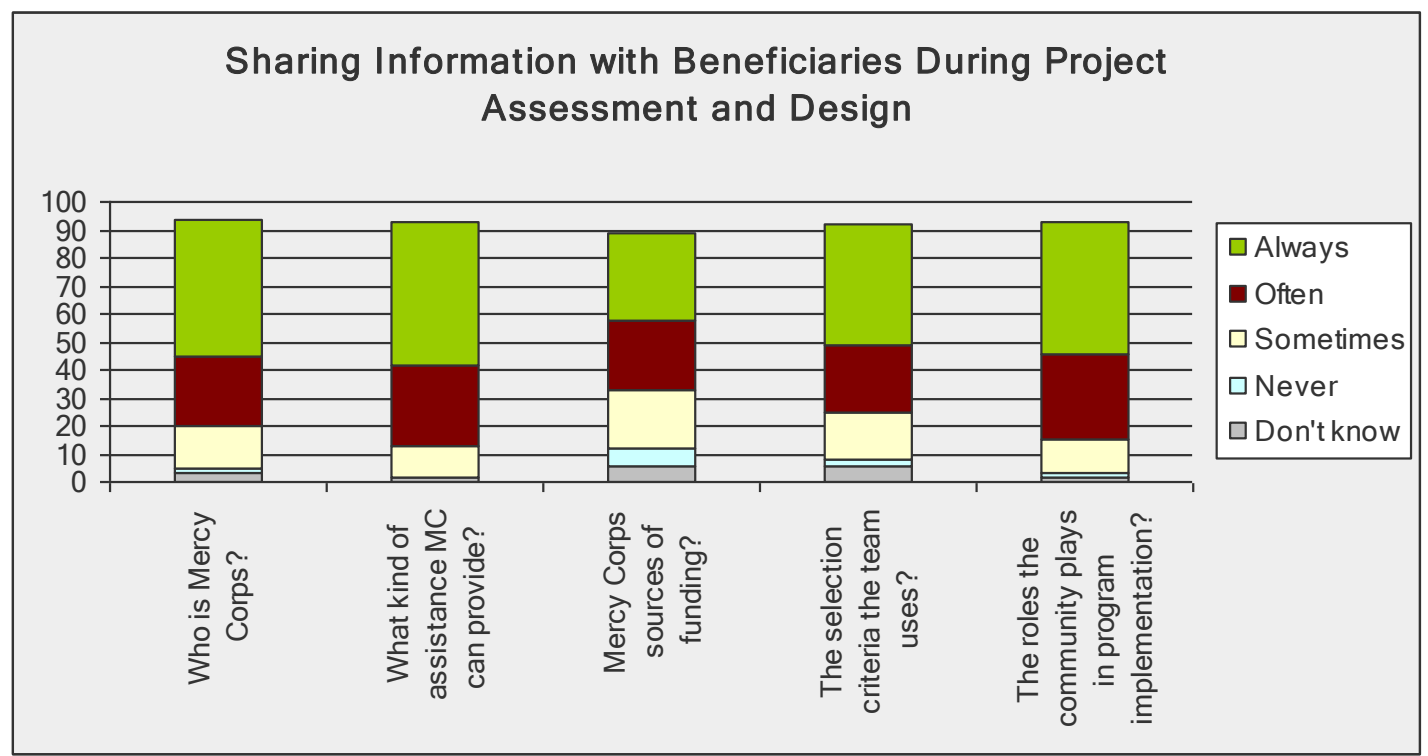

Figure 16. Response to the question, during the assessment and design phases, how often does your team meet with the communities to clarify any of the following?

\section{Accountable How?}

After selecting the beneficiaries and determining what activities Mercy Corps is accountable for, the next step in $\mathrm{SAB}$ is to find the methods and tools to assess accountability. Most of the survey questions asked about opportunities for beneficiaries to participate in the project process through: formal meetings, identifying and prioritizing 


\section{Wardwell, Sarah}

their needs, feedback systems, and other tools. After looking at each of these, the next step is to determine where and how effectively they are used.

Formal meetings: Formal meetings are most consistently used to say goodbye to beneficiaries ( $42 \%$ of respondents report "always" doing this). While proper project close-out is an important step in accountability, beneficiaries should be heavily involved in the design and implementation phases as well. $32 \%$ of respondents meet formally with beneficiaries to review and ask their opinion about lessons learned. Respondents were equally likely to answer either "often" or "sometimes" (32\%) holding formal meetings with beneficiaries to review and provide feedback about project results. Figure 15 below provides the full results for improved clarity and analysis.

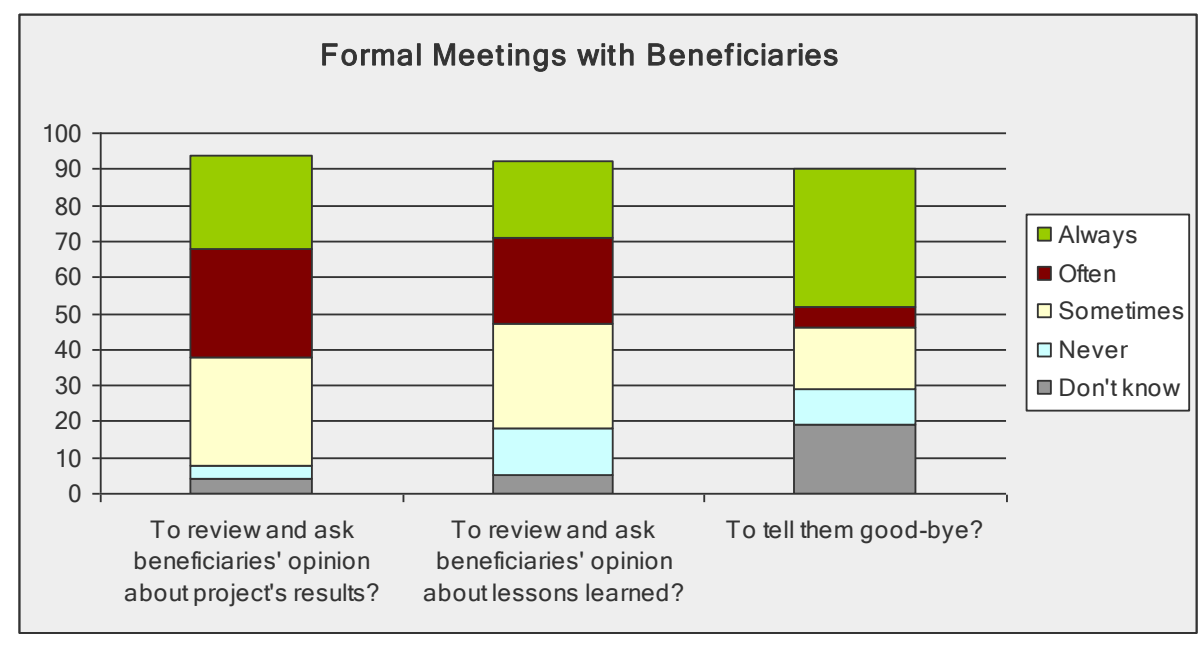

Figure 17. Response to the question, to what extent does your team hold formal meetings with beneficiaries? 94 responses.

Identifying and prioritizing beneficiary needs: Survey respondents indicated that they "always" give beneficiaries the opportunity from first contact to identify and prioritize their needs $49 \%$ of the time. $3 \%$ of respondents reported this "never" happens, 
Wardwell, Sarah

and $24 \%$ said beneficiaries are "often" given the opportunity to identify and prioritize their needs. The percentages decrease when looking at how often this information is used. Only $39 \%$ of respondents reported that they "always" take into account beneficiary prioritization of needs for program design and implementation. The "never" category remained the same, but the "often" category increased to $31 \%$ and the "sometimes" category increased slightly to $23 \%$. This seems to indicate that the prioritization of beneficiary needs is more likely to be understood, but slightly less likely to actually be incorporated into program design and implementation.

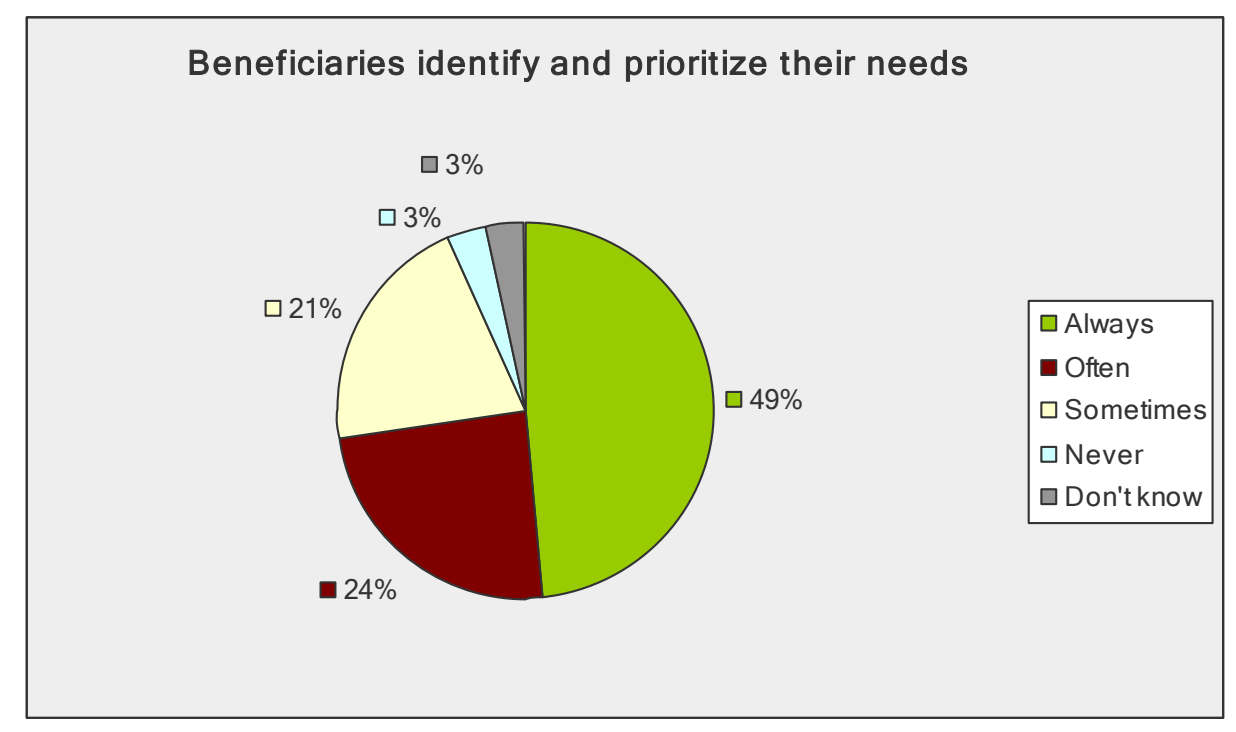

Figure 18. Response to the question, to what degree are beneficiaries given the opportunity from first contact to identify and prioritize their needs. 91 responses.

Feedback systems: Survey respondents are almost evenly split on how consistently they establish formal feedback mechanisms early on in a project, with $33 \%$ responding "often" and 32\% responding "sometimes". Another 19\% reported "always" setting up formal feedback systems and 8\% reported "never" doing so. 39\% of survey 
Wardwell, Sarah

results indicate that beneficiaries are regularly provided with information about the project in order to facilitate their participation and informed feedback. Below are a few selected quotes from survey respondents that further clarify this issue of feedback.

"Ensure a systematic feedback loop that is documented and requires action based on feedback - between community/beneficiaries and MC. Ensure beneficiaries are part of final evaluation design and understand results of same. Ensure wrap up and end of project is done thoughtfully and with community (not just ending project and pulling out for eg.)"

"We need to be more consistent about providing formal and publicly available feedback mechanisms. This does happen in some cases, with posters or transparency boards providing agency contact information, but we are still inconsistent and should be much more intentional. As well, we are not always very good about promoting our own work and as a result, we rarely have printed information available to beneficiaries about the overall program objectives and work-plan."

Survey respondents indicated that they "often" use feedback from community members to inform a project's implementation (45\%). Although possibly not a formal feedback mechanism (the question did not indicate formality), feedback as a reciprocal process between beneficiaries and Mercy Corps is "often" used to respond to problems in a timely manner (47\%). To a lesser extent, such feedback is "often" used to inform beneficiaries about progress based on indicators (35\%). A reciprocal feedback process is "never" used to inform beneficiaries about progress based on indicators according to $16 \%$ of respondents (compared with only $1 \%$ of respondents for responding to problems in a timely manner). Feedback (again not indicated whether formal or informal mechanisms 
Wardwell, Sarah

are used) is used most often to identify new needs ('always" - 52\% of respondents), identifying gaps (“always" - 49\% of respondents) for program improvement ("always" $47 \%$ of respondents), and in decision making (41\% of respondents). Identifying gaps stands out as most frequently being used only sometimes, when compared with the other categories. All categories had similar numbers of respondents claiming they never use feedback in these ways (1-2\% of respondents). Figure 17 below depicts this information.

For $42 \%$ of respondents, this feedback is "always" documented and made available to all staff working on the project ("often" $-22 \%$, "sometimes" - 24\%). Seven percent of respondents claimed that this feedback is "never" documented or made available to all staff. Feedback is shared less often with other humanitarian actors (“always" $-23 \%$ of respondents, "often" - 30\%, “"sometimes" - 33\%, "never" 7\%).

Critical information that requires immediate action (sexual abuse, accusation of corruption, security risk, etc.) is "always" acted upon in a timely manner according to $42 \%$ of respondents. Seven percent of respondents claimed that this information is never acted upon in a timely manner. While the frequency that this information is acted upon in a quick manner is low, often reporting is hindered by the sensitivity of the situation requiring more decision makers to be involved and the decision itself to be belabored in an effort to find the best response to the situation. A SAB system would ask that critical information be at least acknowledged in a rapid manner and acted upon within the shortest time period possible. Individual country programs could draw up standards for this kind of response to help speed up the decision making process as well. 


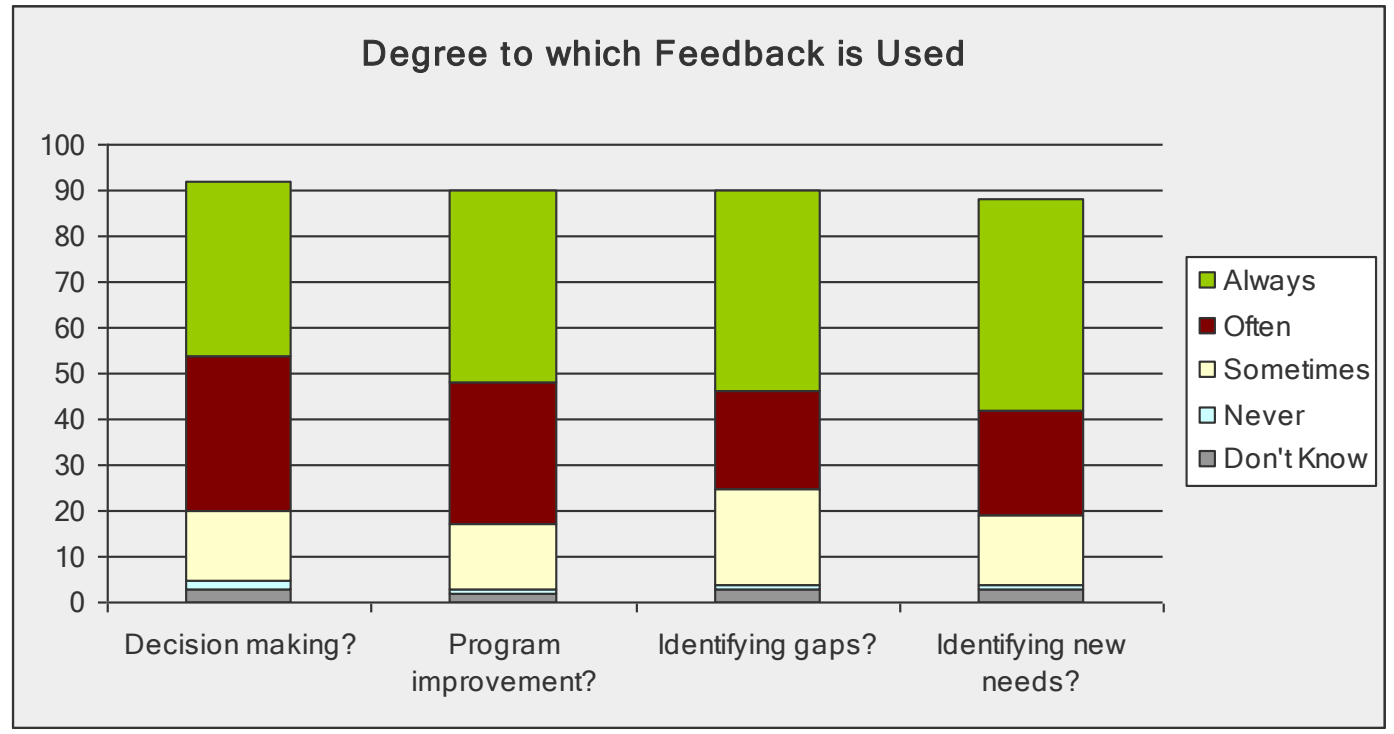

Figure 19. Response to the question, to what degree is feedback used for... 92 total responses.

Other tools: Tables 3 and 4 below outline the various practices survey respondents indicated they are using to share information and ensure accountability to beneficiaries in descending order of frequency. Meetings were frequently cited in both questions. Table three shows how information is shared with beneficiaries, which falls under the transparency function of accountability. Some of these tools simultaneously increase participation in the project, although not all. For example, a focus group is a means of collecting beneficiary information that can be used to inform project decisions, which would mean it is both a transparency and participation tool. Materials are solely transparency tools though. 


\begin{tabular}{|c|c|c|}
\hline $\begin{array}{c}\text { Means for Sharing Info. } \\
\text { With Beneficiaries }\end{array}$ & $\begin{array}{c}\text { Times } \\
\text { Mentioned }\end{array}$ & $\begin{array}{c}\text { Percentage } \\
\text { of Total }\end{array}$ \\
\hline Meetings & 52 & $49 \%$ \\
\hline Verbal Reports & 20 & $19 \%$ \\
\hline $\begin{array}{c}\text { Materials (brochures, } \\
\text { email, leaflets) }\end{array}$ & 10 & $9 \%$ \\
\hline Focus groups & 5 & $5 \%$ \\
\hline Reports & 5 & $5.00 \%$ \\
\hline Site visits & 5 & $5 \%$ \\
\hline Information boards & 3 & $3 \%$ \\
\hline Interviews & 3 & $3 \%$ \\
\hline Information desk & 1 & $1 \%$ \\
\hline $\begin{array}{c}\text { Maintaining constant } \\
\text { communication }\end{array}$ & 1 & $1 \%$ \\
\hline Workshops & 1 & $1 \%$ \\
\hline Total & $\mathbf{8 5}$ & $\mathbf{1 0 0 \%}$ \\
\hline-9
\end{tabular}

Table 3. Content analysis of qualitative responses to the question, through what means - meetings, verbal reports, etc. - are beneficiaries given information about projects, please explain.

Table four addresses mechanisms for accountability. The wide range of responses highlights the confusion around this concept and the need for increased information within Mercy Corps about what accountability mechanisms, tools, and practices look like. A toolkit with information on all of these tools and practices detailed would be a good next step in developing an accountability to beneficiaries framework. A SAB system would take a step further in explaining when to use each of these tools and practices in order to not only "mark off" steps in the framework, but to actually improve the project's accountability. 


\begin{tabular}{|l|c|}
\hline Accountability Practices & $\begin{array}{c}\text { Times } \\
\text { Mentioned }\end{array}$ \\
\hline Informal Verbal/regular contact & 15 \\
\hline Meetings & 13 \\
\hline Local government collaboration & 6 \\
\hline Assessments & 4 \\
\hline Feedback & 4 \\
\hline Formal methodology (CoMo, & \\
DNH, GEG) & 4 \\
\hline Brochures, Success stories & 3 \\
\hline Field & \\
\hline Coordinators/Representatives & 3 \\
\hline M\&E & 3 \\
\hline Evaluations/Reports & 2 \\
\hline Interviews & 2 \\
\hline Not systematic & 2 \\
\hline Program activities & 2 \\
\hline Progress reports & 2 \\
\hline Surveys & 2 \\
\hline Training/workshops & 2 \\
\hline Transparency boards & 2 \\
\hline Complaint mechanism & 1 \\
\hline Don't Know & 1 \\
\hline focus groups & 1 \\
\hline Online & 1 \\
\hline Open office policy & 1 \\
\hline Participatory methods & 1 \\
\hline Procurement & 1 \\
\hline Visits & \\
\hline \hline
\end{tabular}

Table 4. Content analysis of qualitative responses to the question, what other accountability practices do you or your team regularly use to fulfill your accountability to beneficiaries? 50 total responses.

\section{Mercy Corps Example and the Role of Internal Assessments in Accountability Systems}

The Mercy Corps internal survey illustrates a foundational step in the beginning an organizational focus on accountability to beneficiaries. The survey responses provide valuable data for the organization to learn from and influence their next steps towards improving accountability to beneficiaries. The results from this survey were disseminated to the organization through a series of global web-based seminars, individual meetings 
Wardwell, Sarah

with leadership members, and the report was posted on all three major internal information sharing portals.

The results of this survey can help leaders identify areas of improvement for future strategic interventions in the area of SAB. Following a SAB approach doesn't necessarily mean improving on all areas where certain practices were not well used or incorporated into projects. This is a fundamental difference between TAB and SAB. A TAB approach might read the results of this survey as needing to increase the participation of beneficiaries in all areas of projects. A SAB approach though would consider each specific project, and select the areas of the project where participation is most important. Reading this specific section of the results, Mercy Corps should consider improving beneficiary participation in the early phases of the project, specifically the design phase, where participation was reported to be the lowest of the project phases. As this phase is important for beneficiary buy-in to the project and is critical to their perspective of the project, this would be a strategic area to improve upon. The level of participation during the implementation period is already satisfactory, and Mercy Corps doesn't need to commit as many resources to improving in this area.

Other interesting observations from the analysis of these results are that Mercy Corps should find ways to increase the sample size, specifically targeting local staff. A SAB approach demands an increased response rate from these staff that are directly responsible for implementing the projects. Expatriate and headquarter staff may have drastically different opinions of project activities than local staff, so their input is important and needs to be better measured with internal assessments. 


\section{Wardwell, Sarah}

The barriers section of these results should be interesting for leaders to identify reasons why teams may not currently be implementing SAB practices. With this information, they can tailor their future initiatives around these. For example, the number one barrier was "workload/time/resource restrictions", therefore a SAB approach needs to make it clear to teams that using SAB tools will not add work, but will reduce work in the long haul. Basically, this is a simple behavioral economics lesson that any future SAB initiatives from Mercy Corps need to show teams how they will benefit from implementing these. The approach should clearly explain that better results are likely to happen with a focus on $\mathrm{SAB}$, and should reduce the workload of responding to problems with the project. For example, increasing stakeholder input during the design phase of the project, should reduce changes that need to happen during the project implementation. A SAB approach will also use this information on barriers to help staff find solutions to mitigate barriers that are beyond staff's control, such as structural barriers. Some practices already exist to help teams with these barriers, such as guides to Good Governance, SPHERE standards and the Good Enough Guide for emergency management.

The question about profiling the population is interesting to view in terms of understanding how teams are conducting assessments and whether they are including the entire stakeholder population in their assessments. A more targeted question around this may provide clearer results though. Inclusion of these unique groups, such as vulnerable populations, can be an agency decision, such as focusing more on women and girls. From 
Wardwell, Sarah

this, specific follow-up questions could provide more specific information on these indicators.

Figure 13 showing the results of beneficiary inclusion shows some definite need for improvement. These results show a need to improve inclusion of beneficiaries in the design and monitoring phases. A Mercy Corps Haiti project has found an innovative way to include beneficiaries in project monitoring by asking the community to come up with their own indicators of the project's success. The project team has then helped the community design indicators and methods for measuring against these indicators so that they can continue to measure their own progress after the project has finished.

Improving what information is shared with beneficiaries will have ripple effects to other indicators. For example, the results show that teams are hesitant to share their funding sources with beneficiaries. Sharing funding information would actually help communities better under what an INGO is and how they operate, helping to clear up rumors and other misinformation. Selection criteria on the other hand, may be something that the agency may not want to share more frequently. A TAB approach that simply says to increase sharing of information could lead to increased corruption with a project in this specific area. If beneficiaries are aware of the selection criteria there is an increased likelihood that individuals will falsify their information in order to qualify for the services offered from the INGO. In Haiti post-earthquake reports of individuals moving out of the camps but keeping their tent in internally displaced persons (IDP) camp in order to continue receiving benefits is commonly heard. 


\section{Wardwell, Sarah}

A future study should re-frame the question about where information is solicited from to learn more about how information is gathered from the full range of stakeholders. Understanding the whole group of stakeholders would help the agency write this question and then learn more from it.

This study also highlights some agency weaknesses including holding formal meetings with beneficiaries most often at the end of the project cycle and not allowing beneficiaries themselves to identify and prioritize their needs often enough ( $21 \%$ reported never including this information).

\section{Recommendations for a Future Internal Assessment}

It would be interesting to conduct a similar study, using some of the same questions for reliability purposes, following significant inputs in the area of SAB. Later in 2011 Mercy Corps took up a study to define accountability for the organization (results at the beginning of the chapter). This new definition will help improve consistency in the questions for a future survey. The next survey could also help to measure how well the organization's definitions have become integrated into the whole organization (i.e. uptake and acceptance of the definition).

Conducting a similar agency-wide study after significant investments to a SAB system would yield interesting results. This type of large-scale study would best be conducted after a few years of investing in agency-wide changes to a SAB system. An appropriate next-step for individual country programs would be to conduct a simple survey of individual projects to identify which components of accountability to beneficiaries needs the most improvement for the current phase of the project. A survey 
Wardwell, Sarah

like this would clearly break down the four components of accountability to beneficiaries and ask questions targeted to the phase of the project: initial assessment, design, implementation and monitoring, or evaluation. These smaller-scale analyses would help program teams assess their own needs and practices first, and then would provide clearer results for an agency-wide assessment. 
Wardwell, Sarah

\section{Chapter 5. Conclusion}

There is no shortage of critics when it comes to international humanitarian aid efforts, whether it's for long-term development projects or immediate relief and recovery interventions. The 2010 earthquake in Haiti is a recent examples where criticisms are growing ever more loudly, furthering the need for INGOs to think harder and act more accountably not only to their donors, but to the "disenfranchised communities they are trying to serve" 155 . As this thesis has shown, the best way forward to make INGO actions truly more accountable to the populations they intend to serve and to reach better results and ultimately improve the situation of the people they intend to serve, may mean reducing the amount of $\mathrm{TAB}$ activities such as $\mathrm{M} \& \mathrm{E}$ and reporting. Instead INGOs should spend that time actively listening to the needs of populations, increasing participation of all stakeholders throughout the project, incorporating feedback and learning into future project and organizational decisions, listening and acting on complaints, and effectively communicating with communities about their projects and intents of the organization. Complaints leveraged against the actions of INGOs would be better resolved through $\mathrm{SAB}$ than just continuing to do more $\mathrm{TAB}$ activities.

As this thesis has shown, the debate still hangs heavy in between academics and philosophers, which would at first glance provide little hope to implementing practitioners that they could make any headway in this direction any time soon. However, this thesis has taken a practical lens toward the problem, looking at how INGOs can take

\footnotetext{
${ }^{155}$ Lawry, Steven, "Paul Farmer's Call for a New Conversation on Aid to Haiti," review of Haiti: After the Earthquake, by Paul Farmer. http://hausercenter.org/iha/2011/12/09/paul-farmer\%E2\%80\%99s-call-for-anew-conversation-on-aid-to-haiti/
} 
Wardwell, Sarah

the first step towards improving accountability to beneficiaries by taking their own accountability pulse within their agency. Once an agency is aware of where they stand in this measure, they can determine appropriate agency-wide steps through strategic management tools to improve accountability.

This thesis has provided definitions to terms that are often used in academic literature as well as daily parlance but have gone undefined or are used in a myriad of fashions. The complete list of definitions can be found in the appendix. These definitions set the foundation for responding to the three core questions in the debate: Accountable to who? Accountable for what? Accountable how? This last aspect of how to be accountable towards beneficiaries has been the primary focus of this thesis.

\section{Summary of Main Points: SAB vs. TAB}

According to the discussion of this thesis, a strategic approach to accountability to beneficiaries $(\mathrm{SAB})$, will yield a great positive impact for INGO projects. The table below summarizes the main distinctions between the traditional approach, or the current thinking on the subject of INGO accountability to beneficiaries, and the strategic approach. 


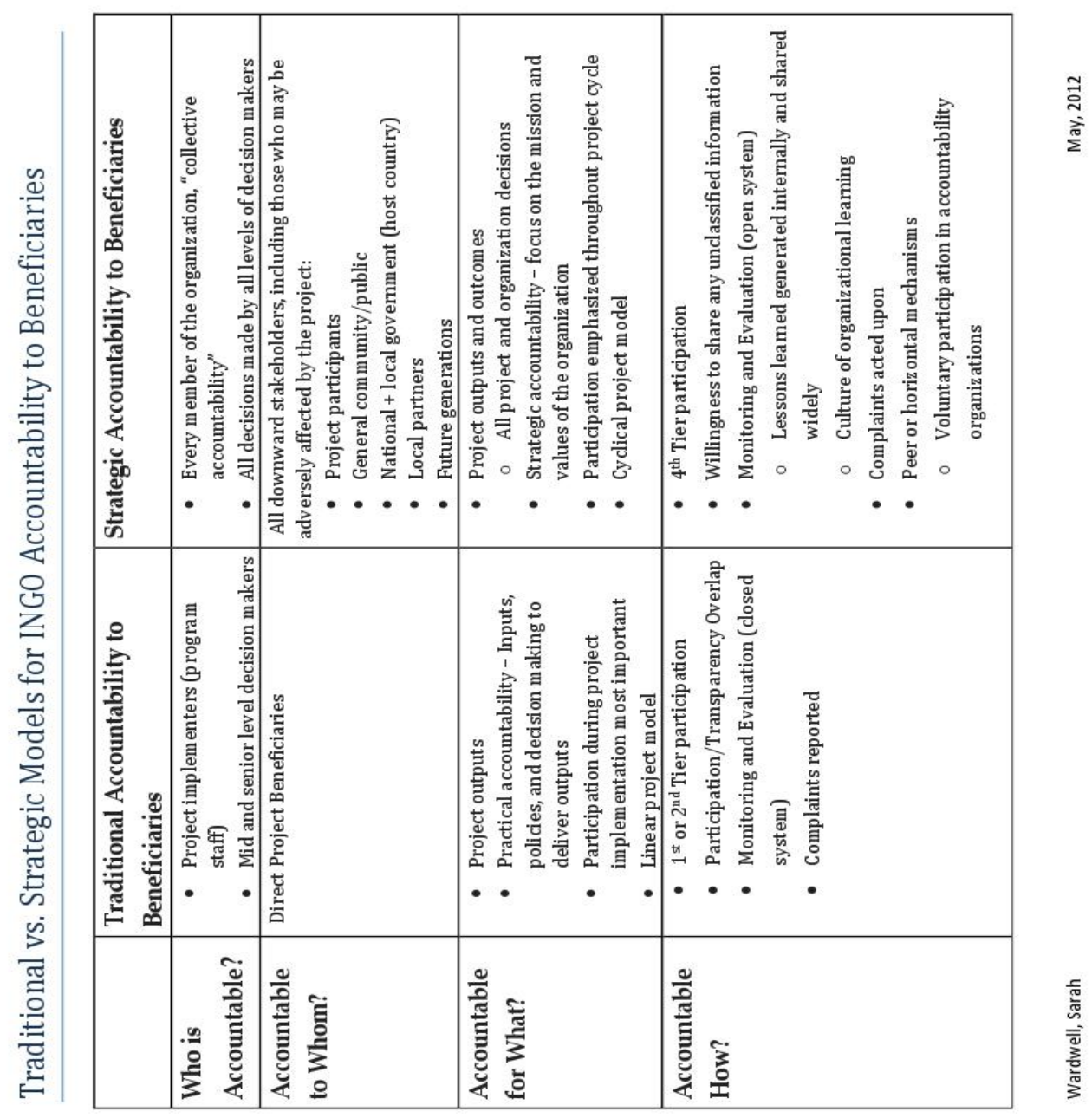

Table 5. Table Summarizing the Differences between SAB and TAB

\section{Limitations}

This thesis has focused on the benefits of accountability. Overall, using an accountability to beneficiaries lens as explained in this thesis will improve impact. As mentioned in chapter two, accountability itself though does not always equal good. This 
Wardwell, Sarah

is an important limitation to reiterate. Simply carrying out an accountability to beneficiaries internal assessment, or implementing accountability measures taken from a toolkit, will not ensure positive impact. Achieving impact requires accountability at all steps in the project cycle, accountable leadership and behavior throughout the agency, plus all of the necessary external factors for individual project success. INGOs work in a rapidly changing environment, one that is often unpredictable. INGOs also work towards admirable, though often lofty ideals, which are much more difficult to attain than can often happen through short-term projects. Yet, taking the first step towards conducting a strategic internal accountability assessment, and then putting in place low-cost measures that fit with the current project stage, along with a shared vision of programmatic outcomes, can in fact lead to greater outcomes.

Another limitation to this thesis is the reality that much of the funding that NGOs accept and rely upon comes with stipulations from the donor. This means that in order to truly increase downward accountability, NGOs and other organizations seeking funding must show donors and governments the importance of listening to the needs of the community before and during the design of a project. This additional level of responsibility bridges upward accountability with downward accountability. Government donor institutions are already sensing the need to improve upon accountability in order to increase the impact of their funds as evidenced by the Paris Declaration in 2005 and the Accra Agenda in 2008. Sweden has taken steps to ensure greater coherence in their official policy on international development to be more supportive of the recipient 
Wardwell, Sarah

country's development goals and in 2008 Canada passed into law the Official Development Assistance Accountability Act ${ }^{156}$.

This thesis has focused on INGOs as groups that voluntarily apply the term to their type of organization. Achieving a greater concept of accountability within a community will require a similar effort to be put forward to improve accountability in all actors - government (local and national), businesses, religious groups, educational organizations, and professional and trade organizations. In Haiti in particular, groups of well-intentioned individuals flock from all over the world to "help Haiti". The variety of structures that support these individuals and their intentions is vast. To improve accountability to beneficiaries in Haiti will eventually require all of these groups to adapt practices that improve the use of the four pillars of accountability - participation, transparency, feedback and learning, and complaints.

This thesis has taken the broad term of accountability and narrowed the discussion to a specific form of accountability affecting the relationship between an organization and its beneficiaries. Working backward from the specific techniques proposed here, accountability as a concept within the humanitarian and international development sectors connects INGO actions with desired development outcomes, especially within the government. There is also a strong link between organizational accountability as discussed in this thesis and democratic accountability, as many organizations hope countries will turn towards such as in the Arab Spring that begun in 2011. Comparing democratic accountability with INGO accountability and drawing links between the two

\footnotetext{
${ }^{156}$ Goody, Allison, "International Development: The Aid Effectiveness Debate," Library of Parliament (24 June, 2009):5, 17. 
Wardwell, Sarah

concepts is a topic in and of itself that was only lightly touched upon in this thesis.

Further research needs to be carried out on this topic as there is a great deal of confusion between the two concepts.

Also above the scope of this thesis is corporate accountability, a term that has become increasingly complex in the globalized world. Accountability within a business context is generally considered clearer than in an NGO context because businesses are forced to respond to the demands of their clientele in order to increase their profits. In a sense, NGOs are like businesses that can choose not to put the needs of their customers first and continue to get more business. However, with the increase in globalized corporations that have the capability to lobby governments, negotiate the rules, regulations and tax structures as they wish, they are avoiding being held accountable at this higher level ${ }^{157}$. Other forms of accountability were also not further explored in this thesis, but may warrant further investigation, especially between the details that separate each type.

Lastly, this thesis has made several assumptions that could be questioned by the reader, including does global governance exist and is it a good/necessary system? Do INGOs deserve the political legitimacy they are receiving in the $21^{\text {st }}$ century? As Anderson notes in his footnotes, these are questions that must continually be addressed simultaneously with the question of INGO accountability.

${ }^{157}$ Bendell, Jem, Debating NGO Accountability, (Geneva, Switzerland: UN Non-Governmental Liaison (NGLS), 2006), 75. 
Wardwell, Sarah

Next Steps

In the 2010 HAP-I assessment of humanitarian accountability, only $37 \%$ responded that they felt INGOs were "highly accountable" to their beneficiaries, down from $39 \%$ the previous year ${ }^{158}$. A majority of respondents to that survey were currently employed by INGOs. If INGO workers themselves do not feel their agencies are accountable to their beneficiaries there clearly exists more room for research and improvement in this area. The ideas presented in this thesis are more than academic rhetoric; they are ideas in motion currently being played out on the international stage in small and large efforts. At Mercy Corps Haiti efforts are underway to identify ways to evaluate and take steps to improve on the four pillars of accountability with low-cost, minimal resource initiatives. Other organizations are taking on the challenge in a more globalized way such as Oxfam's “Accountability Starter Pack”, a guide to help field programs assess and take steps towards improving their accountability. There are also multi-organization initiatives such as the Humanitarian Accountability Project (HAP), connecting organizations with accountability resources and expanding the concept of horizontal or peer accountability. In any case, measures to improve accountability to beneficiaries are greatly needed, especially in countries such as Haiti where large amounts of foreign aid are being spent. As Schwartz states in his self-published book about aid in Haiti, "What I hope to do is call attention to the need for accountability for I believe that the disaster we call foreign aid...comes from the near total absence of control over the distribution of money donated to help impoverished people in the country...lack

${ }^{158}$ HAP, "The 2010 Humanitarian Acccountability Report", 67. 
Wardwell, Sarah

of accountability allows the aid to be distorted into something that arguably does more harm than good,",159.

One of the greatest benefits of focusing on accountability to beneficiaries is the increased linkage between the rhetoric around organizational values and organizational actions. As NGOs work in a myriad of sectors on projects that are sometimes difficult to connect with others within the organization, NGOs frequently claim they are led by their core values that inspire their work in all directions, creating a unity of purpose within the diversity of their practice. With an increased focus on accountability to beneficiaries, NGOs can be more value-driven in reality, not just on paper, and find a greater cohesion within their work. "No longer would people accept describing themselves as what they are not (non-governmental), but what they are for, by articulating the universal values that inspire their work,"

As the 2008 financial crisis has reminded Americans, money spent must be accounted for. Beyond the financial aspect of accountability, INGOs need to pay attention to the perspectives and needs of their beneficiaries and other stakeholders. Just as businesses must listen to the needs and desires of their customers in order to turn a profit, so much INGOs listen to the needs of their clients (beneficiaries) in order to make their work effective and impactful. By providing services that beneficiaries and other stakeholders are pleased with will help INGOs continue to bring in increased funding, both public and private. "The fundamental question facing all NGOs is how to move

\footnotetext{
${ }^{159}$ Schwartz, Timothy T. Travesty in Haiti. Self published, (2010), 3.

${ }^{160}$ Bendell, Jem, Debating NGO Accountability, (Geneva, Switzerland: UN Non-Governmental Liaison (NGLS), 2006), 78-79. 
Wardwell, Sarah

from their current position - as unhappy agents of a foreign-aid system in decline - to being vehicles for international cooperation in the emerging global arena,"161. Therefore, this concept of accountability to beneficiaries cannot be left any longer for academics, philosophers, and politicians to discuss. INGOs themselves need to take action towards understanding this concept and creating tools to become more accountable to the populations they intend to serve in order to remain relevant, provide optimal impact, and improve their public image.

${ }^{161}$ Lewis, David and Tina Wallace, ed., New Roles and Relevance: Development NGOs and the Challenge of Change (Connecticut: Kumarian Press 2000), 14. 
1. Adams, Laurie. "International Accountability Frameworks". Newsletter of the IASL Community, ActionAid, www.actionaid.org.

2. Ahmed, Shamina and David Potter. NGOs in International Politics. West Hartford, Connecticut: Kumarian Press, 2006.

3. Anderson, Kenneth. "What NGO Accountability Means: And Does Not Mean." The American Journal of International Law 10:13 (Jan. 2009): 170-178.

4. Anderson, Mary. "Listening to Improve Accountability." Monday Developments (InterAction), December 2007.

5. Anderson, Mary. Do No Harm: How Aid Can Support Peace - or War. Colorado: Lynne Rienner Publishers, 1999.

6. Bendell, Jem. Debating NGO Accountability. Geneva, Switzerland: UN NonGovernmental Liaison (NGLS), 2006.

7. Castiglione, Dario. "Accountability." Encyclopedia of Governance, 2006. SAGE Publications. 28 April, 2011. http://www.sageereference.com/governance/Article_n1.html

8. Cavill, Sue, and M. Sohail. "Increasing Strategic Accountability: A Framework for International NGOs.” Development in Practice 17:2 (April 2007): 231-248.

9. Center for Global Development. "Accountability and Transparency key to World Bank Disclosure Policy, Ramchandran States in Congressional Testimony." September 14, 2009. http://www.cgdev.org/content/article/detail/1422758/

10. Clements, Paul, Thomaz Chianca, and Ryoh Sasaki. "Reducing World Poverty by Improving Evaluation of Development Aid." American Journal of Evaluation 29:2 (June 2008): 195-214.

11. Clinton, Bill. "Clinton to NGOs: With Great Power Comes Great Responsibility," InterAction, April 14, 2006.

12. Cook, Sccott D. N. and Dvora Yanow. "Culture and Organizational Learning." Journal of Management Inquiry (1993):401-421.

13. CSO Net, "At your Service". NGO Branch of the UN Economic and Social Affairs. csonet.org

14. David, Rosalind, Antonella Mancini and Irene Guijt. "Bringing Systems into Line with Values: The Practice of the Accountability, Learning, and Planning System (ALPS)." In Relationships for Aid, edited by Rosalind Eyben, 133-153. UK: Earthscan, 2006.

15. Davidson, Sara. Good Enough Guide. The Emergency Capacity Building Project, 2006.

16. Dubnick, Melvin. "Accountability and the Promise of Performance: In Search of the Mechanisms." Public Performance \& Management Review 28:3 (March 2005): 376-417.

17. Ebrahim, Alnoor and Edward Weisband, eds. Global Accountabilities: Participation, Pluralism, and Public Ethics. Cambridge: Cambridge University Press, 2007. 
Wardwell, Sarah

18. Ebrahim, Alnoor and V. Kasturi Rangan. "The Limits of Nonprofit Impact: A Contingency Framework for Measuring Social Performance." Harvard Business School Working Paper 10-099, 2010.

19. Ebrahim, Alnoor. "Accountability in Practice: Mechanisms for NGOs." World Development 31:5 (2003): 813-829.

20. Ebrahim, Alnoor. NGOs and Organizational Change: Discourse, Reporting, and Learning. Cambridge: Cambridge University Press, 2005.

21. Edwards, Michael and David Hulme, eds. Beyond the Magic Bullet: NGO Performance and Accountability in the Post-Cold War World. Connecticut: Kumarian Press, 1996.

22. Ellerman, David P. Helping People Help Themselves: Towards a Theory of Autonomy-Compatible Help. Washington, D.C.: World Bank, Development Economics, Office of the Senior Vice President, 2001.

23. Federal Emergency Management Agency. "Preparedness." http://www.fema.gov/prepared/

24. Fogarty, Edward. "Nongovernmental Organization." Encyclopedia of Governance. http://www.sage-ereference.com/governance/Printn353.html

25. Fratianni, Michele and John Pattison. "International Financial Architecture and International Financial Standards.” Annals, AAPSS 579 (January 2002): 183-199.

26. Gelb, Alan. "How can Donors Create Incentives for Results and Flexibility for Fragile States? A Proposal for IDA." Center for Global Development Working Paper 227 (October 2010): 1-23.

27. Goody, Allison. "International Development: The Aid Effectiveness Debate." Library of Parliament (24 June, 2009):1-19.

28. Havrda, Marek, and Petr Kutilek. "Accountability 2.0 - In Search of a New Approach to International Non-Governmental Organisations' Accountability." In Evaluating Transnational NGOs: Legitimacy, Accountability, Representation, edited by Jens Steffek and Kristina Hahn, 157-175. New York: Palgrave Macmillan, 2010.

29. Humanitarian Accountability Partnership. "The 2010 Humanitarian Accountability Report". Geneva, Switzerland.

30. INGO Charter. "About the Charter."

31. Jacobs, Alex, and Robyn Wilford. "Listen First, a Pilot System for Managing Downward Accountability in NGOs." Development in Practice 20:7 (2010): 797 811.

32. Jacobs, Alex. "Creating the Missing Feedback Loop." IDS Bulletin 41:5 (2010): 56-64.

33. Jacobs, Alex. "Five Pillars: Improving Quality and Impact." www.NGOperformance.org, April 19, 2011.

34. Jacobs, Alex. "Helping People is Difficult" in "Social entrepreneurship, new models of sustainable social change", ed Nicholls, OUP, 2006.

35. Jacquet, Pierre. "Evaluations and Aid Effectiveness." In Rescuing the World Bank, edited by Nancy Birdsall, 171-181. Center for Global Development: 2006. 
Wardwell, Sarah

36. Jordan, Lisa, and Peter Van Tuijl, editors. NGO Accountability: Politics, Principles, \& Innovations. Sterling, Virginia: Earthscan, 2006.

37. Kaplan, Robert S. and David P. Norton. "Using the Balanced Scorecard as a Strategic Management System." Harvard Business Review July-August (2007): 151-161.

38. Keck, Margaret, and Kathryn Sikkink. Activists beyond Borders: Advocacy Networks in International Politics. Ithaca: Cornell University Press, 1998.

39. Krakauer, Jon. Three Cups of Deceipt: How Greg Mortenson, Humanitarian Hero, Lost His Way. California: Byliner, 2011. Kindle Single.

40. Kristof, Nicholas and Sheryl Wu Dunn. Half the Sky: Turning Oppression into Opportunity for Women Worldwide. New York, New York: Vintage Books, 2010.

41. Kristof, Nicholas. "Three Cups of Tea Spilled." The New York Times, April 20, 2011. http://www.nytimes.com/2011/04/21/opinion/21kristof.html

42. Lafont, Cristina. "Accountability and Global Governance: Challenging the StateCentric Conception of Human Rights.” Ethics \& Global Politics 3:3 (2010): 193215.

43. Lawry, Steven. "Paul Farmer's Call for a New Conversation on Aid to Haiti," review of Haiti: After the Earthquake, by Paul Farmer. http://hausercenter.org/iha/2011/12/09/paul-farmer\%E2\%80\%99s-call-for-a-newconversation-on-aid-to-haiti/

44. Lewis, David and Tina Wallace, ed. New Roles and Relevance: Development NGOs and the Challenge of Change. Connecticut: Kumarian Press, 2000.

45. Mallaby, Sebastian. The World's Banker. New York, New York: Penguin Books, 2004.

46. Mercy Corps. “Accountability Study.” 2007.

47. Mercy Corps. "Accountability to Beneficiaries TOR.” 2010.

48. Mercy Corps. 2011 Project Management Manual.

49. Merriam-Webster. "Accountability." http://www.merriamwebster.com/dictionary/accountability

50. Miller, Jed. "If Transparency Leads Nowhere." New York Times, January 25, 2012. http://www.revenuewatch.org/news/blog/nyt-op-ed-if-transparency-fallsforest

51. Mulgan, Richard. “ 'Accountability’: An Ever-Expanding Concept?” Public Administration 78:3 (2000): 555-573.

52. Nebot, Vicky, ed. Reforming International Institutions: Another World is Possible. Virginia: Earthscan, 2009.

53. Park, Susan. "Designing Accountability, International Economic Organisations and the World Bank's Inspection Panel." Australian Journal of International Affairs 64: 1 (February 2010): 13-36.

54. Reitman, Janet. "Beyond Relief: How the World Failed Haiti." Rolling Stone, August 4, 2011.

55. Scholte, Jan Aaart. "Civil Society and Democratically Accountable Global Governance." In Government and Opposition Ltd., edited by Held and KoeningArchibugi, 211-233. Oxford: Blackwell Publishing, 2004. 
Wardwell, Sarah

56. Scholte, Jan Aart. "Civil Society and Democratically Accountable Global Governance." In Global Governance and Public Accountability, edited Held and Koening-Archibugi, 87-109. Massachusetts: Blackwell Publishing, 2005.

57. Schwartz, Timothy T. Travesty in Haiti. Self published, 2010.

58. Szporluk, Michael. "A Framework for Understanding Accountability of International NGOs and Global Good Governance." Indiana Journal of Global Legal Studies 16:1 (Winter 2009): 339-361

59. The Monitor. "Uganda; World Bank to Meet on Bujagali Dam". Africa News, April 2, 2007.

60. The World Bank. "World Bank Data." http://data.worldbank.org/

61. Transparency International. "Corruption Perceived Index 2011." http://cpi.transparency.org/cpi2011/

62. United Nations Office for Coordination of Humanitarian Affairs. "UN OCHA Reports," last modified Jan. 28, 2012. http://fts.unocha.org/reports/daily/OCHA_R24_E15797.XLS

63. Wade, Robert H. "Accountability Gone Wrong: The World Bank, Nongovernmental Organisations and the US Government in a Fight Over China." New Political Economy 14:1 (March 2009): 25-48.

64. Woods, Ngaire. The Globalizers: The IMF, the World Bank, and Their Borrowers. Ithaca: Cornell University Press, 2006.

65. Worthington, Sam, moderator. "The Aid System: Does 'Mutual Accountability' Encourage Outcomes?" Panel Discussion at the Civil Society Forum at the World Bank and IMF Board of Governors Meeting, Istanbul, Turkey, October 4, 2009. 
Appendix A. Mercy Corps Survey Questions

\begin{tabular}{|l|l|l|}
\hline No. & \multicolumn{1}{|c|}{ Question } & Possible Responses \\
\hline 1 & Who are you? & National, Expatriate \\
\hline 2 & Are you working in programs or operations? & $\begin{array}{l}\text { Programs, } \\
\text { Operations }\end{array}$ \\
\hline 3 & In your country program, where are you working? & $\begin{array}{l}\text { Country main office, } \\
\text { country field office, } \\
\text { headquarters }\end{array}$ \\
\hline 4 & How much contact do you have with beneficiaries? & $\begin{array}{l}\text { I work more than } \\
\text { half my time with } \\
\text { beneficiaries, I work } \\
\text { less than half of my } \\
\text { time with } \\
\text { beneficiaries, I have } \\
\text { occasional contact } \\
\text { with beneficiaries, I } \\
\text { don't work with } \\
\text { beneficiaries }\end{array}$ \\
\hline 7 & $\begin{array}{l}\text { When creating beneficiaries selection criteria, to what } \\
\text { extent does your team include input and inclusive } \\
\text { participation from: Community representatives? }\end{array}$ & $\begin{array}{l}\text { Always, Often, } \\
\text { Sometimes, Never, } \\
\text { Don't Know }\end{array}$ \\
$\begin{array}{l}\text { selection criteria the team } \\
\text { pros? The roles the community plays in } \\
\text { of assistance MC can } \\
\text { sravide? }\end{array}$ & $\begin{array}{l}\text { Overall, how would you rate your program's efforts to } \\
\text { share program information with beneficiaries? }\end{array}$ & $\begin{array}{l}\text { Strong, adequate, } \\
\text { limited, poor, can't } \\
\text { rate }\end{array}$ \\
\hline 6 & $\begin{array}{l}\text { During the assessment and design phases, to what } \\
\text { extent does your team meet with the communities to }\end{array}$ & $\begin{array}{l}\text { Always, Often, } \\
\text { Sometimes, Never, } \\
\text { Don't Know }\end{array}$ \\
\hline
\end{tabular}


Wardwell, Sarah

\begin{tabular}{|c|c|c|}
\hline & Community leaders? Most vulnerable groups? & \\
\hline 8 & $\begin{array}{l}\text { To what degree does your team involve beneficiaries } \\
\text { during the following phases of the project: Initial } \\
\text { assessment? Design? Implementation of activities? } \\
\text { Monitoring? Evaluation? }\end{array}$ & $\begin{array}{l}\text { Always, Often, } \\
\text { Sometimes, Never, } \\
\text { Don't Know }\end{array}$ \\
\hline 9 & $\begin{array}{l}\text { To what extent does your team provide explanations to } \\
\text { beneficiaries about changes to the program activities? }\end{array}$ & $\begin{array}{l}\text { Always, Often, } \\
\text { Sometimes, Never, } \\
\text { Don't Know }\end{array}$ \\
\hline 10 & $\begin{array}{l}\text { To what extent does your team hold formal meetings } \\
\text { with beneficiaries for the following purposes: To } \\
\text { review and ask beneficiaries' } \\
\text { opinion about project's results? To review and ask } \\
\text { beneficiaries' } \\
\text { opinion about lessons learned? To tell them good-bye? }\end{array}$ & $\begin{array}{l}\text { Always, Often, } \\
\text { Sometimes, Never, } \\
\text { Don't Know }\end{array}$ \\
\hline 11 & $\begin{array}{l}\text { To what degree does your team establish a basic profile } \\
\text { of the population from primary and secondary } \\
\text { sources in a transparent manner including: Gender? } \\
\text { Ethnicity? Religion? Political affiliation? } \\
\text { Vulnerability? }\end{array}$ & $\begin{array}{l}\text { Always, Often, } \\
\text { Sometimes, Never, } \\
\text { Don't Know }\end{array}$ \\
\hline 12 & $\begin{array}{l}\text { To what extent does your team analyze and update } \\
\text { beneficiary information periodically during the project? }\end{array}$ & $\begin{array}{l}\text { Always, Often, } \\
\text { Sometimes, Never, } \\
\text { Don't Know }\end{array}$ \\
\hline 13 & $\begin{array}{l}\text { To what degree does your team maintain a gender } \\
\text { balance between women and men in its composition? }\end{array}$ & $\begin{array}{l}\text { Always, Often, } \\
\text { Sometimes, Never, } \\
\text { Don't Know }\end{array}$ \\
\hline 14 & $\begin{array}{l}\text { To what extent does your team include a fair and } \\
\text { practical representation of all the groups that are } \\
\text { members } \\
\text { of the local populations? }\end{array}$ & $\begin{array}{l}\text { Always, Often, } \\
\text { Sometimes, Never, } \\
\text { Don't Know }\end{array}$ \\
\hline 15 & $\begin{array}{l}\text { To what degree are beneficiaries given the opportunity } \\
\text { from first contact to identify and prioritize their } \\
\text { needs? }\end{array}$ & $\begin{array}{l}\text { Always, Often, } \\
\text { Sometimes, Never, } \\
\text { Don't Know }\end{array}$ \\
\hline 16 & To what extent is beneficiary prioritization of needs & Always, Often, \\
\hline
\end{tabular}


Wardwell, Sarah

\begin{tabular}{|c|c|c|}
\hline & $\begin{array}{l}\text { taken into account for program design and } \\
\text { implementation? }\end{array}$ & $\begin{array}{l}\text { Sometimes, Never, } \\
\text { Don't Know }\end{array}$ \\
\hline 17 & $\begin{array}{l}\text { To what degree are beneficiaries regularly provided } \\
\text { information about the project in order to facilitate their } \\
\text { participation and informed feedback? }\end{array}$ & $\begin{array}{l}\text { Always, Often, } \\
\text { Sometimes, Never, } \\
\text { Don't Know }\end{array}$ \\
\hline 18 & $\begin{array}{l}\text { To what extent is feedback a reciprocal process } \\
\text { between beneficiaries and the Mercy Corps team to: } \\
\text { Inform about progress based on } \\
\text { indicators? Respond to problems in a timely } \\
\text { manner? }\end{array}$ & $\begin{array}{l}\text { Always, Often, } \\
\text { Sometimes, Never, } \\
\text { Don't Know }\end{array}$ \\
\hline 19 & $\begin{array}{l}\text { To what degree is feedback information used for: } \\
\text { Decision making? Program improvement? Identifying } \\
\text { gaps? Identifying new needs? }\end{array}$ & $\begin{array}{l}\text { Always, Often, } \\
\text { Sometimes, Never, } \\
\text { Don't Know }\end{array}$ \\
\hline 20 & $\begin{array}{l}\text { Through what means--meetings, verbal reports, etc.-- } \\
\text { are beneficiaries given information about projects, } \\
\text { please explain? }\end{array}$ & Open ended \\
\hline 21 & $\begin{array}{l}\text { To what extent are formal feedback mechanisms } \\
\text { established early on in the projects? }\end{array}$ & $\begin{array}{l}\text { Always, Often, } \\
\text { Sometimes, Never, } \\
\text { Don't Know }\end{array}$ \\
\hline 22 & $\begin{array}{l}\text { To what degree is the feedback from community } \\
\text { members used to inform projects' implementation? }\end{array}$ & $\begin{array}{l}\text { Always, Often, } \\
\text { Sometimes, Never, } \\
\text { Don't Know }\end{array}$ \\
\hline 23 & $\begin{array}{l}\text { To what degree is the feedback information } \\
\text { documented and made available to all staff working on } \\
\text { a project? }\end{array}$ & $\begin{array}{l}\text { Always, Often, } \\
\text { Sometimes, Never, } \\
\text { Don't Know }\end{array}$ \\
\hline 24 & $\begin{array}{l}\text { To what degree is the feedback information also shared } \\
\text { with other humanitarian actors for coordination and } \\
\text { to prevent duplication of efforts and improve impact? }\end{array}$ & $\begin{array}{l}\text { Always, Often, } \\
\text { Sometimes, Never, } \\
\text { Don't Know }\end{array}$ \\
\hline 25 & $\begin{array}{l}\text { To what degree is critical information that requires } \\
\text { immediate action (sexual abuse, accusation of } \\
\text { corruption, } \\
\text { security risk) acted upon in a timely manner? }\end{array}$ & $\begin{array}{l}\text { Always, Often, } \\
\text { Sometimes, Never, } \\
\text { Don't Know }\end{array}$ \\
\hline
\end{tabular}


Wardwell, Sarah

\begin{tabular}{|l|l|l|}
\hline 26 & $\begin{array}{l}\text { What other accountability practices do you or your } \\
\text { team regularly use to fulfill your accountability to } \\
\text { beneficiaries responsibilities? (Please, provide concrete } \\
\text { examples) }\end{array}$ & Open ended \\
\hline 27 & $\begin{array}{l}\text { What barriers to Accountability to Beneficiaries do you } \\
\text { face? }\end{array}$ & Open ended \\
\hline 28 & $\begin{array}{l}\text { What elements do you think are most important to } \\
\text { include in any future Mercy Corps Accountability } \\
\text { Framework? (Please, provide concrete examples) }\end{array}$ & Open ended \\
\hline 29 & Please, include any final comments below: & Open ended \\
\hline
\end{tabular}


Wardwell, Sarah

Appendix B . Institutionalization of Accountability to Beneficiaries: The World Bank

The World Bank, a major actor in international politics, has taken some significant steps towards institutionalizing accountability to beneficiaries measures. The World Bank plays several roles in globalized politics including acting as a donor to INGOs and governments who carry out projects for them, and also as a direct project implementer. When the World Bank directly interacts with beneficiaries as a project implementer they are in a similar position as INGOs. Looking at the World Bank from this perspective, this section will briefly examine how the World Bank has incorporated accountability to beneficiaries measures and what implications this has for INGOs.

\section{Accountable to whom?}

Over sixty years ago the US signed the Articles of Agreement at Bretton Woods to start the World Bank and during that same decade drafted the Marshall Plan, beginning US involvement in foreign aid and yet its effectiveness at improving social and economic conditions remains unclear ${ }^{162}$. As with INGOs, critics of the Bank's work have become more numerous and vociferous with their complaints in the past few decades, prompting calls for accountability from all of these institutions.

Cash flows for the World Bank originate primarily from state resources: paid-incapital, retained earnings, loan repayments, and borrowing on the world capital markets $^{163}$. The World Bank then operationalizes these resources with the intent to improve livelihoods around the world. Most often, scholars have been interested in

\footnotetext{
${ }^{162}$ Clements, Paul, Thomaz Chianca, and Ryoh Sasaki, "Reducing World Poverty by Improving Evaluation of Development Aid," American Journal of Evaluation 29:2 (June 2008), 195.

${ }^{163}$ Woods, Ngaire. The Globalizers: The IMF, the World Bank, and Their Borrowers. (Ithaca: Cornell University Press, 2006 ), 24. 
Wardwell, Sarah

studying the relationship between the states giving their money to the organization, or upward accountability, rather than looking at the other end of this relationship

As the example about the dam project in Uganda from chapter two points out, listening to the needs of the beneficiaries is important to improve effective project delivery for the Bank and INGOs alike. Defining the beneficiaries or stakeholders is the first step in this process. In the case of the INGO that was fighting to stop the World Bank dam construction in Uganda, they were focused on the individuals inhabiting the community that would need to be relocated for the dam building and ignored the large number of individuals who would have benefitted from the electricity generated by the dam. For this reason, it's important to expand the definition of beneficiaries beyond those immediately affected by the project. In this case beneficiaries included:

1. the community where the dam was built,

2. the communities that would receive electricity from it,

3. local governments who would monitor and distribute the electricity,

4. construction companies that would create the rest of the infrastructure to support the electricity,

5. energy companies who would profit from the electricity,

6. other companies that would profit from electricity in their town,

7. the national government who would benefit politically and economically from the dam,

8. international companies who would potentially increase their investment in the affected region, and so on.

This laundry list of groups and individuals exemplifies the type of stakeholder analysis that is warranted to understand accountability to beneficiaries in the sense that this paper intends it to be understood. Since World Bank interventions will have longlasting impacts, the issue of time is also important to consider. The dam project in Uganda, for example, would continue to impact communities for many years depending 
Wardwell, Sarah

on the amount of support the Bank gave for upkeep of the dam. The general list of stakeholders in a World Bank project includes:

1. project/direct beneficiaries,

2. the community or public accountability,

3. the host state, local government, any local partners involved in the actual implementation, and

4. future generations.

\section{Accountable for What?}

The impacts of World Bank interventions can be classified as: direct, indirect, short term, long term, and structural. Direct impacts are the outputs of a project. With the Uganda example, this would have been the building of the dam, the displacement of the people supported by the INGO, and the introduction of electricity to those villages affected. Indirect impacts include environmental effects, political effects (changes to diplomatic relations, also related to upward accountability), and social effects (how would electricity change those communities?), capacity building (educating workers about dam maintenance, educating communities about how to use electricity), and changing social norms. Each of these impacts can be broken down into individuals and groups that will be affected. These beneficiaries can be divided into how the impact will affect them either negatively or positively. In the case of individuals learning new skills and acquiring employment, this group of beneficiaries would clearly be "winners". However, other energy suppliers, especially those that previously supplied energy, possibly petroleum suppliers, and those involved in that industry (vendors, maintenance, transportation, etc.) could suffer losses from the dam. Of course the INGO that halted the dam construction was focused on the community to be displaced by the construction. These groups would thus be "losers" in the project cost-benefit analysis. 


\section{Wardwell, Sarah}

Defining the ways the World Bank is accountable first requires assessing who the various stakeholders are and then determining the potential impacts on them. A costbenefit analysis for the project, including computing future effects, helps to measure what the organization is accountable for. The World Bank is obviously accountable for direct impacts, but indirect impacts and the impacts on the full range of beneficiaries current and future should also be considered.

\section{Accountable How?}

The World Bank is rhetorically committed to "working for a world free of poverty" ${ }^{\prime 164}$. This chapter argues that improving accountability will help the World Bank and other international organizations achieve their missions. The question then becomes, how can an organization bridge the divide between the theoretical discussions about accountability and implementation? If organizations merely rhetorically commit to improving accountability to beneficiaries, including a clause in project proposals or job announcements does not necessarily lead to an improvement in accountability to beneficiaries. Several suggestions have been made to lead to an actual commitment to accountability to beneficiaries, which can be broadly lumped into these categories: a global authority (upward and horizontal accountability), giving ownership of monitoring international organizations to local governments, and internal accountability mechanisms.

Some of the advantages of a global financial authority are that it would not deal with inconsistencies of national regulators, and would not have the incentives to deviate

\footnotetext{
${ }^{164}$ The World Bank, "World Bank Data," http://data.worldbank.org/ 
Wardwell, Sarah

from a coordination strategy ${ }^{165}$. However, any global authority would most likely still feel pressures from individual powerful states to act in a certain way. In order for such an authority to exist at all would require commitment and enforcement from powerful states. This solution seems more necessary for INGOs because they are such a large and diverse community versus international finance organizations, which is a much more limited group, with the World Bank and the IMF as the main actors. Some scholars argue that in the absence of such a global authority, it is "inconsistent" to demand that global institutions be accountable to all those subject to their decisions while also requiring that all members of the institution be accountable to the citizens of their home states ${ }^{166}$.

Another option is that minimum standards should be developed and regulated by local authorities is compelling ${ }^{167}$. In order for this idea to be successful it would require buy-in from local governments, as Fratianni and Pattison suggest. They recommend that the US and the UK be largely involved in developing these standards, but it seems that a better approach would be to involve a greater range of states, especially those with emerging markets such as Brazil, India, Ghana, South Africa, Indonesia, etc. This type of accountability mechanism though is not necessarily going to lead to accountability to beneficiaries. Local governments are often plagued by ingrained systems of corruption, nondemocratic systems of official selection, and leaders that are neither representative nor accountable to the populations they serve.

\footnotetext{
${ }^{165}$ Fratianni, Michele and John Pattison, "International Financial Architecture and International Financial Standards," Annals, AAPSS 579 (January 2002), 187.

${ }^{166}$ Lafont, Cristina, "Accountability and Global Governance: Challenging the State-Centric Conception of Human Rights,” Ethics \& Global Politics 3:3 (2010): 193.

${ }^{167}$ Fratianni, Michele and John Pattison, "International Financial Architecture and International Financial Standards," Annals, AAPSS 579 (January 2002), 193. 
Wardwell, Sarah

One way to overcome the problem posed by Lafont is through internal accountability mechanisms that would the incentives for project staff from outputs to outcome generation $^{168}$. Internal accountability mechanisms are included in monitoring and evaluation (M\&E) systems, using a variety of tools such as baseline analysis (before the program start), participatory analysis, surveys, interviews, focus groups, measuring outputs (such as assessing that the physically dam installed), and writing reports on these findings. One of the problems with any reports written in conventional M\&E systems is that they are "on average weak and positively biased"169. There are two main reasons they are weak: political consequences for the organization and the relationship with their donors and internal struggles for resources among staff. International organizations want to continue their funding by displaying positive project performance therefore potentially biasing reports. M\&E systems are necessary to monitoring the successes and failures of projects, but failures need to be studied, reported on, and acted upon more than they currently are in order to improve accountability to beneficiaries. "Only including the immediate outputs raises the risk that the project's objectives lack relevance to development outcomes,, 170 .

Evaluations build knowledge about the states where donors operate, their societies, their institutions, and of course their needs, adding dramatically to the body of

\footnotetext{
168 Gelb, Alan, "How can Donors Create Incentives for Results and Flexibility for Fragile States? A Proposal for IDA," Center for Global Development Working Paper 227 (October 2010): 1-23.

${ }^{169}$ Clements, Paul, Thomaz Chianca, and Ryoh Sasaki, "Reducing World Poverty by Improving Evaluation of Development Aid,” American Journal of Evaluation 29:2 (June 2008), 196.

${ }^{170}$ Gelb, Alan, "How can Donors Create Incentives for Results and Flexibility for Fragile States? A Proposal for IDA,” Center for Global Development Working Paper 227 (October 2010): 13
} 
Wardwell, Sarah

information that exists about each ${ }^{171}$. Additionally, as Clements et al. (2008) argue, evaluations need to estimate a broader range of impacts attributed to a project. Secondly, within a project team or even the greater organization, there are competitions amongst individuals for resources (budget allocations), making objective information in a report both a liability and an asset ${ }^{172}$.

Most current internal mechanisms lack a sufficient mechanism to overcome these internal biases. More advanced accountability systems include opportunities for beneficiaries to complain about the project, such as through complaint boxes, emails to a project manager or other project administrator, or information desks where beneficiaries can ask project staff questions or raise concerns about the project. Most importantly, these evaluation systems need to involve a feedback process where the information attained is used for learning purposes within the organization, which would require an increase in time and resources dedicated to this ${ }^{173}$. Individual staff members should also be held accountable for their role in project implementation. High staff turnover and the reality that many staff will retire before negative outcomes can be realized limit the plausibility of this idea ${ }^{174}$.

The World Bank has a separate department committed to carrying out relatively independent evaluations, originally called the Operations Evaluation Department (OED)

\footnotetext{
171 Jacquet, Pierre, "Evaluations and Aid Effectiveness," In Rescuing the World Bank, edited by Nancy Birdsall, 172. Center for Global Development: 2006.

${ }^{172}$ Clements, Paul, Thomaz Chianca, and Ryoh Sasaki, "Reducing World Poverty by Improving Evaluation of Development Aid," American Journal of Evaluation 29:2 (June 2008), 198.

173 Jacquet, Pierre, "Evaluations and Aid Effectiveness," In Rescuing the World Bank, edited by Nancy Birdsall, 173. Center for Global Development: 2006.

${ }^{174}$ Gelb, Alan, "How can Donors Create Incentives for Results and Flexibility for Fragile States? A Proposal for IDA," Center for Global Development Working Paper 227 (October 2010): 1-23.
} 
Wardwell, Sarah

and recently renamed the Independent Evaluation Group (IEG). These evaluations are an attempt to generate external accountability and also external legitimacy. Generally staffs for these departments come from operational positions within the Bank ${ }^{175}$. The directorgeneral of the group reports directly to the executive board, where representatives from donor states consider the evaluations of projects. Evaluations are usually carried out 2-5 years after program completion, and are heralded as being relatively independent from project implementer staff or donor incentives and pressure ${ }^{176}$. Responding to increased vitriolic complaints, the Bank created the Inspection Panel in 1993, specifically to assess external accountability issues ${ }^{177}$. The Inspection Panel can take complaints from any group able to show that:

"1) they live in the project area (or represent people who do) and are likely to be affected adversely by project activities: 2) they believe that the actual or likely harm they have suffered results from failure by the Bank to follow its policies and procedures; 3) their concerns have been discussed with Bank management and they are not satisfied with the outcome"178.

This mechanism helps to overcome the positive bias cited previously as a major problem with evaluations. This method has some limitations though, since not all groups are likely to bring complaints before the group. Often, the Inspection Panel has relied on NGOs, especially INGOs to bring complaints to their attention ${ }^{179}$. The involvement of INGOs

\footnotetext{
${ }^{175}$ Clements, Paul, Thomaz Chianca, and Ryoh Sasaki, "Reducing World Poverty by Improving Evaluation of Development Aid," American Journal of Evaluation 29:2 (June 2008), 200.

${ }^{176}$ Clements, Paul, Thomaz Chianca, and Ryoh Sasaki, "Reducing World Poverty by Improving Evaluation of Development Aid," American Journal of Evaluation 29:2 (June 2008), 200.

${ }^{177}$ Park, Susan. "Designing Accountability, International Economic Organisations and the World Bank's Inspection Panel." Australian Journal of International Affairs 64: 1 (February 2010): 14.

178 Woods in Ebrahim, Alnoor and Edward Weisband, eds., Global Accountabilities: Participation, Pluralism, and Public Ethics, Cambridge: Cambridge University Press (2007), 41.

${ }^{179}$ Woods in Ebrahim, Alnoor and Edward Weisband, eds., Global Accountabilities: Participation, Pluralism, and Public Ethics, Cambridge: Cambridge University Press (2007), 41. 
Wardwell, Sarah

and NGOs risks the complaints being skewed based on the organization's objectives, such as was seen in the Ugandan example.

A study conducted by Clements et al. comparing case study evidence finds that despite these mechanisms, "significant positive bias" still remains endemic and "no institutional mechanism to make impact estimates consistent" exists ${ }^{180}$. A recent congressional testimony about World Bank accountability stated that independent evaluations, conducted outside of the World Bank or any of its branches are necessitated along with increased product innovation ${ }^{181}$. Chairman Barney Frank, who steers the House Financial Services Committee that oversees matters relating to international economic policy and development, including the Bank, is committed to improving accountability at the Bank. While his concern may be mostly based on the idea of upward accountability, the idea of adding independent evaluations may help to achieve greater accountability to beneficiaries as well. Often the different types of accountability can be mutually reinforcing. Whether independent evaluation would improve accountability to beneficiaries depends on their choice of methodology. A thorough stakeholder analysis and participation of a wide range of beneficiaries would improve the common evaluation methodology.

Implications for INGOs

${ }^{180}$ Clements, Paul, Thomaz Chianca, and Ryoh Sasaki, “Reducing World Poverty by Improving Evaluation
of Development Aid,” American Journal of Evaluation 29:2 (June 2008), 212.
${ }^{181}$ Center for Global Development, “Accountability and Transparency key to World Bank Disclosure
Policy, Ramchandran States in Congressional Testimony,” (September 14, 2009)
http://www.cgdev.org/content/article/detail/1422758/. A Strategic Model for INGO Accountability Systems 154| P a g e 


\section{Wardwell, Sarah}

As INGOs and other non-state actors have increased in importance, they have increased their influence over Bank policies as well ${ }^{182}$. The World Bank under James Wolfensohn began consulting with NGOs to coordinate policies as much as possible ${ }^{183}$. Today, there are more than 3,500 NGOs (international and local) registered as consultative status with the World Bank ${ }^{184}$. As such, INGOs have been in largely a lobbying position with the World Bank. In some cases, the World Bank will rely upon an INGO to implement a project once the World Bank has decided to fund the project. In this sense, the INGO acts as an intermediary between the World Bank as a donor and the beneficiaries. The local NGO or INGO then accepts greater responsibility to ensuring accountability to beneficiaries. The INGO can then hold the World Bank accountable through horizontal or peer accountability in a sense that they are both working to achieve the same goal in a project they collaborate on. Ultimately, though the World Bank falls more into an upward accountability position for the INGO since they are a donor in these cases. Below is a representation of chain of accountability.

\section{Donor state $\rightarrow$ World Bank (donor) $\rightarrow$ INGO (project implementer) $\rightarrow$ Beneficiaries}

Improving accountability to beneficiaries is a problem similarly faced by all bilateral and multilateral development institutions ${ }^{185}$. As the World Bank works to improve accountability to beneficiary measures, pressure will increase for INGOs to

\footnotetext{
${ }^{182}$ Wade, Robert H. "Accountability Gone Wrong: The World Bank, Non-governmental Organisations and the US Government in a Fight Over China." New Political Economy 14:1 (March 2009): 28.

${ }^{183}$ Anderson, Kenneth, "What NGO Accountability Means: And Does Not Mean," The American Journal of International Law 10:13 (Jan. 2009), 171.

${ }^{184}$ CSO Net, "At your Service," NGO Branch of the UN Economic and Social Affairs, csonet.org.

185 Jacquet, Pierre, "Evaluations and Aid Effectiveness," In Rescuing the World Bank, edited by Nancy Birdsall, 171. Center for Global Development: 2006. 
Wardwell, Sarah

acquire their own methods for being accountable to beneficiaries. If the Bank were to require particular methods, such as an independent evaluation, this would directly affect how the INGO operates. Funding could become more competitive for agencies that have accountability to beneficiary frameworks and tools already developed. Currently the European Commission (EC) is leading this movement, but as the Bank looks for ways to increase its legitimacy and improve its community relations, it seems plausible they would follow suit.

\section{Institutionalization of Accountability}

This chapter has discussed one of the political aspects of fighting poverty through the World Bank system, accountability to beneficiaries. The World Bank faces no small number of challenges to being more accountable to beneficiaries, including upward accountability constraints from donor states (especially the US), a lack of internal commitment or incentives, and the lack of beneficiary abilities to voice their complaints without the support of NGOs (which has been demonstrated to be problematic). The overwhelming and conflicting number of constraints and demands made upon the World Bank and other international institutions is often seen as a major blockade for considering accountability to beneficiaries ${ }^{186}$. As complaints against the Bank have been steadily increasing since the 1980's, it is increasingly important for the Bank to consider taking measures to improve in this area.

As the World Bank struggles to maintain legitimacy and a competitive advantage in the modern era, reform has been on the tip of the tongue for many policy makers in

\footnotetext{
186 Jacquet, Pierre, "Evaluations and Aid Effectiveness," In Rescuing the World Bank, edited by Nancy Birdsall, 178. Center for Global Development: 2006. 
Wardwell, Sarah

states that fund the Bank ${ }^{187}$. The US has been particularly vociferous in matters relating to the Bank since its inception. These struggles typify the competing incentives that exist in the struggle to improve economic and social development globally ${ }^{188}$. As with INGOs, the World Bank is still struggling to define the beneficiaries they would target through accountability to beneficiaries mechanisms. Throughout this chapter instances of how the World Bank is institutionalizing accountability to beneficiaries and future challenges and recommendations for improving this have been examined.

Scholars and practitioners have argued that improving the World Bank's accountability to beneficiaries will have trickle down effects to partners, INGOs, and even governments. Improving accountability to beneficiaries will make aid more attractive to constituencies in donor states as well and could increase the Bank's funding because it focuses organizations and institutions on outcomes rather than simply outputs $^{189}$. It will also shift the discussion from "how much" aid and assistance, to “where we can really add value", ultimately improving aid effectiveness ${ }^{190}$.

\footnotetext{
${ }^{187}$ Nebot, Vicky, ed. Reforming International Institutions: Another World is Possible. Virginia: Earthscan, 2009.

${ }^{188}$ Clements, Paul, Thomaz Chianca, and Ryoh Sasaki, "Reducing World Poverty by Improving Evaluation of Development Aid," American Journal of Evaluation 29:2 (June 2008), 197.

${ }^{189}$ Worthington, Sam, moderator. "The Aid System: Does 'Mutual Accountability' Encourage Outcomes?" Panel Discussion at the Civil Society Forum at the World Bank and IMF Board of Governors Meeting, Istanbul, Turkey, October 4, 2009.

${ }^{190}$ Gelb, Alan, "How can Donors Create Incentives for Results and Flexibility for Fragile States? A Proposal for IDA," Center for Global Development Working Paper 227 (October 2010): 20. 